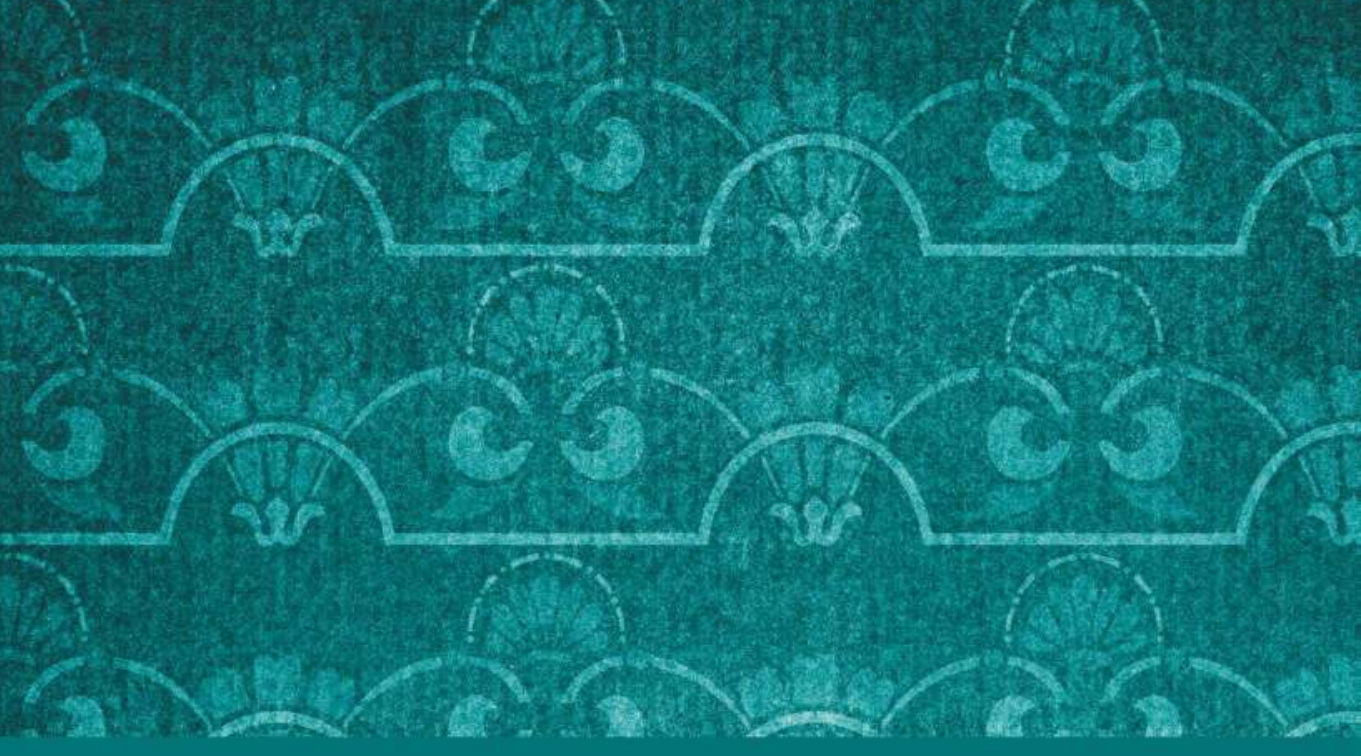

\title{
DESIGNS FOR RESEARCH, TEACHING AND LEARNING
} A FRAMEWORK FOR FUTURE EDUCATION

Edited by

Lisa Björklund Boistrup and Staffan Selander 


\section{Designs for Research, Teaching and Learning}

This book offers a coherent theoretical and multimodal perspective on research, teaching, and learning in different non-formal, semi-formal, and formal learning environments.

Drawing on examples across a range of different settings, the book provides a conceptual framework for research on learning in different environments. It provides conceptual models around learning design which act as a framework for how to think about contemporary learning, a guideline for how to do research on learning in different sites, and a tool for innovative, collaborative design with other professionals. The book highlights concepts like multimodal knowledge representations; framing and setting; transformation, transduction, and re-design; signs of learning and cultures of recognition in different social contexts.

The book supports innovative thinking on how we understand learning, and will appeal to academics, scholars, and postgraduate students in the fields of education research and theory, learning sciences, and multimodal and social semiotics. It will also be of interest to school leaders, university provosts, and professionals working in education.

Lisa Björklund Boistrup is Professor in Mathematics Education at the Department of Science, Mathematics and Society, Malmö University, Sweden.

Staffan Selander is Senior Professor in Didactic Science at the Department of Computer and Systems Sciences, Stockholm University, Sweden. 


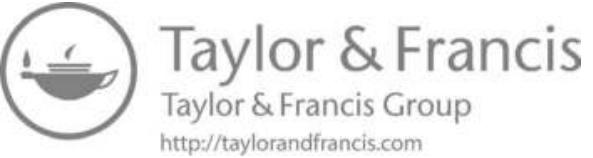




\section{Designs for Research, Teaching and Learning}

A Framework for Future Education

\section{Edited by Lisa Björklund Boistrup and Staffan Selander}


First published 2022

by Routledge

2 Park Square, Milton Park, Abingdon, Oxon OXI4 4RN

and by Routledge

605 Third Avenue, New York, NY 10158

Routledge is an imprint of the Taylor \& Francis Group, an informa business

(C) 2022 selection and editorial matter, Lisa Björklund Boistrup and Staffan Selander; individual chapters, the contributors

The right of Lisa Björklund Boistrup and Staffan Selander to be identified as the authors of the editorial material, and of the authors for their individual chapters, has been asserted in accordance with sections 77 and 78 of the Copyright, Designs and Patents Act 1988.

The Open Access version of this book, available at www. taylorfrancis.com, has been made available under a Creative Commons Attribution-Non Commercial-No Derivatives 4.0 license.

Trademark notice: Product or corporate names may be trademarks or registered trademarks, and are used only for identification and explanation without intent to infringe.

British Library Cataloguing-in-Publication Data

A catalogue record for this book is available from the British Library

Library of Congress Cataloging-in-Publication Data

A catalog record for this book has been requested

ISBN: 978-0-367-56I24-6 (hbk)

ISBN: 978-0-367-56I26-0 (pbk)

ISBN: 978-I-003-09649-8 (ebk)

DOI: $10.4324 / 9781003096498$

Typeset in Bembo

by Apex CoVantage, LLC 


\section{Contents}

Foreword $x$

RICHARD HALVERSON

Illustrations xiv

List of contributors xvii

Prologue xxi

STAFFAN SELANDER AND LISA BJÖRKLUND BOISTRUP

1 Designs in and for learning - a theoretical framework 1 STAFFAN SELANDER

Introduction 1

A detour on "basic knowledge" 5

Design as a dynamic perspective 6

Designs for learning — designs in learning 8

Framing 9

Setting 10

Re-design - the transforming and forming processes 10

Knowledge representations 11

Signs of learning 12

Learning design sequences 13

Concluding remarks on designs for learning 14

References 17

2 Designs in learning and rhizomatic webs

FREDRIK LINDSTRAND AND STAFFAN SELANDER

Introduction 23

Rhizomatic webs as a metaphor for learning 24

Multimodal knowledge representations 24

Epistemological commitments 25 
Re-design by way of transformation and transduction 26

Making film in schools-a case study 27

Searching for a shared interest 27

Writing a synopsis 28

Storyboard 29

Conclusion 30

References 31

\section{A semiotic and design-oriented approach to affordance}

FREDRIK LINDSTRAND

Drawing a dinosaur 33

A focus on resources 35

Affordance 36

What the environment offers 36

Affordance as a relational notion 37

Agency and acts of distinction 38

Semiotic potential and meaning potential 39

Beyond things: semiotic and modal affordances 41

The social affordances of discourses 43

Another level-institutions and their rituals 44

Conclusion 45

References 46

4 Design and research: ethical considerations

ANNA ÅKERFELDT AND LISA BJÖRKLUND BOISTRUP

Introduction 48

The setting 48

Formal ethical protocols - an obstacle or a necessity? 49

Ethical protocols and participants in the research 51

Capturing the institutional setting of the participants' context 52

Transformation units 53

Professionals' and researchers' roles 55

Principles for roles in research where participants are taken

as partners 56

Collaboration with professionals 56

Discussion 57

References 59 


\section{Designing and researching vocational} mathematics education

LISA BJÖRKLUND BOISTRUP AND MATILDA HÄLLBACK

Introduction 61

Other frameworks in the literature 62

The context of the chapter 63

Designing teaching 65

Theoretical and practical aspects of knowledge:

praxeology 66

A framework for the analysis of collaborative

teaching 68

$A$ revised version of the learning design sequence 68

Four examples from the makeup lesson 69

One example from the hair styling lesson 75

Conclusions 78

References 80

6 Design workshops to develop a digital educator's tool

SUSANNE KJÄLLANDER

Introduction 82

Aim and research question 82

Digital tools to support children's learning and teacher's professions 83

Workshop as a research method 84

Designs for learning and the learning design sequences 84

Methodological and ethical considerations 86

Design of the workshop series 86

Design of the workshops-analysis and results 87

Pre-workshops-autumn 201888

WS1-empirical example 89

WS2-empirical example 96

WS3-empirical example 99

WS4-empirical example 101

WS5-empirical example 104

Concluding discussion 106

Final remarks on the methodology 108

References 109 
7 Sites for learning and knowledge representationsthe Middle Ages

EVA INSULANDER, FREDRIK LINDSTRAND AND STAFFAN SELANDER

The Middle Ages in our (European) society 111

The ubiquity of the Middle Ages in our late-modern society 112

Gaming the Middle Ages-examples of designs for learning in non-formal settings 112

Learning about the Middle Ages 115

The Middle Ages in museums - examples of designs for learning in a semi-formal setting 116

The Middle Ages in schools-examples of designs for learning in a formal setting 118

Concluding remarks 119

References 121

8 The Touring Science Centre-an example of collaboration between a museum and a school

EVA INSULANDER AND ELISABETH ÖHMAN

Museum and school partnerships 123

A partnership focussing on digital resources 124

Context of the study and research design 125

Analytical approach 126

Findings 127

Programming as edutainment vs. education? 127

Power relations and institutional clashes 130

Importance of materiality and place 131

Empowerment vs. competence 132

Conclusion and discussion 133

References 135

9 Exhibition development through cross-institutional collaborative design

EVA INSULANDER AND EVA SVÄRDEMO ÅBERG

Introduction 137

The collaborative design project 138

Cultures of recognition and esoteric and exoteric ideas 139

Some central activities within the collaborative design process 141

Initial orientation 141 
Designing a series of workshops 142

Evaluation and critical reflection on practice and on moving theory forward 145

Conclusions 147

References 148

\section{Epilogue: design beyond the classroom}

\section{and for the future of learning}

LISA BJÖRKLUND BOISTRUP AND STAFFAN SELANDER

Learning in different, and intersecting, contexts 149

Educational research taking new steps 150

Stability and change 151

Learning, teaching, and research in a digitized era 151

Dynamic and innovative designs 152

References 152

Index 


\section{Foreword}

Design is among the most important and underexplored topics in education. The domain of education is experiencing phenomenal growth as more nations and communities are turning to institutions of formal and informal learning that support the systemic acquisition of knowledge and skills as a pathway to progress. The emergence of Internet culture has greatly reduced the cost of access to knowledge and to knowledge communities, and has led to an overwhelming expectation for educators to continuously reinvent their institutions to keep pace. Each aspect of the teaching and learning family of practices, from standards to curriculum, from technologies to learning environments, are being constantly shaped and reshaped by designers at all levels. Design is the continuous process where models of education are transformed and maintained around the world.

While education research has been expanding at a similar pace as education itself, its traditional epistemological models can overlook the design processes that guide the dynamic evolution of education. Much of current education research is organized into four families of interest:

- Many education researchers and leaders study and propose models for what should be learned in our schools. These researchers often collaborate with policymakers and political leaders to establish learning standards at the state and national level; and work with educators and publishers to develop standards-based curricula to guide classroom learning.

- Another set of researchers, influenced by psychology, study how we learn. These researchers propose social and cognitive methods to describe the learning process, and increasingly turn to neurological, computational and sociocultural methods to develop more sophisticated approaches to studying learning. Research on teaching focuses on how these ideas are, and can be, translated by educators into lessons and activities to guide learners.

- A third kind of education research is organized around assessing learning. These researchers typically use advanced statistical methods to trace the effects of lessons on learners to hold educators accountable for the quality of schooling. Another tradition for assessment couples research on how 
people learn with techniques and practices to provide information to learners as formative feedback.

- Critical researchers call into question the mismatch of the assumptions, structures and practices of existing schooling models with the social and cultural aspirations for education. This family of scholars uses methods from across the social sciences to document how our present situations reproduces inequity and reminds us of our need to continue to strive toward fulfilling the transformational power of education.

Design is the quiet, persistent and necessary partner for each of these families of education practice and inquiry. Learning is a natural activity that happens all the time for everyone. Education, on the other hand, is a designed process directs learners toward certain outcomes. Education does not happen accidentally-it is the result of translating the intentions of educators (as designers) into standards, lessons, assessments, tools, and learning environments. Education requires imposing a designed structure that directs the natural human process of learning toward an intended state. Education is design for learning.

What does design mean in this context? Design is the production of artefacts intended to shape the practices of users. Designers build intentions into artefacts in the form of features to guide the actions of users in certain directions. From a user's perspective, some features are seen as affordances for use, and other features are ignored or used in contrast to the designer's intention. This gap between intended purpose and actual use, between feature and affordance, makes design into an act of imperfect, asynchronous communication between designer and user. Iterative design elicits data on user perceptions and implementations of affordances in order to refine features to better direct artefact usage. In some case, however, user affordances open up unanticipated domains of usage that enable designers to take artefact features in new directions.

Design is a powerful metaphor to describe education across all learning and research contexts. It can be used to explore how studies are assembled, as well as to study the policies, lessons and environments that educators build and use to teach. Design provides an excellent model to understand the learning process itself. Learning can be analyzed as a design process where students construct representations of understanding to demonstrate and share what they know and can do. The artefacts produced by educators and learners, in a variety of media, provide powerful anchors for critical inquiry into the scope of aspirations promised by education by documenting the shortcomings that result from an imperfectly designed learning process.

At the national and global level, policymakers and researchers design standards and curricular artefacts to shape what should be learned in schools. At the local level, educators design artefacts, such as lessons, projects, technologies and learning spaces, to mediate the actions of learners in the classroom. Durable artefacts (such as textbooks and worksheets) can be shared across time to form routines of practice to transmit values and lessons to future 
generations of learners. When designers introduce iteration into their process, the resulting artefacts can be continuously refined to reflect the preferences of teachers and learners. Assessment designers typically use iterative methods of validation and user-testing to create more accurate measures of how teaching artefacts and learning environments result in desired learner outcomes. Each aspect of the traditional education research process-from intention, through instruction and assessment, and on to critique-can be framed as part of a shared design process. Design is the invisible method that mediates all education experience and research.

The inattention to design as a silent partner has resulted in a collective inability in our field to capture the dynamic, evolving properties of teaching and learning. Our shared lack of vocabulary to describe design at the level of policy, teaching, learning, and assessment, in formal and informal spaces, has hobbled our ability to account for the active role that educators, learners, and researchers take in making their worlds. New media spaces, for example, greatly expand the range of resources designers can use to shape learning lessons and environments as well as transform the forms of representation learners produce to show what they can do. Understanding education as design for learning opens up new possibilities for studying teaching and learning as a dynamic, multimedia domain.

This volume provides an excellent example of how the language and theory of design can inform research, teaching and learning. Lisa Björklund Boistrup and Staffan Selander have assembled an impressive collection of perspectives to bring the concept of designs for research, teaching and learning alive. The authors share a common reference to Selander's Learning Design Sequence that tracks design inputs (learning resources, curricula and institutional norms) through an iterative model of representation through media, discussion, reflection, and presentation. The Learning Design Sequence unfolds on multiple planes that correspond to the roles of teaching, assessment, and student interaction. The resulting artefacts are shaped and reshaped through cycles of datadriven adaptation. The Learning Design Sequence thus provides a dynamic model to consider education research, teaching, and learning in a multilevel framework.

The chapters of this volume share a focus on how educators collaboratively design with media and tools, and how learners negotiate, make choices, and design their learning spaces and outcomes. These powerful models of designs in and for learning greatly enhance our vocabulary to describe the education process. Each chapter considers a new angle on the power of design to illuminate education. For example, Frederik Lindstrand's chapter considers how the concept of affordances can serve as a resource for research as well as guide for understanding the artefacts children make, and Susanne Kjällander shows how the design workshop model makes each aspect of the Learning Design Sequence accessible for educators. Other chapters show how design concepts can be used to analyze collaborative teaching (Chapter 5), representations of 
historical knowledge (Chapter 7) and collaborative design efforts between educators and museums (Chapters 8 and 9). Each of these chapters offer clear explanations of what design concepts mean in an education context as well as vivid illustrations of how to use design language to describe teaching, learning, and collaboration.

The rate of technological change and the chronic global demand for highquality teaching and learning will continue to accelerate the development of new channels for education. Adding a viable model for how we can use a design perspective to guide education research will improve our collective ability to keep pace with the changing landscape. The ideas and examples presented here provide an important contribution, from authors who have invented the field, to the repertoire of tools available to education researchers and developers in their efforts to analyze where we have been, where we are, and where we need to go in the ongoing evolution of the field of education.

Richard Halverson Professor of Educational Leadership and Policy Analysis University of Wisconsin-Madison 


\section{Illustrations}

\section{Figures}

1.1 Non-formal Learning Design Sequence 2

1.2 Semi-formal Learning Design Sequence 3

1.3 Formal Learning Design Sequence 4

2.1 Detail from storyboard 30

3.1 Drawing titled "The coolest dinosaur in the world" 33

3.2 Drawing titled "Triceratops attacks Tyrannosaurus rex (!)" $\quad 34$

3.3 Shooting tower/outdoor kitchen 40

4.1 Formal Learning Design Sequence 49

5.1 (a) Student's face chart. (b) Clip from film with a student drawing triangles 64

5.2 (a) A student sheet with angles. (b) Student clarifies an angle of 90 degrees 64

5.3 A Learning Design Sequence 65

5.4 A revised version of the Learning Design Sequence, with aspects of praxeology included 68

5.5 Matilda (M) talks to a student about using a face chart $\quad 70$

5.6 Divo (D) discusses how students should place triangles in the face

$\begin{array}{lll}\text { 5.7 Lisa (L) asks a student about the benefits of triangles } & 74\end{array}$

5.8 Matilda (M) and a student are looking for triangles in the face 74

5.9 Divo (D) poses questions about what signifies different hairstyles 77

6.1 The Learning Design Sequence 85

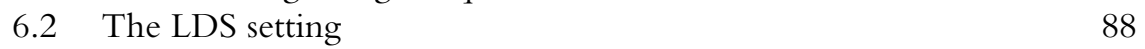

6.3 The LDS primary transformation unit $\quad 89$

6.4 Invitation letter to educators introducing the setting and the aim of the project 90

6.5 Photo: The interests and social interaction and the researcher's intervention at the beginning of the first transformation unit 
6.6 The oral brainstorm in one group is transducted to written text on paper

6.7 The very first prototype of the educator's tool formed by the educators in WS1

8.1 A LEGO robot on the wax cloth

8.2 The rattle to be attached to the LEGO robot

\section{Tables}

1.1 Dominant understandings of "Texts" in relation to social and technological conditions

5.1 An analytical model for the analysis of praxis and logos, where the columns reflect a continuum between Styling and Mathematics. In the middle column there is an equal mixture of Styling and Mathematics

7.1 Learning in non-formal, semi-formal, and formal learning sites

8.1 Documented activities within the educational program

\section{Excerpts}

5.1 $M$ talks to a student about using a face chart. $M=$ Mathematics teacher (Matilda), $\mathrm{S}=$ Student

5.2 D discusses how students should place triangles in the face.

$\mathrm{D}=$ Styling teacher (Divo), $\mathrm{S}=$ Student

5.3 L asks $\mathrm{S}$ about the benefits of triangles. $\mathrm{L}=$ Researcher (Lisa), $\mathrm{M}=$ Mathematics teacher (Matilda), $\mathrm{S}=$ Student

5.4 $\mathrm{M}$ and a student are looking for triangles in the face.

$\mathrm{M}=$ Mathematics teacher (Matilda), $\mathrm{S}=$ Student

5.5 Divo poses questions about what signifies different hairstyles. $\mathrm{D}=$ Styling teacher (Divo), $\mathrm{S}=$ Student

6.1 This excerpt illustrates a discussion when no one knows what kind of tool will be developed

6.2 Instructions given to the educators in the primary transformation unit

6.3 Educators' ideas about the educator's tool have developed and are in this part of the LDS more concrete with innovative suggestions on design, content, and functions

6.4 Discussions in this part of the LDS focus on the educators' everyday teaching at the preschool. The subject of mathematics is also discussed, what is embraced, and how it should be inclusive as well as physical

6.5 Suggestions on what the tool can be called

6.6 A summary of questions and discussions in focus in the primary transformation unit 
6.7 The educators' questions about the different parts of the educator's tool

6.8 Questions asked by the researchers to intervene in the educators' discussion of the educator's tool 


\section{Contributors}

Eva Svärdemo Åberg holds a PhD in Education and she is Senior Lecturer at the Department of Education, Stockholm University, Sweden. Her main research focuses on designs for teaching and learning, meaning-making processes in different settings and representations of knowledge in different assessment practices. She has an interest in social semiotics and multimodal analysis of interaction and learning activities in different educational settings. She is on the advisory board of the peer-reviewed journal Designs for Learning as well as on other scientific journals. Among her publications we can find Multimodal analys av klassrumsinteraktion (Multimodal analysis of classroom interaction, with Insulander, Rydell \& Majlesi, Liber 2021).

Anna Åkerfeldt is a PhD and researcher at the department of mathematics and science education, Stockholm University, and project leader at Ifous, which has its focus on innovation, research and development in schools and preschools. She also works with Sweden's first national EdTech testbed. Her research interest is learning, teaching and assessment in digital learning environments, programming didactics and digital learning environments. Anna is Editor-in-Chief for the open access journal Designs for Learning, www.designsforlearning.nu. Some more recent publications are: Didaktik $i$ omvandlingens tid. Text, representation, design (Education in a time of change. Text, representation, design; with Insulander, Kjällander \& Lindstrand, eds., Liber 2017), and Programmering. Introduktion till digital kompetens i grundskolan (Programming. An introduction to digital competence in compulsory schools; with Kjällander \& Selander, Liber, 2018).

Lisa Björklund Boistrup, $\mathrm{PhD}$, is Professor in Mathematics Education, and Head of Research at the department of Science, Mathematics and Society, Malmö University. Her research covers critical perspectives on assessment, feedback and communication in mathematics classrooms, and interfaces between mathematics and vocational teaching content. In her research she adopts designs for learning, with an interest in institutional framings and the roles of modes, such as writing, symbols, images and the like, in interactions. She has led a number of research projects, carried out in and outside schools 
(for example, workplaces). Some of her publications are "Mathematics in pre-vocational education" (with Bellander \& Blaesild, in Yasukawa et al., eds., Numeracy as social practice: Global and local perspectives, Routledge, 2018), "Resistance from within the mathematics classroom" (with Samuelsson, in Gellert, ed., Inside the mathematics class: Sociological perspectives on participation, inclusion, and enhancement, Springer 2018), "Diversity in mathematics education" (with Abreu \& Gorgorio, in Dreyfus et al., eds., Developing research in mathematics education - twenty years of communication, cooperation and collaboration in Europe, Routledge 2018), and "You must learn something during a lesson': How primary students construct meaning from teacher feedback" (with Eriksson \& Thornberg, Educational Studies, 2020).

Matilda Hällback is currently a $\mathrm{PhD}$ student in Mathematics Education at Uppsala University. At the time of writing the chapter in this volume with Lisa Björklund Boistrup, she was working as a teacher in an Upper secondary school specializing in (pre)vocational education. The chapter derives from an action research project, where Matilda was the project leader at the school. In the project, design theoretical aspects were adopted and related to a model for practical and theoretical aspects of mathematics and vocational knowledge. Matilda has made presentations about this project at conferences for teachers and researchers.

Eva Insulander, $\mathrm{PhD}$, is an Associate Professor and Senior Lecturer at the Department of Education at Stockholm University. Her research focuses mostly on designs for learning, with an interest in social semiotics and multimodal analysis of social interaction and learning, primarily in the context of museum and history education. She has been involved in several research projects focusing on museums as arenas for learning and communication. She is a member of the research group History of Education and Sociology of Education, and associate editor of the peer-reviewed, open access journal Designs for Learning. Some of her latest publications are: "Design för lärande-Historia. Medeltiden som exempel" ("Designs for learningHistory. The Middle Ages as an example;" with Lindstrand \& Selander, Liber 2019), "Representations of migration, borders and memories in exhibitions: a multimodal text analysis" (Museum \& Society, 2019), and "Multimodal analys av klassrumsinteraktion" ("Multimodal analysis of classroom interaction;" with Rydell, Majlesi \& Svärdemo Åberg, Liber 2021).

Susanne Kjällander has a PhD in Didactic Science and is Associate Professor and Senior Lecturer at the Department of Child and Youth Studies at Stockholm University, Sweden. Her research has a multimodal design theoretical approach and concerns students learning in digital learning environments such as preschool and school. Her research focus is on designs for and in learning in relation to programming, Social Science, explorative works, entrepreneurial learning, and adaptive games in mathematics. She has 
recently initiated a national research hub focusing on research on preschool digitalization, and she is section editor of the peer-reviewed, open access journal Designs for Learning. Some of her latest publications are: "Early Math in a Preschool Context: Spontaneous extension of the digital into the physical" (with Gulz, Frankenberg \& Haake, Early Childhood Research Quarterly, 2021), "Designs for learning with adaptive games and Teachable Agents" (with Pilner Blair, in: Brooks, Dau \& Selander, eds., Digital Learning and Collaborative Practices - Lessons from Inclusive and Empowering Participation in Emerging Technologies, Routledge 2021).

Fredrik Lindstrand, $\mathrm{PhD}$, is Professor of Media Theory in Relation to Visual Arts Education at Konstfack University of Arts, Crafts and Design, Stockholm. He has been engaged in a number of research projects and has published extensively on topics related to multimodality and learning. His research interests focus on issues regarding multimodal communication, social semiotics, meaning-making, knowledge representations and designs for learning in different settings, and especially in relation to creative processes. He is section editor of the peer-reviewed, open access journal Designs for Learning, and is on the advisory boards of other scientific journals. Some of his latest publications are: Didaktik i omvandlingens tid. Text, representation, design (Education in a time of change. Text, representation, design; with Insulander, Kjällander \& Åkerfeldt, eds, Liber 2017), and Design för lärandeHistoria. Medeltiden som exempel (Designs for learning-History. The Middle Ages as an example; with Insulander \& Selander, Liber 2019).

Lisa Öhman, $\mathrm{PhD}$, holds a position as a Senior Lecturer at the Department of Humanities and Social Sciences Education, Stockholm University, Sweden. Her research focus is on issues regarding multimodal communication, social semiotics, meaning-making, knowledge representations and designs for learning in the context of media and visual arts education. She has been engaged in different collaborative projects in cooperation with schools, and in her recent work, she explores the teaching of equality and norms in a project on sex education in schools, funded by the Swedish Research Council. One of her latest publications is "Additional adjustment in visual arts education" (with Johansson, InSEA ART Education VISUAL Journal IMAG, 2020).

Staffan Selander, PhD, became the first professor of Didactic Science in Sweden at the Stockholm School of Education, and is now Professor Emeritus in Education/Didactic Science at the Department of Computer and Systems Sciences, Stockholm University. A major part of his research has focused on pedagogic texts, theories of interpretation, designs for and in learning, multimodal knowledge representations and digital learning environments. He has been leading several external, international research projects, and has also been engaged in smaller projects in cooperation with school communities. In 
1993, he took the initiative to develop IARTEM (the International Association for Research on Textbooks and Educational Media, www.iartem.org) and was its president 1997-2005. Selander also started the peer-reviewed, open access journal Designs for Learning (www.designsforlearning.nu) in 2008, and was its Editor-in-Chief until 2019. Some of his more recent publications are: "Learning resources at stake. Main trends and new challenges in research on text books and educational media" (with Knudsen, in Rodríguez Garcia \& Bruillard, eds., IARTEM 1991-2016: 25 years developing textbook and educational media research, Andavira Editora, 2019), Dybde//laring-en flerfaglig, relasjonell og skapende tilnarming (Deep//learning- a trans-subject oriented, relational and creative approach; with Østern et al., eds., Universitetsforlaget 2019), "Games and Education-Designs in and for Learning" (with Arnseth et al., eds., Brill/Sense 2019), Learning as Social Practice. Beyond Education as an Individual Enterprise (with Kress, Säljö \& Wulf, eds., Routledge 2021), Digital Learning and Collaborative Practices-Lessons from Inclusive and Empowering Participation in Emerging Technologies (with Brooks \& Dau, eds., Routledge 2021), and "Multimodal Texts in Disciplinary Education. A Comprehensive Framework" (with Danielsson, Springer 2021). 


\section{Prologue}

This book has a history. Around 2006 we started to discuss a design-theoretic and multimodal perspective, and in 2008 we presented the first issue of the (now) open access journal Designs for Learning (www.designsforlearning.nu)—and at that time we also organized the first international Designs for Learning conference in Stockholm. Early on, we developed collaborations with a group of researchers in Copenhagen ${ }^{1}$ as well as with a group of researchers in London. ${ }^{2}$ Later on, we worked with other researchers-from the University of Wisconsin-Madison to researchers in Sydney and Singapore. Over the years, we have produced several books and dissertations, as well as worked with international research projects financed by The Swedish Research Council, among others.

This book has a theoretical aim. During this time, we discussed the crossroads between a broader, sociological understanding of the conditions for teaching and learning and the narrower social semiotic and multimodal analysis of communication and knowledge representations (see Chapter 1 in this volume), which led us to formulate our own theoretic grounding: Designs for Learning. In addition, we also started to discuss ethical issues in relation to a designoriented perspective on research.

This book offers a frame for doing empirical research. In our work, the relation between methodology and theory has been central. Our thinking on Designs for Learning therefore relates to our model for doing empirical research in different formal, semi-formal, and non-formal contexts: The Learning Design Sequences model (LDS; described in more detail in Chapter 1 of this volume). This model can be used for doing research on framing and setting, as well as the learner's choices and use of modes and media, in order to design a new knowledge representation; it casts light on cultures of recognition and evaluation standards.

This book has a practical aim. In addition to developing a theoretic grounding and a methodology for doing empirical research, we also want to collaborate with professionals in different contexts, supporting them to develop innovative work for change. In such work, the Learning Design Sequences model can be used for making decisions on what to teach and how to measure learning, for planning (framing and setting), and for performing (orchestration of modes, 
media and content, sequences and tempo). In this work, it is important that we as researchers take the responsibility for the theoretic development, and have reflective discussions with our collaborative partners concerning our different roles and responsibilities (see Chapter 4 in this volume).

The structure of the book. In Part I (Chapters 1-4) we address some vital questions concerning our design-oriented and multimodal perspective for doing research on learning in different contexts, on teaching, on affordances, and also on ethical considerations. In Part II (Chapters 5-9), we want to show our theoretical thinking at play, in different projects with a focus on empirical research as well as on innovative, collaborative work.

In this volume, we provide examples from different contexts, for example, computer games, schools and museums, and utilization of different learning resources. We also address learning content from different disciplines, such as mathematics, computer programming, vocational knowing, and historical knowing.

Finally, we want to say thanks to all of our colleagues and the professionals who have worked with us during this time. Our perspective has developed thanks to our projects and discussions over the years. However, the responsibility for this book lays with us, the authors of the book. We would also like to say thank you to Emilie Coin, who has been our contact and sparring-partner in the finalizing of the book, and to Gail FitzSimons, who in such a thorough and constructive way has language checked all chapters.

Malmö and Stockholm in June, 2021

Staffan Selander and Lisa Björklund Boistrup

\section{Notes}

1 The group of researchers-Thorkild Hanghøj, Morten Misfeldt, Birgitte Holm Sørensen, Karin Tweddell Levinsen, and Rikke Ørngreen - worked at the Institute of Education in Copenhagen, which later became a part of Aarhus University, and finally of Aalborg University.

2 Especially with Gunther Kress, at the time at Institute of Education (IOE), which later merged with University College London (UCL). 


\title{
Designs in and for learning-a theoretical framework
}

\author{
Staffan Selander
}

\section{Introduction}

I would like to start with two examples of different learning contexts. The first example stems from a period of time in my life when I couldn't read novels (they all seemed to be about authors going to Paris trying to write a novel), and when my own writing seemed dull and heavy. It so happened that I attended a weekend course on doing glassworks, and to my own surprise, I found that the glass "told me" what to do. I worked intensely with the glassworks during these two days, and later that summer I went to the glass-factory in Kosta in southern Sweden for a course in glass-blowing. I also took a course in Stockholm during the fall on how to make leaded glass.

I deepened my knowledge and skills during the following years. I bought a glass-kiln and learned about where to buy glass, and the characteristics of Bullseye glass, as well as how one could, or could not, mix older glass and re-melt it. I learned about the tools I needed to cut the glass into lines or circles, as well as how to drill and grind glass. I also learned how to prepare glass for burning and about burning curves, and when it was thereafter possible to open the kiln without damaging the glass. Finally, I studied glass designers from different periods of time, and the ways they had developed their glass craft/art. I went to Murano in Venice, and I visited glass galleries, museums and educational sites in Australia, Sweden, and Denmark. I came to a point when the form of a line on the glass could fill me with happiness. I enjoyed the aesthetic experience, and I planned to melt glass to build something new. I actually became quite good—as an amateur.

I even thought of changing my occupation, to be able to work at least half-time with glass, but realized soon enough that it was too late in my life. I would never become a professional glass designer or glass worker. It would also take me too many years to develop enough skills as well as to develop contacts with galleries and a public, not to mention the special niche of art and craft critique. However, the experience with glass led me back to my own writing, and to reading novels again, and I realized that the "word" was my "true" element.

This is first and foremost an example of a mixture between a non-formal learning context, developed by chance and deepened by personal interest and 


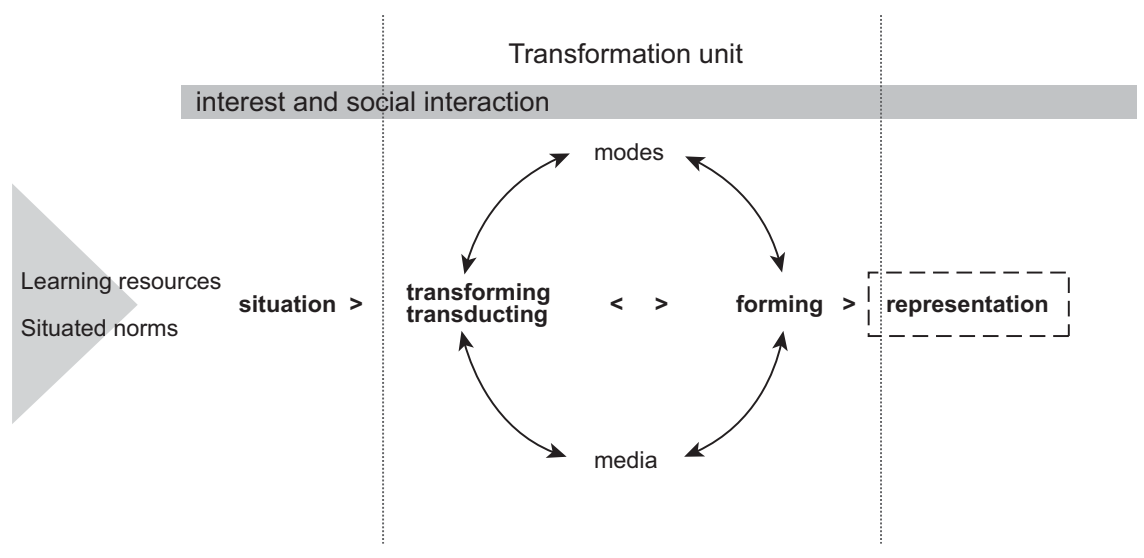

Figure I.I Non-formal Learning Design Sequence.

curiosity, and a semi-formal learning context - the different glass courses and glass museums. It also seems obvious that the glassworks I could do were not only a result of my personal interests and skills, but also of my social environment and my financial opportunities: the availability of courses with experienced glassworkers, the documentation of glass design through history, the possibility to buy tools, a kiln and special glass, as well as to visit glass galleries and museums. My own interest did not develop in an empty space.

This learning experience could theoretically be discussed in terms of a "Non-formal Learning Design Sequence" (Figure 1.1) and a "Semi-formal Learning Design Sequence (Figure 1.2). The first framing of my learning was when I went to a glass course, with its special material and semiotic resources, its norms and values, and its situated challenges. In different sequences I learned about glass, glass design and glass craft-both during the courses I took and by way of my own exploration of the characteristics of different glass materials. My glassworks could be seen as representations of my knowledge and skills, but they were not formally valued, and I did not have to pass any formal test to be able to continue with them. I learned from my own mistakes, even though we had teachers showing us the elementary ways of doing things, and from the more or less enthusiastic comments from my classmates and from my family and friends.

The main difference between the learning sequences in these two learning environments is that the non-formal learning sequence could start fortuitously, whilst the semi-formal learning sequence often has a clearer starting point (such as the setting of a museum exhibition) and is also framed by institutional aims and traditions, available objects, or the aspirations of the curator, for example. I think that it would be fair to say that most learning (as in these two different contextual framings) actually follows what we could call "rhizomatic webs" 


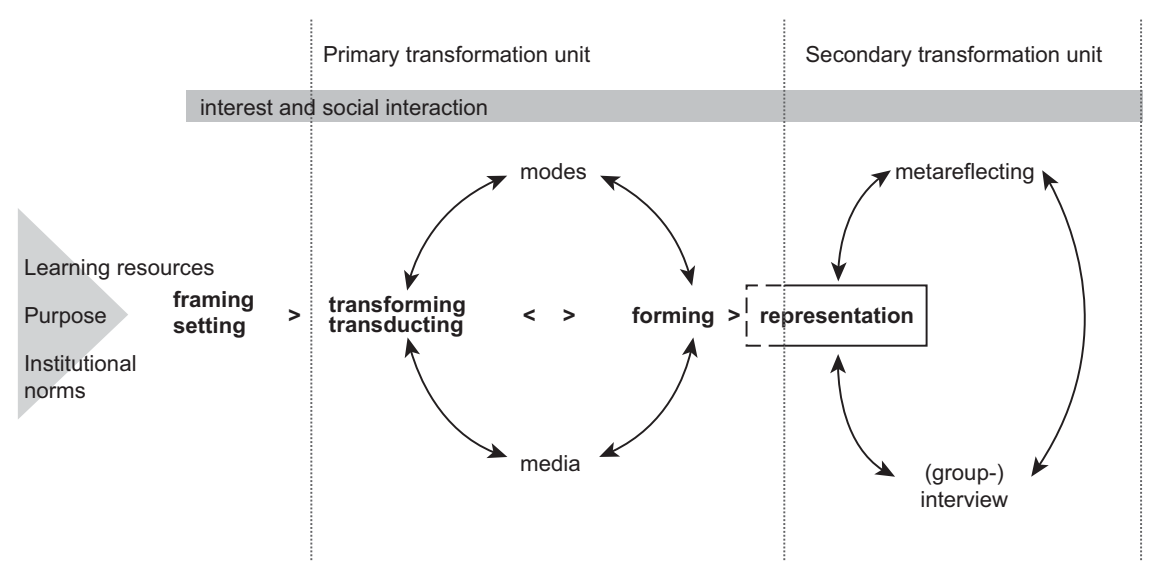

Figure I.2 Semi-formal Learning Design Sequence.'

(see Chapter 2 by Lindstrand \& Selander in this volume). A new idea, and new information, may lead to new questions; it may encourage us to continue on or change direction. Additionally, there is no curriculum to be fulfilled, and no necessary test to pass.

As a contrast, my next example stems from a formal learning context-the school. The subject is educational sloyd, here with a focus on woodcraft. ${ }^{2}$ When I went to school, sloyd was a part of the curriculum, stemming from the needs and skills in the pre-industrial society. I was 11-12 years of age, and the sloyd education focused on such things as the tools and the names of the different tools, and of course on the handicraft skills. ${ }^{3}$ Basic skills were taught first, and we had to learn (as it was seen at the time) formal, elementary things like sawing and planing before we were allowed to create something out of the material. While I was still planing-and it was important that my piece of wood should be absolutely plane from each side and angle-one of our classmates was allowed to make a chair.

After many weeks of planing, I was finally allowed to do carving, and during the rest of that semester I managed to make a little bowl. However, we were not taught anything about aesthetics or design related to three-dimensional forms and proportions, such as the relation between width and length, inner and outer proportions, or, for example, thickness in relation to cavity (Thorsnes, 2009). The idea was not that we should create or experience new possibilities out of our own interest, nor that we should find out new ways of exploring different materials. The important thing was to complete the curriculum, where one goal was that each individual should learn the same terminology and reach the same basic handicraft skills as everyone else. At the end, all our products were evaluated according to specific school-standards, including good order and good behaviour. 
To sum up, our second example could be discussed in terms of the "Formal Learning Design Sequence" (Figure 1.3). In this model, learning is understood as an activity that is formally framed and assessed. The learning was also in this case carried out in sequences, but with a heavy emphasis on common goals and testing standards, ${ }^{4}$ but this is not to say that evaluation as such is wrong. Evaluation cannot be avoided in a social context; it always takes place in one way or another (Boistrup, 2015). ${ }^{5}$ Here, the point is that that evaluation in a formal context is different from that in a non-formal or semi-formal (as in a museum) context, which may have consequences for individual engagement in a specific knowledge area.

In the formal Learning Design Sequence, we can notice a more clearly framed beginning, based on the purpose, and the curriculum and the standards of the school, as well as on the potential resources, norms, formal regulations, and so on. The "setting" starts with the teacher's interpretation of the frames, and the pupil's attention to-and understanding of-what is expected from them. The pupils can then, during the "First Transformation Cycle," work with available (and accepted) material and semiotic resources, test different solutions, and sketch out possible ways to talk about, or show, their understanding. Here we can also focus on other aspects, for example, how the teacher or the pupils position themselves in the learning space, and how their social interaction is carried out.

At the end, during "The Second Transformation Cycle," the pupils are expected to present their learning and new knowledge by way of a test, an essay, a film, or

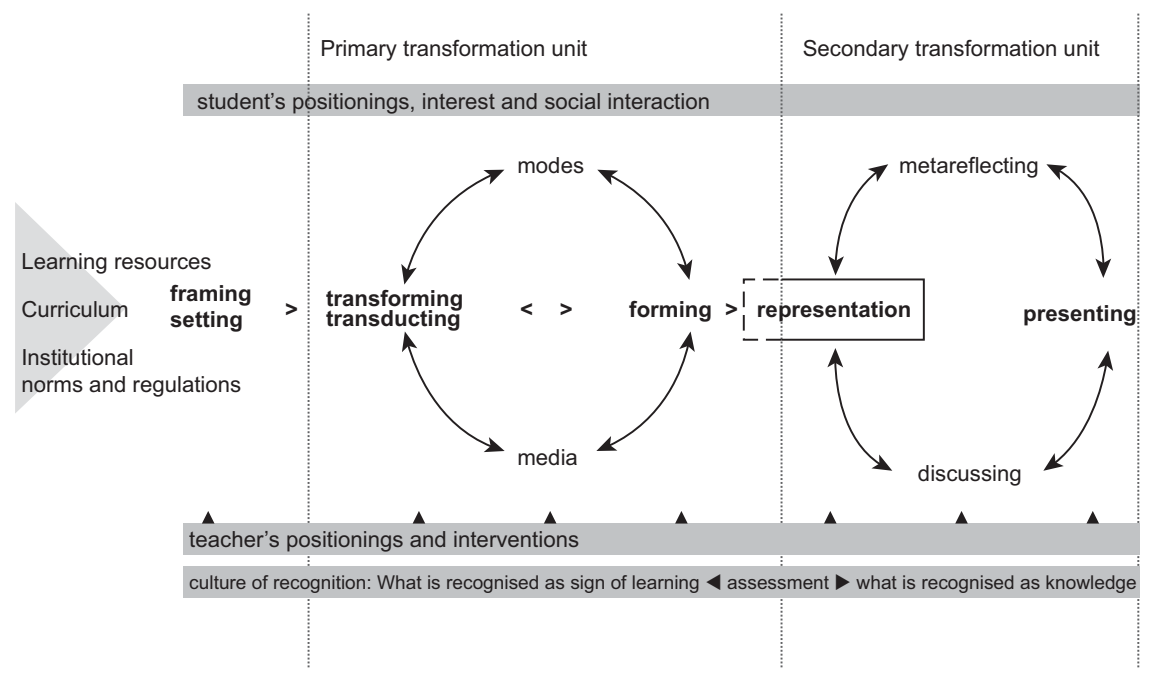

Figure I.3 Formal Learning Design Sequence. ${ }^{6}$ 
a PowerPoint; in other words, they produce a new knowledge representation. Their work is formally evaluated-sometimes also publicly discussed and reflected upon. $^{7}$ With these two examples in mind, we shall now move on to the basic concepts in a multimodal and design-oriented approach to learning. However, I would first like to make a short remark on "basic knowledge."

\section{A detour on "basic knowledge”}

The second example above also exemplifies the role of schooling in the industrial society, with the uttermost purpose to see that everyone, after education, could be employed in his or her "right" place in working life. Everyone had to acquire the same "core knowledge" or "basic knowledge," and they were evaluated and ranked according to standardized tests, no matter their individual interests, talents, or ideas about future work.

However, there seem to be at least two epistemological and ideological roots and implications of the idea of "necessary basic knowledge" for everyone. We can identify "basic knowledge" as that kind of knowledge that binds a society together-like social rules and habits, religious beliefs (and their variations), or, for example, knowledge about democracy and how one could handle conflicts (Burman, 2021). During earlier periods of time in history, such as the Renaissance and the Middle Ages, those things were discussed in religion, philosophy, and literature. The aim of schooling during those times was to learn about such things as rhetoric and grammar, music and mathematics, and to learn about oneself and what characterizes "good judgement" as well as "a good life" (Selander, 2017).

As a contrast to this ideal, the idea of "basic knowledge" changed at the end of the 20th century: from an overarching, common knowledge and individual grow th ${ }^{8}$ to the details of each separate school subject. ${ }^{9}$ So instead of seeing "basic knowledge" as that kind of knowledge that binds a society together (whatever that might be), the development seems to be accelerating towards a more and more fragmented and factual knowledge. Much of contemporary debate seems to be about "facts" and (the return of) "objective knowledge." At the same time, we seem to lack a serious debate on what kind of knowledge would be needed to meet future demands with complex and tricky problems, and what kind of knowledge would give insights into, for example, conflicting interests and power relations, as well as those things that characterize a good life (Bauman, 2012; Collins \& Halverson, 2009; Morin, 1999, 2008)..$^{10}$

So, if we are actually interested in "knowledge," we might as well develop a new kind of individually and digitally based tutoring system-within new social framings. For example, the Nobel prize-winning Swedish author Selma Lagerlöf had a governess, and learned, among other things, five languages. Today, we can likewise learn many things from distributed information and hybrid education, for example, by way of game-like elements in teaching, 
games, and simulation programs. Therefore, we would need new insights into what we mean by "knowledge," "learning," and "playing"11 in our contemporary time, as well as a more accurate understanding of how one could represent and assess multimodal knowledge representations (Arnseth et al., 2019; Brooks et al., 2021; Höglund, 2017; Lim, 2021; Kress \& Selander, 2012; Kress et al., 2021; Selander, 2008b).

\section{Design as a dynamic perspective}

Let us now return to the two examples above and the question of different designs for learning in different learning environments, and by way of different learning resources, learning goals, and cultures of recognition. If we ask ourselves how we could do research on learning in these two different cases, many possibilities are at hand. My own research journey started with sociology and the sociology of education, and it was not a big step to begin the study of the works of Vygotsky and the sociocultural understanding of collective memory, institutional framing, or social classes or strata, as well as the child's growing understanding of the world when she or he has developed language in her or his own milieu. But how to study the learning on different levels, both in terms of individual learning and learning within groups? Behavioural observations alone do not seem to be a good idea, because we then focus on behavioural change, which does not involve meaning-making. Likewise, to interview people on their meaning-making misses actual changes in their capacity to act in new ways, simply because people are blind to their own practice. Therefore, interview data alone do not give evidence of peoples' new skills and capacities in terms of their new abilities to act in different contexts, even though such additional information could be of importance. ${ }^{12}$

Later on, I came into contact with social semiotics and multimodal understandings of communication and meaning-making. Here I found detailed analysis of sometimes very short, communicative sequences with different resources, but much of these analyses took the "social" for granted. So, this tension between sociological (and social-psychological) views on learning, on the one hand, and the language-based, social semiotic view on meaningmaking, on the other, called for attention. And it was in this gap that I (and the research group in this volume ${ }^{13}$ ) started to elaborate on some basic questions:

1 How can we study situated meaning-making and new capacities to act in different, more or less formally framed, institutional contexts?

2 How can we construe a rigorous and productive methodology, which is based in a theoretical perspective, and which also takes the ethical research questions into consideration? 
3 How could a research perspective, which often analyzes what has happened, be combined with a perspective that is interested in innovative and problem-solving practices-what might happen - without losing our ambition to investigate and explain the processes? ${ }^{14}$

Out of these questions, we started to build a design-oriented perspective, with a focus on:

(a) how a multimodal analytical approach can be used to study multimodal communication and texts (in its wider sense), with an understanding of the institutional conditions for learning and knowledge representations (which in different ways are exemplified in Part 2 of this volume);

(b) the development of a theoretically, methodologically, and ethically oriented design-perspective (as in Part 1of this volume); and

(c) the different roles and responsibilities of researchers and professionals involved in collaborative, innovative processes.

Traditionally, the concept "design" refers to such activities as thinking and planning in order to manufacture a model or prototype that combines form and function - as in designs of cars, buildings, kitchen utensils, furniture, and clothing, or in the development of organizational structures and routines. During recent decades, the concept of design has changed character, towards meaning and function, collaborative cultures, digital design, and re-design. In line with this understanding of design, our perspective has a focus on meaning and function, especially on such aspects as learning and meaning-making, framing, re-design, knowledge representations, Learning Design Sequences, cultures of recognition, and signs of learning (see, e.g., Boistrup, 2010; Elm Fristorp \& Lindstrand, 2012; Insulander, 2010; Insulander et al., 2019; Kempe ${ }^{15}$ \& West, 2010; Kjällander, 2011; Rostvall \& Selander, 2010; Selander, 2008a, 2015; Selander et al., 2021; Selander \& Kress, 2017; Selander \& Svärdemo-Åberg, 2008; Åkerfeldt, 2014).

At large, this perspective draws upon two different, albeit related, educational and problem-solving traditions and experiences: the Nordic tradition of equal education, project-based learning, and further education as well as on "VolkBildung" (Arnseth et al., 2019; Sørensen, 2008; Sørensen et al., 2010) and the orientation of design towards meaning and function, collaborative work, user-oriented design and re-design (Brooks et al., 2021; Brandes et al., 2009; Brown, 2009; Dorst, 2015; Dunne, 2018; Knutsson et al., 2021; Marion \& Fixson, 2018; Verganti, 2009). We were especially inspired by design-oriented research perspectives, not least the relation between "doing research" and "doing innovative work" (Barab \& Squire, 2004; Clarke, 2018; Löwgren \& Stolterman, 2004; Redström, 2017); and a multimodal understanding of communication, semiotic resources and meaning-making (Bezemer \& Kress, 2016; Jewitt, 2012; Kress, 2010; van Leeuwen, 2005); as well as different design-oriented, sociocultural and anthropological research on education and learning (Collins 
et al., 2004; Laurillard, 2012; Lim, 2015, 2021; Säljö, 2005; Sheridan \& Rowsell, 2010; Sørensen et al., 2010; Wulf, 2013; Østern \& Strømme, 2014). ${ }^{16}$

In sum, our overarching concept of "design" refers to learning environments and resources, meaning-making and communication as institutionally and individually framed social practices. It is a theoretical and methodological tool for doing research and making detailed analyses of knowledge representations and learning processes, which look both at existing knowledge representations and at the representations and resources that are used by the learners in their multimodal production and re-design of new representations (Boistrup \& Selander, 2009; Insulander et al., 2019; Selander, 2017; Selander et al., 2021). It is also a theoretical and methodological tool for finding a way to take part in collaborative, systematic, innovative and developmental work in different sites, as, for example, with schools, museums, and communities (Glawe \& Selander, 2021; Halverson \& Kelly, 2017, also see Chapters 5 (Boistrup \& Hällback), 6 (Kjällander), and 9 (Insulander \& Svärdemo-Åberg, in this volume).

\section{Designs for learning-designs in learning}

"Designs for learning" also entails the perspective of "Designs in learning." Designs for learning refers to such things and processes that are produced and organized for learning, like school and museum buildings, school textbooks, schedules (or timetables), curricula, tests, teacher education, selection principles, school laws and regulations, objects, and artefacts. It also includes institutional traditions and social norms that have been developed over time, and so on.

Designs in learning, on the other hand, refers to learning processes and products, like interests, knowledge styles, ${ }^{17}$ habits concerning the use of different sources of information as well as different resources and techniques to produce sketches of the learning along the way (see "re-design" below). It also concerns aspects such as the preferable time of day to work with school tasks, whether the individual learner likes to discuss with others or not, and so on. And since the individual learner also can follow arbitrary associations and information tracks, their learning paths can be talked about as "rhizomatic webs" (see Chapter 2 by Lindstrand \& Selander in this volume). It is therefore important to know more about individual learners, and to develop the tools to handle massive and diverse individual data-by way of Artificial Intelligence, for example (Swiecki et al., 2017). It is also important that the individual learner is given a chance to learn more about his or her own learning (so called meta-learning) and that he or she learns how to use cultural tools for thinking (Barth, 2015; Säljö, 2005).

The model of Learning Design Sequences (Figures 1.1, 1.2, and 1.3) can be used to analyze the specific, contextual learning situation, to follow both the learner's and (as in Figure 1.3) the teacher's actions, or, for example, to study which resources are used, and how they are used, as well as to see what kinds of evaluative arrangements (formal tests, performances, etc.) are at play. 


\section{Framing}

Framing is a term with many different meanings, depending on its theoretical grounding. ${ }^{18}$ Here, we will use framing as a spatial and temporal bounding of significant bits of information. Framing can be studied both from the point of view of formal, institutional framing (as in a school with its curriculum and explicit goals and testing procedures, norms and regulations, teachers' planning, etc.) and from the point of view of individual framing (derived from social background, dispositions, ${ }^{19}$ hopes for the future, individual interests, and situated focus, ${ }^{20}$ - and therefore not primarily psychologically based). In our case, the concept of framing is also used to analyze and understand epistemic differences and power relations in the "between"-in the social meeting between the formal or semi-formal (institutionally framed) offerings, its demands and potential resources, and the individual's interests and acting.

However, we could also focus on the epistemological framing-on theoretically based definitions, hierarchies and networks of important or significant concepts (Bowker \& Star, 2000; Haack, 1996; Selander, 2018). In an educational, institutional context, epistemological framing highlights the formalized, subject-oriented concepts and procedures, and the educational task is to help the individual learner to re-frame his or her preliminary understanding and to learn to use the subject-oriented repertoire, in order to be able to talk about, or analyze, more domain-specific questions and problems. ${ }^{21}$

Epistemological framing could be discussed further in terms of emblematic and thematic framings, where the first concept points at the overarching organizing principle and the second at different specific sub-themes (Insulander et al., 2019). As an example, knowledge about the heart can be framed in many different ways. In an encyclopedia, the focus could be on such aspects as the heart, heart-diseases, cardiopulmonary rescue, or, for example, myocardial infarction, described by an expert for the non-expert.

In a school-textbook for the upper secondary school, the heart can be described under the heading "The blood and the circulation," where heartrelated problems are related to smoking, drinking, and snuffing-including a moral undertone. In a school textbook, a description usually ends with control-questions concerning some basic facts. In another textbook-under the heading "Heart and vascular diseases," aimed at vocational training for assistant nurses - the focus is rather on descriptions of heart problems, including such things as how to monitor patients.

The last example is from an edutainment game (an old CD-ROM disc!) with different concepts like the cardiac muscle, as well as pictorial illustrations to explore. Here, by way of gaming, we may also be transported inside a patient's body, asked to "save the patient" by zapping injured cells (Selander, 2003). These four examples show different epistemic framings: the first one focuses on the medical knowledge of organic structures and functions, presented for the interested non-expert; in the second, the school 
textbook frames the information from the curricular perspective (some basic facts and organic functions) with an additional moral tone of what is good and healthy behaviour, and what is not; the third example-aimed at preprofessional education of assistant nurses-frames the information from the point of view of medical treatment; and our last example combines descriptions and exploration with gaming elements. Each of these emblematic framings leads to different sub-themes, but they all represent "knowledge" about the heart.

The broader understanding of framing in problem-solving and innovative processes of products or in organizations (Dorst, 2015; Marion \& Fixson, 2018) can therefore also be used to analyze teaching and learning, in smaller or larger contexts (Halverson \& Kelly, 2017; Glawe \& Selander, 2021; Selander, 2017).

\section{Setting}

The concept of setting (in the Learning Designs Sequence model) can be used in the analysis of teaching and learning in a formal school-context to emphasize the duality of 1) the teacher's setting of the task for the pupils to work with, institutionally framed in terms of rules and regulations, norms and traditions, testing and grading, and so on; and 2) the individual pupil's setting of his or her own role as a learner, for example, as: (a) a person interested in this particular domain, and perhaps preparing him- or herself for a future job in the field; (b) a person who is uninterested in this particular knowledge domain, but who wants to have good grades for future studies, and therefore shows (some) interest in the knowledge domain; or (c) a person uninterested in the field or any future studies, and therefore disregards (this particular) schoolwork task.

However, setting can also be used to analyze the processes in a semi-formal museum-context, and the meeting between, on the one hand, the institutional resources and the aspirations of the curator and, on the other hand, the museum staff at large with the visitors (Insulander, 2010; also see Chapters 7 (Insulander, Lindstrand \& Selander), 8 (Insulander \& Öhman) and 9 (Insulander \& Svärdemo-Åberg) in this volume). It can also be used to analyze and reflect upon learning in a non-formal framing (as shown above in my introductory description of glassmaking).

\section{Re-design-the transforming and forming processes}

In a wider sense, re-design involves activities to change a given design in order to create something anew, as when you use an old teacup as a toothbrush stand, remake a chair to serve as a clothes hanger, or when you take information from the Internet and adapt it to the needs of a special group of pupils. Re-design 
can take the form of transformation to the same mode, as when text is transformed into a new text (Kress, 2010), or transduction, when, for example, a text is transformed into a pictorial illustration (Kress, 2010; also see Höglund, 2017; Lindstrand, 2006; Öhman-Gullberg, 2008). ${ }^{22}$

Here, I would also like to use the concept of re-design (as a metaphor) for learning activities. In a school context, a lesson may start by the setting of a learning task. The re-design includes (a) the reading and interpretation of existing knowledge representations, as well as (b) the different modes and media that individuals (or groups) are using to sketch their new understanding and finally create a new knowledge representation (see Figure 1.1, Figure 1.2, and Figure 1.3).

\section{Knowledge representations}

A knowledge representation can be understood as a frozen moment that produces a context-bound, situated affordance (see also Chapter 3 by Lindstrand in this volume). In a school context, pupils use knowledge representations in the form of different learning resources, which they must interpret before they design their own understanding; in our terminology this is a re-design of the (given) knowledge representation. This view also entails the idea of learning as a creative engagement which adds something to the world, as a contrast to the idea of learning as reproduction of "the given." 23 Knowledge representation underlines the role of materiality and semiotic modes for how something can be designed and interpreted, including such aspects as what is in focus and what is more in the periphery, what is taken for granted and what is seen as new, and so one (Kress, 2010; Kress \& van Leeuwen, 2021). Knowledge representation is, in this perspective, therefore different from the ideas of knowledge representations as "true representations," or, for example, "mirrors of reality." However, this does not mean that we have to leave behind the idea of solid scientific knowledge (Haack, 1996). ${ }^{24}$

Knowledge representations may also be discussed in terms of a wider concept of text, as in multimodal texts, and how different semiotic resources "go together" or "contradict" each other (Danielsson \& Selander, 2016). This includes a wider understanding of the concept of text as a multimodal, semiotic resource and a visual representation (Archer \& Newfield, 2014; Kress, 2003). In addition, I would also like to include interactive texts (if we see a game as a text) since this kind of text clearly involves action as a part of the understanding (Arnseth et al., 2019; see further Table 1.1).

In each of these ways to represent knowledge (as text, multimodal text, or interactive text), we can see different affordances according to choices of materiality, semiotic resources, and activities, and therefore also different possibilities to express knowledge and learning-something which relates to cultures of recognition and assessment standards in different domains as well (Kress \& Selander, 2012; Nouri et al., 2017). Of course, it is also possible to mix modes 
Table I.I Dominant understandings of "Texts" in relation to social and technological conditions. (modified from Selander, forthcoming)

\begin{tabular}{|c|c|c|}
\hline $\begin{array}{l}\text { Written and printed (ver- } \\
\text { bal) texts }\end{array}$ & $\begin{array}{l}\text { Multimodal texts/Visual } \\
\text { representations }\end{array}$ & Interactive texts \\
\hline $\begin{array}{l}\text { Text is defined as written } \\
\text { or printed letters } \\
\text { and words. Texts are } \\
\text { sequenced in a linear } \\
\text { way. }\end{array}$ & $\begin{array}{l}\text { A wider understanding of } \\
\text { text as visual representations } \\
\text { (pictorial illustrations, } \\
\text { graphs, etc.) and the role } \\
\text { of layout for meaning- } \\
\text { making. Multimodal texts } \\
\text { are sequenced according } \\
\text { to spatial principles }\end{array}$ & $\begin{array}{l}\text { Interactive texts change } \\
\text { according to the user's/ } \\
\text { actor's capabilities and } \\
\text { choices, and they are } \\
\text { sequenced on different } \\
\text { levels. }\end{array}$ \\
\hline $\begin{array}{l}\text { Reading is understood as } \\
\text { the capability to read } \\
\text { and decode letters } \\
\text { and words. You (most } \\
\text { often) learn to read } \\
\text { early on in life. }\end{array}$ & $\begin{array}{l}\text { A wider understanding of } \\
\text { reading as a capability to } \\
\text { understand multimodal } \\
\text { texts. You learn to read } \\
\text { different genres and types } \\
\text { of text throughout your } \\
\text { lifetime. }\end{array}$ & $\begin{array}{l}\text { Interactive texts relate to } \\
\text { the user's actions and give } \\
\text { constant feedback. To } \\
\text { understand a text is to act } \\
\text { in an accurate way. }\end{array}$ \\
\hline $\begin{array}{l}\text { Writing is understood as } \\
\text { the capability to write } \\
\text { letters, words and } \\
\text { sentences. }\end{array}$ & $\begin{array}{l}\text { A wider understanding of } \\
\text { writing also includes the } \\
\text { capability to compose } \\
\text { multimodal texts. }\end{array}$ & $\begin{array}{l}\text { Writing in relation to } \\
\text { interactive texts includes } \\
\text { acting with the program, and } \\
\text { also the (basic) capability } \\
\text { to program a game. } .^{25}\end{array}$ \\
\hline
\end{tabular}

and media in hybrid-teaching. In a Norwegian project aimed at developing pupils' understanding of music by way of composing music on iPads, the performative aspect of learning was strongly emphasized (Bandlien, 2019; Bandlien \& Selander, 2019).

\section{Signs of learning}

The question "How can we see that learning has taken place?" is of course central, yet very difficult to answer. We cannot see into the head of the learner; we have to judge from how learning manifests itself in the form of new capacities and new understandings, for example, in communication, in actions or through testing. This also means that it is possible that someone has learnt something which is not fully demonstrated or visible at a certain moment, or that one and the same person may show different aspects of what he or she has learnt depending on the test-situation (Säljö, 1998; see also Chapter 5 by Boistrup \& Hällback in this volume). It is, furthermore, the case that learning is an ongoing process-including new "aha moments" or insights as well as small adjustments in what has already been learnt - and therefore, learning is hard to capture at one single moment in time. We rather need a sequential thinking process, where we observe activities between (at least two) different "points in time." We should 
also remember that there is no such thing as the "same" testing situation on two different occasions - there are always some kind of intermediate variables that to some extent affect the testing situation. ${ }^{26}$

The term "learning" can mean many things. Learning is not only about increased individual and mental capacities. It also involves such aspects as bodily learning and social learning; it involves creativity and responsibility, as well as judgements of what is proper to do at a certain moment, and what is not (Nussbaum, 2011). Our learning depends on our brains, our bodies, and our social environment. Learning is not a "thing," but a "process." Still, even if "learning" is a floating term, it seems valuable and fruitful to talk about "learning," if we specify from which perspective we speak and what we include in the term. ${ }^{27}$ Learning involves ongoing change, and involves aspects such as acquiring a greater variety of stories, explanations, descriptions, and skills. From this point of view, it does not seem that fruitful to use metaphors like "surface learning" and "deep learning." A design-oriented understanding involves other perspectives and metaphors, oriented towards the richness of variations. ${ }^{28}$

We learn from school textbooks, but also from a rich variety of other resources. We learn in school-contexts, but also in all other contexts. And we learn different things depending on our personal (and socially embedded) aspirations and interests. We learn when we play, but also when we are focused on the learning of new things per se (e.g., multiplication or verbs in a new language). We learn what seems important in a certain environment, but also a lot of things besides (sometimes talked about as the "hidden curriculum") since we more or less consciously adapt to new situations.

To understand learning, we have to understand it as a process in a certain social environment-as a social practice (Kress et al., 2021). We can study learning by focussing on situated sequences, searching for "signs of learning," as well as being aware that these signs of learning are context-bound-dependent on what counts as learning in a certain assessment practice, which is bound by existing "cultures of recognition" (Kress \& Selander, 2012). ${ }^{29}$

\section{Learning design sequences}

Our model Learning Design Sequences (LDS) (Figures 1.1, 1.2 \& 1.3) is a theoretically-based, methodological tool to do empirical research on learning in different contexts. It is a tool that can help us to sort out important aspects, for example, communication and social interaction, activities, knowledge representations, or signs of learning. However, it is not a rigid model, to be followed in perfect detail. It is rather a heuristic tool, which in combination with other perspectives can give a structure for how to collect and analyze data (see Chapter 5 by Boistrup \& Hällback in this volume). Therefore, we can use a social semiotic and multimodal analysis of communication-but we do not have to do this. Such an analysis is rich and fruitful, but also time-consuming. The important thing is rather to keep in mind that we observe aspects of 
communication, activities, and the transformation of knowledge representations into new ones - which can be studied as signs of learning.

When we do this type of analysis, we first take a closer look at the conditions and frames, norms and regulations, traditions and potential resources, and so on. We then analyze the communication and the meaning-making activities and the outcome of these activities. Finally, we look more closely at the practices of evaluation and metareflections. However, elements from each of these three parts may also be present in other parts: we evaluate during the whole process, not only at the end of that process; students try out new ideas when learning, but teachers also do this when planning for new teaching activities (as in the first phase), and the communication between, for example, teachers and pupils, or between pupils, also takes place in the third phase. And, as we see in Chapter 4 by Åkerfeldt and Boistrup in this volume, the model can also be used to reflect upon ethical dilemmas that might occur during different stages in the research process.

Besides this, the LDS model can also be used as an instrument for planning learning sequences as a teacher. If so, the order is likely to be changed. The starting point is rather the third phase: what is the result we want to achieve? Then comes the reflection on the first phase: curricula, norms, traditional habits, new resources for learning, and so on. Finally comes the second phase in the model: the activities and signs of learning we want to plan for, and observe, during the learning process.

\section{Concluding remarks on designs for learning}

Designs for Learning is a way to discuss and study learning in different (nonformal, semi-formal, and formal) contexts. It is a way to conceptualize learning in different hybrid environments, where information is distributed and playful elements may be a part of the learning process (Lindstrand et al., 2016). It gives attention to such framing aspects such as norms, regulations and traditions, as well as to which material and semiotic learning resources are at hand. It focuses on learning sequences and the ways the learner expresses and communicates his or her understanding, and it gives attention to activity spaces, mimetic learning, and agency, as well as to cultures of recognition. In other words, this is a way to conceptualize learning as a social practice (Kress et al., 2021).

We use the concept of "design" as a metaphor in a wider sense, but also to outline a theoretical grounding, and a methodological strategy - the Learning Design Sequence model - for doing empirical research. Furthermore, design also outlines a way to organize partnerships in innovative learning processes (Glawe \& Selander, 2021; Insulander et al., 2017; Selander, 2017; Selander \& Kress, 2017). ${ }^{30}$

\section{Notes}

1 Figures 1 and 2 are slightly changed compared to the first models from 2008, and developed from discussions in Kvinge (2019), Nouri (2014), Åkerfeldt (2014), and others. 
2 "Sloyd" in Swedish "slöjd," focuses on different materials and techniques: woodwork like sawing and planing; metalwork like soldering and welding; or work with fabrics like sewing and knitting. Today we can find a slightly more creative approach, with, for example, designs of patterns and combinations of mixed materials and techniques (including digital devices).

3 Perhaps someone thinks that it is unfair to compare the learning of a grown-up man with that of a young boy, since the former can think of the consequence of his choices in another way than a boy could. However, if we think of learning in a broader sense as a social practice (see Kress et al., 2021) and what drives learning, there might not be that sharp a difference. It is rather a matter of how we institutionally and epistemically frame communication and learning (also see Selander, 2018).

4 The rhetoric about school standards is often related to individual achievements and "just" evaluations, but school-testing is more often steered by the need to sort individuals from each other, and to rank them.

5 Just think of all the evaluative statements or expressions we use in everyday life, like wonderful, beautiful, delicate, smart, or elegant, and their possible contrasts, like horrible, ugly, stale, stupid, or clumsy.

6 Figure 1.3 is slightly changed compared to the first models from 2008, and developed from discussions in Kvinge (2019), Nouri (2014), Åkerfeldt (2014), and others.

7 Reflections and discussions on a smaller scale also take place in relation to each "choice" during the learning process in "The First Transformation Cycle."

8 Which have been discussed in terms of "Bildung" and "Liberal Arts."

9 It seems that the only outcome of this is that youngsters spend more and more time in schools to do (more or less) the same thing, and that the official purpose seems to be to uphold a good ranking in international testing. A vital question we could ask is: for how long will it be possible (economically speaking) to uphold, and further expand, this system (given that a fifth or a fourth of youngsters will fail)? And another is: what would it take to develop individual interests within a common, social framing?

10 When the Swedish government recently encouraged lowering the age of starting schooling from seven years of age to six, one of the main arguments was the need to reach "knowledge goals." However, such goals are historically situated, and seem in this case to be mainly devoted to international "contests" on testing. We can notice that the main argument was not, as in the discussions within other OECD-countries, to develop knowledge and skills and prepare for a future, complex democratic society with creative and collaborative individuals. We could also think of what democratic value the argument above would have had during the time of fascistic regimes of the 1930s and '40s, when textbooks in, for example, Germany and Italy praised the dictator and his party (see, e.g., Teistler, 2006). And what would this have meant in terms of "knowledge goals"?

11 To play indicates in many contexts something different from work, something you do for fun, or something you do in your spare-time-in other words, something that is not really serious. As a contrast, we can find more interesting and elaborated ideas on play by, for example, Caillois (1967), Gallagher (2015), Karoff (2013), and Pellegrini (1995).

12 Outcomes of social actions are not one-directed consequences of intentions, even if intentions and endeavors towards certain goals give some directions for our acting. It is also the case that our intentions and endeavors are partly consequences of social conditions, embedded in habits, expectations, and world view, and so on. It can also be of interest to notice that the role of interviews in sociological research rapidly increased at the end of the 1960s, when portable tape recorders made mobile recording possible. Then we also had many so called "report" books. Today, we can see something like this, since digital and portable cameras make it possible to film many different social interactions and activities, and thus enable more detailed multimodal analysis of social communication and ways of working with different resources.

13 Also see Selander et al. (2021). 
14 This question also involves a perspective on what scientific work is about. During the peak of logical empiricism in Vienna during the 1920s, the dominant idea was that natural science should be the guide for all kind of scientific work. Later on, in 1959, the physical chemist Charles Percy Snow (2012) gave a famous talk about the two cultures and the differences between the humanities and the natural sciences (something which had already been discussed at the end of the 19th century by, for example, Wilhelm Dilthey, 1996). As a next step, Jerome Kagan (2009) introduced the idea of the three cultures: the natural sciences, humanities, and social sciences, and the differences between them in terms of questions, types of evidence, vocabulary, the influences of historical and social parameters, the role of ethical reflections, and the criteria for elegance in the presentation of findings. Perhaps it is now time to talk about the four cultures, since design-oriented thinking includes involvement in innovative work as well as reflections on designs as a basis for theoretical work (Selander, 2017; also see Barab \& Squire, 2004; Redström, 2017).

15 Previously Anna-Lena Rostvall.

16 Even though we as a research-group share many of the central thoughts on "designs for learning," each individual researcher has his or her own take on this perspective, depending on research interest and research questions. As the reader will find out, some relate more strongly to multimodal semiotics, others move towards ethnographic, communicative studies, and so on. As I see it, these variations uphold a dynamic discussion, and make it possible to further develop the perspective of "designs for learning."

17 It may be all too vague to talk about "learning styles" since there seems to be no real evidence for the value of this. However, "knowledge styles" refers to such aspects as: ways of reasoning, for example, going from the whole to the parts or the parts to the whole, or which kinds of knowledge representations are preferable for different individuals, like longer text, tables, illustrative examples, and so on.

18 We can find organizational perspectives (like the frame-factor theory (Lundgren, 1972); Goffman's analysis of front-stage and back-stage as different ways to frame social communication (Goffman, 1990); or, for example, different psychological or sociological views on "schemes of interpretation").

19 What Bourdieu (2010) also discusses in terms of habitus.

20 Kress (2010) has a similar discussion on "affordance" as a potential meaning, and "prompt" as an actualized meaning in relation to individual interests.

21 Similar concepts are, for example, contextualization, and the social principles of de-contextualizing and re-contextualizing, as Basil Bernstein (1973) formulated this: "Any formal educational experience entails de-contextualizing and re-contextualizing. In ways we do not properly understand, informal everyday experience, everyday communication within the family and peer group, creates procedures and performances fundamental to formal education. However, formal education selects, refocusses and abstracts from such experience, and in so doing de-contextualizing" (Bernstein, 1973, p. 30). Bernstein also talked about the differences between the working-class kids' "restricted and contextbound codes," and the middle-class kids" "elaborated and context-independent codes," where the latter was closer to the codes that dominated in the school-context.

22 This definition may be tricky. Kress (2010) uses the definition of transformation as a change within "the same" mode, and transduction as a change to "a different" mode, and that "mode" should be understood in relation to Halliday's three communicative aspects (p. 87). Kress also relates the use of the term "mode" to: (a) What is the social and cultural domain that it covers? and (b) What can a mode do in the cultural domain that it "covers"? (p. 84). The term "mode" becomes even more complex if we discuss "mode" in relation to "medium:" for example, is "writing" the same mode when it is produced by hand, by typing on a typewriter or using the computer keyboard? Kress also discusses whether image, speech, gesture, or, for example, writing are "modes" or not (p. 84) noting that what we "do" in these three different cases seems to be different kinds of 
activities in terms of planning, and changing a text, linking it to other texts, and so on. There seems to be no absolute definition of the term "mode;" still it can be useful as a stipulated definition and context-bound clarification, to analyze aspects of knowledge representations and communication within a specific cultural domain.

23 In fact, humans never reproduce "the same," not in rituals, nor in learning. Even if we reshape anew, like in rituals and performances or in mimetic learning, we always change something, even if it may "only" be a tiny little bit — as a contrast to computer logarithms, which can produce "the same" (Deleuze, 2001; Wulf et al., 2010). This standpoint is also close to Bakhtin's (1982) idea that you can never totally "close" an utterance. There is always something new to add.

24 Haack also has an interesting discussion of the differences between "foundationalism" vs. "coherentism," and discusses variations of "foundationalism" in terms of: 1) theory of justification builds on "basic" or "derived" beliefs; 2) justification as an "analytic enterprise"; and 3) criteria of justification stand in need of "objective grounding" Haack, 1996, p. 186). She argues that this does not mean we cannot make rigorous and serious scientific analysis.

25 Programming is a part of computational thinking, which includes the capacity to analyze a phenomenon and create a solution by way of coding a program. Coding can be done by way of words and symbols, or by way of pre-produced visual segments.

26 This is also a reason for having portfolios on which pupils/students work over time.

27 A "word" is defined by its lexical and social use; a "term" is related to a more restricted, professional use; and a "concept" is defined within a theoretical frame. Therefore, the "same" word may mean different things in different social and epistemic contexts.

28 A similar change of perspective is discussed by Chomsky. In his earlier works, Chomsky developed a critique against Skinner's behaviouristic perspective on language-learning, and emphasized that language is something unique to the human species, based on the construction of the brain, making a distinction between the "surface" structure (the speech) and the "deep" structure (the grammar). Inspired by computer research, Chomsky now rather talks about the capacity of the brain to take any syntactic elements and construct new, hierarchical structures (Berwick \& Chomsky, 2016). Here, the emphasis is on the capacity to create structures, rather than any elementary language structure.

29 However, it is not always clear which kind of rationality actually lies behind a specific assessment practice. For example, is musical skill and knowledge the only thing that counts in a musical testing situation (Sandberg-Jurström et al., 2021)?

30 Our approach can also be seen as one answer to the dilemmas of educational research and the role of designs for learning discussed by Halverson \& Halverson (2020).

31 The title reflects a playing with words: "Kobran" was a telephone introduced by the company L M Ericsson in 1956, named "the cobra" due to its shape. "Nallen" was another word for the teddy-bear, but also a nickname for the cellphone when it became largely used in the 1990s, and "Majjen" was a nickname for the teacher. The title of the book implies the question of what changes and what does not (Selander, 2003).

\section{References}

Åkerfeldt, A. (2014). Didaktisk design med digitala resurser. En studie av kunskapsrepresentationer $i$ en digitalisera skola [Didactic design with digital resources: A study of knowledge representations in a digitized school]. Doctoral dissertation. Stockholm University.

Archer, A., \& Newfield, D. (Eds.). (2014). Multimodal approaches to research and pedagogy: Recognition, resources, and access. Routledge.

Arnseth, H. C., Hanghøj, T., Henriksen, T. D., Misfeldt, M., Ramberg, R., \& Selander, S. (Eds.). (2019). Games and education: Designs in and for learning. Brill/Sense. 
Bakhtin, M. (1982). The dialogical imagination. University of Texas Press.

Bandlien, B. T. (2019). Ungdomsskoleelevers komponering med garageband på iPad. En musikdidaktisk studie av performative stopp-punkter $i$ et kritisk designteoretisk perspektiv [Secondary school pupils composing with GarageBand on iPad: A music educational study of performative stop-moments in a critical design-theoretic perspective]. Doctoral dissertation. NTNUNorges teknisk-naturvitenskaplige universitet.

Bandlien, B. T., \& Selander, S. (2019). Designing as composing music with iPads: A performative perspective. In A.-L. Østern \& K. N. Knudsen (Eds.), Performative approaches in arts education: Artful teaching, learning and research (pp. 81-96). Routledge.

Barab, S., \& Squire, K. (2004). Design-based research: Putting a stake in the ground. The Journal of Learning Sciences, 13(1), 1-14.

Barth, B.-M. (2015). Le savoir en construction. Former à une pédagogie de la compréhension. Retz. Bauman, Z. (2012). Liquid modernity. Polity Press.

Bernstein, B. (1973). Class, codes and control: Vol. 3: Towards a theory of educational transmission. Routledge \& Kegan Paul.

Berwick, R. C., \& Chomsky, N. (2016). Why only us? Language and evolution. The MIT Press.

Bezemer, J., \& Kress, G. (2016). Multimodality, learning and communication: A social semiotic frame. Routledge.

Boistrup, L. B. (2010). Assessment discourses in Mathematics classrooms. A multimodal social semiotic $s t u d y$. Doctoral dissertation. Stockholm University.

Boistrup, L. B. (2015). Governing through implicit and explicit assessment acts: Multimodality in mathematics classrooms. In M. Hamilton, R. Heydon, K. Hibbert, \& R. Stooke (Eds.), Negotiating spaces for literacy learning: Multimodality and governmentality (pp. 131-148). Bloomsbury Books.

Boistrup, L. B., \& Selander, S. (2009). Coordinating multimodal social semiotics and an institutional perspective in studying assessment actions in mathematics classrooms. In V. Durand-Guerrier, S. Soury-Lavergne, \& F. Arzarello (Eds.), Proceedings of CERME 6, Sixth Conference of European Research in Mathematics Education (pp. 1565-1574). Institut national de recherche pédagogique.

Bourdieu, P. (2010). Distinction. Routledge.

Bowker, G. C., \& Star, S. L. (2000). Sorting things out: Classifications and its consequences. The MIT Press.

Brandes, U., Stich, S., \& Wender, M. (2009). Design by use: The everyday metamorphosis of things. Birkhäuser Verlag AG.

Brooks, E., Dau, S., \& Selander, S. (Eds.). (2021). Digital learning and collaborative Practices: Lessons from inclusive and empowering participation in emerging technologies. Routledge.

Brown, T. (2009). Change by design: How design thinking transforms organizations and inspires innovation. Harper Business.

Burman, A. (2021). Dissensus. Drömmar och mardrömmar i demokratins idéhistoria [Dissensus: Dreams and nightmares in the history of ideas of democracy]. Natur \& Kultur.

Caillois, R. (1967). Les jeux et les hommes. Gallimard.

Clarke, A. J. (Ed.). (2018). Design anthropology: Object cultures in transition. Bloomsbury Academic.

Collins, A., \& Halverson, R. (2009). Rethinking education in the age of technology: The digital revolution and schooling in America. Teachers College Press.

Collins, A., Joseph, D., \& Bielaczyc, K. (2004). Design research: Theoretical and methodological issues. The Journal of Learning Sciences, 13(1), 15-42. 
Danielsson, K., \& Selander, S. (2016). Reading multimodal texts for learning: A model for cultivating multimodal literacy. Designs for Learning, 8(1), 25-36.

Deleuze, G. (2001). Difference and repetition. Continuum.

Dilthey, W. (1996). Hermeneutics and the study of history: Selected works: Volume IV [From Gesammelte Schriften 1860-1903]. Princeton University Press.

Dorst, K. (2015). Frame innovation: Create new thinking by design. The MIT Press.

Dunne, D. (2018). Design thinking at work: How innovative organizations are embracing design. University of Toronto Press.

Elm Fristorp, A., \& Lindstrand, F. (2012). Design för lärande i förskolan [Designs for learning in pre-schools]. Norstedts.

Gallagher, C. (Ed.). (2015). Minecraft in the classroom: Ideas, inspiration, and student projects for teachers. Peachpit Press.

Glawe, M., \& Selander, S. (2021). Innovativ design för lärande [Innovative designs for learning]. Liber.

Goffman, E. (1990). The presentation of self in everyday life. Penguin Books.

Haack, S. (1996). Evidence and inquiry: Towards reconstruction in epistemology. Blackwell.

Halverson, R., \& Halverson, E. (2020). Education as design for learning: A model for integrating education inquiry across research traditions. In T. Popkewitz \& G. Fan (Eds.), International handbook on education policy studies (pp. 201-222). Springer Singapore.

Halverson, R., \& Kelly, C. (2017). Mapping leadership: The tasks that matter for improvng teaching and learning in schools. Jossey-Bass.

Höglund, H. (2017). Video poetry: Negotiation literary interpretations: Students' multimodal designing in response to literature. Doctoral dissertation. Åbo Academy University Press.

Insulander, E. (2010). Tinget, rummet, besökaren. Om meningsskapande på museum [The object, the room, the visitor: Meaning-making in museums]. Doctoral dissertation. Stockholm University.

Insulander, E., Kjällander, S., Lindstrand, F., \& Åkerfeldt, A. (Eds.). (2017). Didaktik $i$ omvandlingens tid. Text, representation, design [Education in a time of change: Text, representation, design]. Liber.

Insulander, E., Lindstrand, F., \& Selander, S. (2017). The design of knowledge representations in different multimodal texts about the Middle Ages. Journal of Educational Media, Memory and Society, 9(2), 1-14.

Insulander, E., Lindstrand, F., \& Selander, S. (2019). Design för lärande-Historia. Medeltiden som exempel [Designs for learning: History: The Middle Ages as an example]. Liber.

Jewitt, C. (2012). Technology, literacy and learning: A multimodal approach. Routledge Falmer.

Kagan, J. (2009). The three cultures: Natural sciences, social sciences and the humanities in the 21st century. Cambridge University Press.

Karoff, H. S. (2013). Om leg. Legens medier, praktikker og stemninger [About play: The media and practices of play, and play moods]. Akademisk Forlag.

Kempe, A.-L., \& West, T. (2010). Design för lärande i musik [Designs for learning in music]. Norstedts.

Kjällander, S. (2011). Designs for learning in an extended digital environment: Case studies of social interaction in the Social Science classroom. Doctoral dissertation. Stockholm University.

Knutsson, O., Ramberg, R., \& Selander, S. (2021). Designs for learning and knowledge representations in collaborative settings. In E. Brooks, S. Dau, \& S. Selander (Eds.), Digital learning and collaborative practices: Lessons from inclusive and empowering participation in emerging technologies (pp. 12-21). Routledge. 
Kress, G. (2003). Literacy in the new media age. Routledge.

Kress, G. (2010). Multimodality: A social semiotic approach to contemporary communication. Routledge.

Kress, G., \& Selander, S. (2012). Multimodal design, learning and cultures of recognition.

The Internet and Higher Education, 12. https://doi.org/10.1016/j.iheduc.2011.12.003

Kress, G., Selander, S., Säljö, R., \& Wulf, C. (Eds.). (2021). Learning as social practice: Beyond education as an individual enterprise. Routledge.

Kress, G., \& van Leeuwen, T. (2021). Reading images: The grammar of visual design. Routledge.

Kvinge, Ø. R. (2019). Presentation in teacher education. A study of student teachers' transformation and representation of subject content using semiotic technology. Doctoral dissertation. University of Bergen.

Laurillard, D. (2012). Teaching as a design science: Building pedagogical patterns for learning and technology. Routledge.

Lim, K. Y. T. (2015). Disciplinary intuition and the design of learning environments. Springer.

Lim, V. F. (2021). Designing learning with embodied teaching: Perspectives from multimodality. Routledge.

Lindstrand, F. (2006). Att göra skillnad. Representation, identitet och lärande i ungdomars arbete och berättande med film [Making difference: Representation, identity and learning in youth film production]. Doctoral dissertation. HLS Förlag.

Lindstrand, F., Insulander, E., \& Selander, S. (2016). Mike the Knight in the neo-liberal era: A multimodal approach to children's multi-media entertainment. Journal of Language and Politics, 15(3), 337-351.

Löwgren, J., \& Stolterman, E. (2004). Thoughtful interaction design: A design perspective on information technology. The MIT Press.

Lundgren, U. P. (1972). Frame factors and the teaching process: A contribution to curriculum theory and theory on teaching. Almqvist \& Wicksell.

Morin, E. (1999). Le sept savoirs nécessaires à l'éducation du futur. Seuil.

Morin, E. (2008). On complexity. Hampton Press.

Marion, T. J., \& Fixson, S. K. (2018). The innovation navigator: Transforming your organization in the era of digital design and collaborative culture. University of Toronto Press.

Nouri, J. (2014). Orchestrating scaffolded outdoor mobile learning activities. Doctoral dissertation. Stockholm University.

Nouri, J., Åkerfeldt, A., Fors, U., \& Selander, S. (2017). Assessing collaborative problemsolving skills in technology-enhanced learning environments: The PISA framework and modes of communication. Journal of Emerging Technologies in Learning, 12(4), 163-174.

Nussbaum, M. (2011). Creating capabilities: The human development approach. The Belknap Press of Harvard University Press.

Öhman-Gullberg, L. (2008). Laddade bilder. Representation och meningsskapande i unga tjejers filmberättande [Charged pictures: Representation and meaning-making in young girls' film creations]. Doctoral dissertation. Stockholm University.

Østern, T. P., \& Strømme, A. (Eds.). (2014). Sanselig didaktisk design. SPACE ME [Aesthetic educational design: SPACE ME]. Fagbokforlaget.

Pellegrini, A. D. (Ed.). (1995). The future of play theory. State University of New York Press. Redström, J. (2017). Making design theory. The MIT Press.

Rostvall, A.-L., \& Selander, S. (Eds.). (2010). Design för lärande [Designs for learning]. Norstedts. Säljö, R. (1998). Thinking with and through artifacts: The role of psychological tools and physical artifacts in human learning and cognition. In D. Faulkner, K. Littleton, \& M. Woodhead (Eds.), Learning relationships in the classroom (pp. 54-66). Routledge. 
Säljö, R. (2005). Lärande och kulturella redskap: om lärprocesser och det kollektiva minnet [Learning and cultural artefacts: On learning processes and collective memory]. Norstedts Akademiska Förlag.

Sandberg-Jurström, R., Lindgren, L., \& Zandén, O. (2021). Musical skills, or attitude and dress style? Meaning-making when assessing admission tests for Swedish specialist music teacher education. Research Studies in Music Education. Advance online publication. https://doi.org/10.1177/1321103X20981774

Selander, S. (2003). Skolans blick—världen som text [The gaze of the school: The world as text]. In S. Selander (Ed.), Kobran, nallen och majjen. Tradition och förnyelse $i$ svensk skola och skolforskning [The cobra, the cell-phone and the teacher: ${ }^{31}$ Tradition and renewal in Swedish schools an in educational research] (pp. 91-109). Forskning i fokus, nr. 12. Myndigheten för skolutveckling.

Selander, S. (2008a). Designs for learning: A theoretical perspective. Designs for Learning, 1(1), 10-24.

Selander, S. (2008b). Designs for learning and ludic engagement. Digital Creativity, 19(3), 199-208.

Selander, S. (2015). Conceptualization of multimodal and distributed designs for learning. In B. Gros, Kinshuk, \& M. Maina (Eds.), The futures of ubiquitous learning: Learning designs for emerging pedagogies (pp. 97-113). Springer.

Selander, S. (2017). Didaktiken efter Vygotskij—design för lärande [Post-Vygotskian education: Designs for learning]. Liber.

Selander, S. (2018). Can a sign reveal its meaning? On the question of interpretation and epistemic context. In S. Zhao, E. Djonov, A. Björkvall, \& M. Boeriis (Eds.), Advancing multimodal and critical discourse studies (pp. 67-79). Routledge.

Selander, S. (forthcoming). A design-theoretic and multimodal approach to language teaching and learning. In S. Ørevik \& S. Diamantopoulou (Eds.), Multimodality and English: Affordances of multimodal texts in the teaching and learning of English as an additional language (pp. $\mathrm{xxx}-\mathrm{xxx}$ ). Routledge.

Selander, S., Insulander, E., Kempe, A.-L., Lindstrand, F., \& West, T. (2021). Designs for learning: Designs in learning. In G. Kress, S. Selander, R. Säljö, \& C. Wulf (Eds.), Learning as social practice: Beyond education as an individual enterprise (pp. 30-40). Routledge.

Selander, S., \& Kress, G. (2017). Design för lärande—ett multimodalt perspektiv [Designs for learning: A multimodal perspective]. Studentlitteratur. (original work published by Norstedts in 2010).

Selander, S., \& Svärdemo-Åberg, E. (Eds.). (2008). Didaktisk design i digital miljö—nya möjligheter för lärande [Didactic design in digital environments: New opportunities for learning]. Liber.

Sheridan, M. P., \& Rowsell, J. (2010). Design literacies: Learning and innovation in the digital age. Routledge.

Snow, C. P. (2012). The two cultures. Cambridge University Press.

Sørensen, B. H. (2008). Didaktisk design för "seriösa spel" [Didactic design for "serious games”]. In S. Selander \& E. Svärdemo-Åberg (Eds.), Didaktisk design i digital miljö—nya möjligheter för lärande [Didactic design in digital environments: New opportunities for learning] (pp. 172-186). Liber.

Sørensen, B. H., Audon, L., \& Tweddel Levinsen, K. (2010). Skole 2.0 [Education 2.0]. Klim.

Swiecki, Z., Misfeldt, M., Stoddard, J., \& Shaffer, D. W. (2017). Dependency-centered design as an approach to pedagogical authoring. In Y. Baek (Ed.), Game-based learning: Theory strategies and performance outcomes (pp. 169-188). NOVA. 
Teistler, G. (Ed.). (2006). Lesen lernen in Diktaturen der 1930er und 1940er Jahre. Fibeln in Deutschland, Italien und Spanien [Learning how to read during the German, Italian, and Spanish dictatorships in the 1930s and 1940s]. Studien zur Internationalen Schulbuchsforschung, Schriftenreihe des Georg-Eckert-Instituts, Band 116. Verlag Hahnsche Buchhandlung.

Thorsnes, T. (2009). Studier i tredimensionell form [Studies in three-dimensional form]. In F. Lindstrand \& S. Selander (Eds.), Estetiska lärprocesser-upplevelser, praktiker, kunskapsformer [Aesthetic learning processes: Experiences, practices, and forms of knowledge] (pp. 31-49). Studentlitteratur.

van Leeuwen, T. (2005). Introducing social semiotics. Routledge.

Verganti, R. (2009). Design-driven innovation: Changing the rules of competition by radically innovating what things mean. Harvard Business Press.

Wulf, C. (2013). Anthropology: A continental perspective. University of Chicago Press.

Wulf, C., Althans, B., Audehm, K., Bausch, C., Göhlich, M., Sting, S., Tervooren, A., Wagner-Willi, M., \& Zirfas, J. (Eds.). (2010). Ritual and identity: The staging and performing of rituals in the lives of young people. Tufnell Press. 


\title{
Designs in learning and rhizomatic webs
}

\author{
Fredrik Lindstrand and Staffan Selander
}

\section{Introduction}

In this chapter we will focus on designs-in-learning, that is, those aspects that refer to how individuals (by themselves or in groups) negotiate, make choices, and design their understanding of a phenomenon and of a knowledge area (Selander, 2017; Selander \& Kress, 2017). In these processes, they develop their vocabulary, skills, and techniques along different lines. Our focus is on the learner, on how he or she re-designs different multimodal knowledge representations and makes new representations. Here, we are not primarily interested in the curriculum, or the aims and purposes of an exhibition, or questions about effective learning and learning in relation to specific goals. Learning takes place in many different ways, but schools (and museums) are often eager to understand learning through special institutional lenses, that is, those grids and standards by which learning is measured.

Learning can be discussed and analyzed from many different points of view, based on different theoretical positions (Säljö, 2021). Our starting point here is that learning is part of a social practice, and that learning only can be "seen" through multimodal representations-signs of learning. However, even if we can see changes over time in different representations, we cannot see all the learning that takes place. "What is being learnt?" is thus a very tricky question with many possible answers, depending on the specific interest and theoretical background of the professional teacher or the researcher.

Those traces that individuals leave behind in their different knowledge representations can be a ground for analysis and interpretation-if we have the possibility to compare how they have designed their understanding at different fixing-points. To be able to adequately understand signs of learning, it is necessary to be able to follow learning activities in different sequences over time, something which also is time-consuming and therefore not always possible for, let's say, a teacher to do in detail. This is not to say that it always will be impossible for teachers to follow the learning that takes place. It depends on how teaching sequences are carried out, and what kinds of knowledge representations are asked for during these sequences. In the future, it might also 
be possible to use AI (Artificial Intelligence) solutions to collect and analyze many different kinds of data-but that is beyond the focus of this chapter.

\section{Rhizomatic webs as a metaphor for learning}

Learning takes place all the time, and can be understood as an ongoing change and expansion of capabilities to understand different phenomena, and also to act in the world. What we see as learning depends on the focus, what we call cultures of recognition - that is, what is seen, and understood, as learning in a specific context (Kress \& Selander, 2012). Thus, how we see learning differs between let's say a school context and the context of playing a game, even though both activities could lead to deep insights into a phenomenon (Rigby \& Ryan, 2011). Learning depends on communication, through the use of symbolic resources such as words, gestures, or pictorial illustrations. Learning could therefore be seen as an aspect of communication (Kress, 2010). On the other hand, we could also say that learning emphasizes other aspects - such as increasing knowledge, capacities, and competencies; things which do not necessarily characterize communication.

Since learning follows different paths, depending on interest and earlier knowledge, as well as on habitus, ${ }^{1}$ we would like to use the metaphor rhizomatic learning. Rhizomatic structures, as in root systems, expand in different ways, but can also be understood as self-regulating systems where information follows different paths. Our nervous systems work like this, depending on intra- and interrelated forces which build patterns. Individual knowledge always develops in a social context, and we build information structures and habits to be able to navigate and act in that context.

It is also the case that the capacity to connect two or more items of data helps us to build systems of symbolic understanding. This capacity seems to be fundamental, and the insights into how this works have even led Chomsky to abandon the idea of built-in linguistic structures in favour of an understanding that the pre-condition to understand and use language is based on the capacity of the brain to combine (any) two or more different elements and thereby build structures (Berwick \& Chomsky, 2016). Also, from a philosophical point of view, it has been argued that our capacity to build symbolic forms is fundamental for our species (Cassirer, 1996).

\section{Multimodal knowledge representations}

We see the idea of symbolic forms as a figure of thought connected with a multimodal understanding of knowledge representations. We communicate and learn, and we do this by way of semiotic resources like words. Over a very long period of time, the spoken and written "word" has been the cultural centre of understanding, of how we learn and communicate (Gadamer, 2002). However, during the last twenty years, social semiotic and multimodally 
oriented, linguistically-based research has shown the role of other modes to express knowledge and to communicate, for example, through gestures, intonation, graphic layout, or pictorial illustrations (Kress \& van Leeuwen, 2020). In addition, Pippin (2020) discussed how we can express, for example, moral conflicts and standpoints through the medium of film.

These new and different traditions offer both a deeper and a wider understanding of how knowledge can be designed and expressed-what we call knowledge representations. In this chapter, we will give an example of how we can follow and understand learning-in film-making. However, before we continue to our example, we would like to introduce a few more theoretical concepts that guide our analysis: epistemological commitments of modes, and re-design by way of transformation and transduction.

\section{Epistemological commitments}

Different modes (e.g., image, gesture, speech, writing) operate with different logics in terms of how they afford communication, representation, and meaning-making (cf. Bezemer \& Kress, 2008, 2016; Kress, 2003, 2010). In image, for example, spatial composition has a central role for the construal of meaning; a change in composition alters the meaning of the image. Similarly, syntax has a central role for construing meaning in language. Based on the logic of syntax instead of spatial composition, we can alter the meaning of a sentence by changing the order of words. In film, due to its multimodal nature, both composition and syntax, as well as rhythm, are central principles. This has to do with how different modes lend themselves as resources for communication, representation, and meaning-making (see Chapter 3 on affordances by Lindstrand, this volume). Due to their different ways of operating (following the logics referred to above), different modes lend themselves differently to us when used in a meaning-making process. They provide different kinds of access to the world when used in representations. This aspect is what we refer to as the epistemological commitments of modes. As Bezemer and Kress (2016) explain:

The units and principles of arrangement that each mode provides offer sign-makers both potentials and limitations, as well as prompts to engage with and so to see the world in certain ways - that is, to see the world through a lens shaped in specific ways.

Epistemological commitments provide both a certain lens on the worldenabling a certain kind of access to a certain kind of knowledge about a phenomenon-and prompt the meaning-maker to make certain decisions based on the mode used for representing something. Bezemer and Kress (2008) exemplify this aspect by comparing the work to represent something in writing 
versus in image. In writing we need to give some information regarding the events and agents in focus in order to compose an intelligible message. An example could be: "two children are watching TV." If we want to convey a similar message in image we need to make a few more choices, for example: "approximately what ages are they?," "are they standing or sitting?," "with what proximity between them?," and so on. The mode itself prompts a number of decisions to be made.

This is relevant in relation to learning in several important ways. The critical points where decisions need to be made prompt active processes in relation to the topics at hand; the decision-making emphasizes the agency of learners and asserts that their interests influence the process. Furthermore, the decisions made steer the learning process in new directions where new prompts call for new decisions, new possibilities for learning, and so on. This chain of processes points towards the rhizomatic nature of learning mentioned above.

\section{Re-design by way of transformation and transduction}

In order to understand the complexity and the potentials of film-making as a vehicle for learning, we also need to mention the notions of re-design, transformation and transduction (cf. Kress, 2017). All these notions imply changes to semiotic materials but in slightly different ways. Transformation describes changes within a mode-for example when people engaged in fan art continue the stories about characters in popular culture by adding new narratives that expand the original story in some way. It also describes the changes that occur during the work with something - the development from a sketch to a finished painting or from a draft to a finished text of some sort. As Kress (2017) explains:

As transformation operates on and within a mode, the materiality of the mode is not affected. Its semiotic entities and relations of entities are affected, but at a relatively slower rate, and within the ontological frame of the materiality. Consequently, transformation produces epistemological change.

The epistemological changes mentioned in the quotation above point to the relationship with learning. Learning is a transformative process where our understandings of a particular aspect change as we work with them in different ways. Transduction describes the semiotic change that occurs when meaning is "moved," or interpreted, from one mode to another-for example, in the adaptation of a novel into a film, or when characters from an anime series are interpreted and performed with costumes, wigs, and make-up in cosplay. According to Kress (2017):

In transduction, by contrast, the materiality (and not infrequently, the logic — spatial versus temporal) of the two modes involved - the 'originary' 
and the 'target' mode-differ. Given that materiality, entities, process (and at times logics) change, transduction always produces ontological change. In the process of transduction meaning is not transferred, it is newly materialized in the different (material) entities and processes of the 'recipient mode'; and, where that applies, in the different logic of the recipient mode. In transduction both profound change, and-for want of a better word-'continuity' are at issue. A change of materiality or logic or both produces ontological change. Paradoxically, the purpose of transduction is an attempt to preserve 'core aspects' of meaning.

Both notions fit well into a design-oriented approach to learning as they deal with the type of changes that are central to design, re-design, and learning. In relation to film-making, transformation is useful for describing the change in meaning that occurs within each part of the process and for describing the changes in how the teenagers, in our example, reflect upon various things during their work. Transduction is productive in highlighting what the move between different parts of the process actually implies for the film-makers, as each step from one process to the next in fact involves the necessity to transduce meanings into new modes, with new epistemological commitments that open up new perspectives and prompt other decisions to be made.

\section{Making film in schools-a case study}

Our example in this chapter stems from a research project that investigated youth collaborative documentary film-making processes as sites for learning, identity work, and social action (Lindstrand, 2006, 2008). The example we will focus on involved six students in upper secondary school. The film-making process was initialized as a school project, introduced by a media educator from a local resource center. The work with film, in the form discussed here, took place over a number of different processes, each characterized by work with different modes, media, and materials. The representations that were communicated in the finished films were processed and articulated in many different forms during the course of the work, before they finally took the shape that reaches the audience. However, since we have limited space and our main intention is to exemplify how the theoretical concepts presented above could be applied to a learning situation, we will focus on only some aspects of the film-making process. We will attend especially to the pre-production parts of the film-making process and focus on how the ideas for the film were framed in different ways.

\section{Searching for a shared interest}

The first step in the film-making process is to come up with ideas for the film. As a starting point, some of the group members presented and discussed various 
ideas based on their individual experiences and observations of situations they thought could be investigated and addressed critically within the frames of a documentary film. An example of this was the feeling of being unfairly treated in a certain situation. The other group members made associations and contributed their own experiences of similar situations. By looking for the core meaning of the different examples and pinpointing what they had in common, parallel and step-by-step developments of the subject for the film and of the reasoning around the choice of topic were initialized. The process gradually led to a reframing of the topic, from the personal experiences to more general issues in society. Individual accounts of personal experiences of injustice were transformed into a story about social injustice at a societal level. More specifically, the group concluded that they wanted their film to deal with questions about social injustice and welfare issues from a global perspective.

Even though the initial accounts of personal experiences became a starting point for the process and thus set a direction for the work, the process was not linear. The interaction among the students - through the sharing of thoughts, experiences and associations - led to a rhizomatic development of the ideas for the film, from specific individual experiences to questions at a more general societal (and even global) level. The agency and performativity of the students were central to this development as they drove the process through their interaction.

\section{Writing a synopsis}

Once the group decided on a topic for their film, a new process began. The rather abstract idea about "social injustice and welfare issues from a global perspective" had to be re-designed and reframed in relation to another medium (pen on paper), another genre (synopsis), and another mode (writing), with other epistemological commitments. In other words, the group was facing the challenge of transducing their idea into a written text that further specified how they intended to deal with this issue in the form of representations in film. This prompted the group to search for examples that they saw as possible parts of a multimodal argumentation that corresponded with their intentions, and from situations that were possible to capture on video. The work can be described as a process of making distinctions, where the group identified those aspects that best contributed to conveying their message (cf. Kress, 2003). At the end of this session, the synopsis was articulated in the following way:

\section{Synopsis}

With our film, we want to shed light on welfare problems.

The film will show the contrasts between the developed and developing countries. We will address the issues of water, stress, and hunger.

We will start each problem with a humorous angle and then an interview with a person in the street. Each problem will end with a black box stating the situation in the developing countries. 
We want to make those who see the film reflect on problems in developed and developing countries. As a viewer, you can also reflect on the problems that welfare brings with it.

What we want to say is: Too much and too little spoils everything!

(Lindstrand, 2006, p. 120, our translation from Swedish)

The process of writing the synopsis involved a reconfiguration of the meanings articulated in the previous process, as the work to transduce the more general idea about "social injustice and welfare issues from a global perspective" led the group to make connections between this overarching topic and the various examples presented in the synopsis above. For example, they specified that social injustice and welfare issues could involve issues related to water, stress, and hunger.

\section{Storyboard}

In the third part of the film-making process the agenda was to create a storyboard based on the ideas developed in the previous parts. A storyboard could be described as a visual manuscript with sketched images representing the various shots in terms of what they depict, how the image is composed, and so on (see Figure 2.1). There is also space for including written notes about each shot-for example, describing qualities that are difficult to capture in image, such as actions and sounds. As the shots are represented in a chronological order and they are placed in correspondence with where and when they are planned to appear in the film, the storyboard enables an overview of how the planned narrative and argumentation are structured.

For the group of students, the move towards a storyboard implied yet another change of conditions, as visual aspects were brought to the fore. Their interests, the overarching theme, and the specification of this theme in terms of "water, stress, and hunger"-as well as the other aspects presented in the synopsis - had to be re-designed and reframed again, in relation to yet another genre (storyboard) and another mode (image). Once again, other epistemological commitments called for new aspects for the group to consider. At this point, the task was to construct the narrative for the film visually, piece by piece. The transduction from written synopsis to multimodal storyboard required the group of students to further specify and visualize the still rather vague examples (i.e., water, stress, and hunger). What specific situations could be shown in order to make the point about social injustice in relation to water, stress, and hunger? How should these situations be depicted and how should the depictions be juxtaposed with other materials (shots, informational texts, etc.) to effectively build an argumentation that corresponded with the interests of the filmmakers? And so on.

In their work with hunger, the group decided to present the issue of selfstarvation (e.g., anorexia \& bulimia) in western cultures in different ways. The 


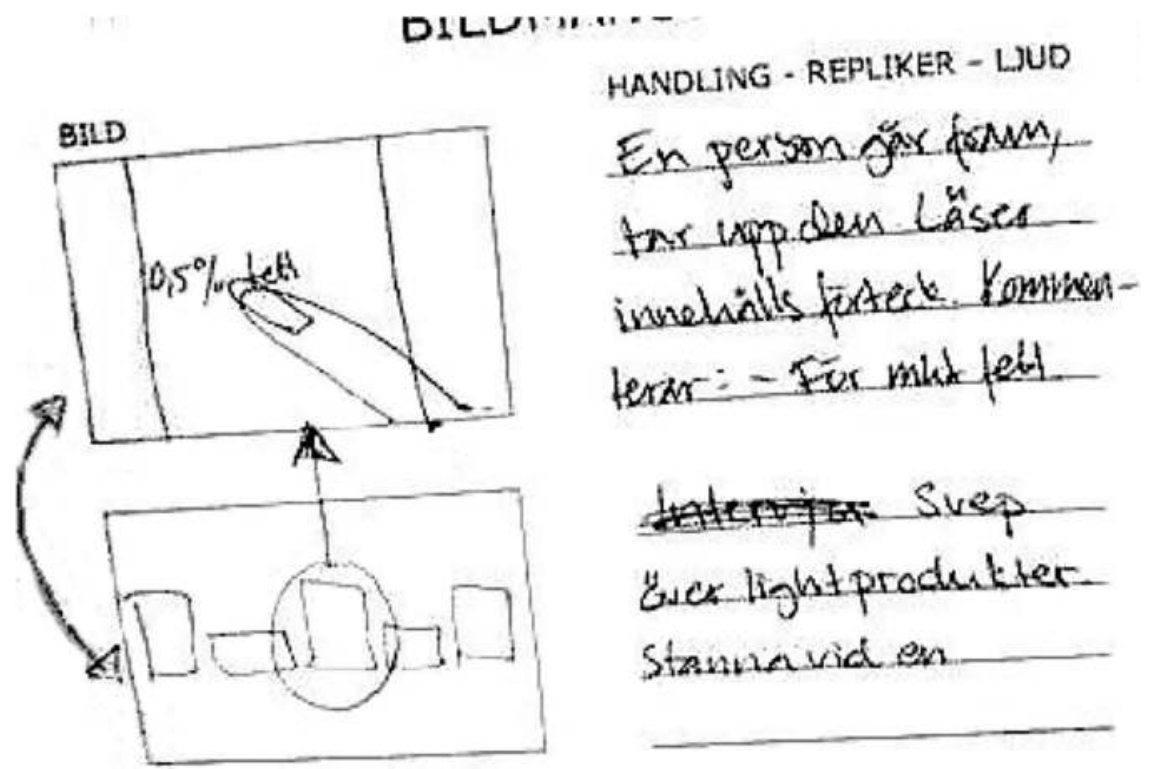

Figure 2.I Detail from storyboard.

Source: (Lindstrand, 2006, p. 123)

first was to interview staff at a food store about the consumption of diet and low-fat products. The second, with a sequence of shots, presented a series of staged situations where two friends interacted around the issue of self-starvation in different ways. In the first of these sequences, the two friends were out shopping for food and discussing whether to buy low-fat products or not. In the following shot they were sitting at a table and one of them encouraged the other to eat. The final part showed how the person who was presented as anxious about eating made herself throw up in the bathroom. The sequence was followed by two shots with informational text in white on a black background, saying: "while we starve ourselves" and " 1.2 billion people starve involuntarily."

Again, as we saw in the previous examples from the process, the understanding of the issues in focus was transformed as the young filmmakers had to break overarching ideas down into more concrete examples. The understanding of social injustice and welfare issues from a global perspective were reconfigured into specific utterances that elaborated how the problems addressed may appear in everyday situations.

\section{Conclusion}

In this chapter we have focused on aspects related to what we referred to as designs-in-learning, emphasizing the role of learners in their learning 
processes. In the example from the collaborative film-making endeavor, it is clear the agency of the students was central. They decided what issues they wanted to address in their film, and in doing so they set a direction for their learning process. In our account here, this was most obviously related to the topics and subject areas dealt with by the students, but their decisions also affected their learning trajectories in relation to filmmaking, communication with moving images, and representation more generally (cf. Lindstrand, 2006).

These learning processes, that could be traced by attending to how the topics of their film were transformed, reframed, and transducted in different ways as they moved from one part of the film-making process to the next, were not linear, but evolved rhizomatically. The group started out with open discussions where individual stories about personal experiences prompted associations in others, leading to an accumulation of thematically-related stories. By looking at these stories as a body of material, the group was able to look beyond the personal and to focus on common features at a more general level. Instead of individual experiences of being treated unfairly, the theme of injustice appeared as a more general topic. The group decided to elevate the theme even more by including a global perspective and by adding welfare issues as a domain.

As the process continued, new frames for the group's work were introduced in terms of new genres, new media, and new modes with other epistemological commitments. Step by step, the group had to specify and materialize their ideas in accordance with these frames, spurring the rhizomatic process to continue. Where we left the group in our example, their idea for the film had been transformed and transducted from personal experiences of being treated unfairly to a general theme of social injustice and welfare issues globally, broken down into the subcategories of water, hunger, and stress, and finally rearticulated as images representing everyday situations related to self-starvation (as one of three themes). In these processes, the students worked intensely with making connections and seeing patterns by means of associations, leading to a gradual reconfiguration (re-design) of their understanding of the themes in focus, articulated in multimodal knowledge representations of various kindsfrom open discussions to a completed film.

\section{Note}

1 Habitus is here understood as a social disposition to act and behave in certain ways, depending on the social environment in which it develops. See, for example, Bourdieu (1977, 2010).

\section{References}

Berwick, R. C., \& Chomsky, N. (2016). Why only us? Language and evolution. MIT Press. Bezemer, J., \& Kress, G. (2008). Writing in multimodal texts: A social semiotic account of designs for learning. Written Communication, 25(2), 166-195. 
Bezemer, J., \& Kress, G. (2016). Multimodality, learning and communication: A social semiotic frame. Routledge.

Bourdieu, P. (1977). Outline of a theory of practice. Cambridge University Press.

Bourdieu, P. (1979/2010). Distinction: A social critique of the judgement of taste. Routledge.

Cassirer, E. (1996). The metaphysics of symbolic forms: The philosophy of symbolic forms (Vol. 4). Yale University.

Gadamer, G. H. (1960/2002). Sanning och metod [Truth and method]. Daidalos.

Kress, G. (2003). Literacy in the new media age. Routledge.

Kress, G. (2010). Multmodality: A social semiotic approach to contemporary communication. Routledge.

Kress, G. (2017). Semiotic work: design, transformation, transduction. In E. Insulander, S. Kjällander, F. Lindstrand, \& A. Åkerfeldt (Eds.), Didaktik i omvandlingens tid. Text, representation, design. Liber.

Kress, G., \& Selander, S. (2012). Multimodal design, learning and cultures of recognition. The Internet and Higher Education, 15(4), 265-268. https://doi.org/10.1016/j. iheduc.2011.12.003

Kress, G., \& van Leeuwen, T. (2020). Reading images: The grammar of visual design (3rd ed.). Routledge.

Lindstrand, F. (2006). Att göra skillnad. Representation, identitet och lärande i ungdomars arbete och berättande med film [Making difference: Representation, identity and learning in youth film production]. Doctoral dissertation. HLS Förlag.

Lindstrand, F. (2008). Lärprocesser i den rörliga bildens gränsland [Learning processes at the intersections of filmmaking]. In F. Lindstrand \& S. Selander (Eds.), Estetiska lärprocesserupplevelser, praktiker och kunskapsformer (pp. 153-174). Studentlitteratur [Aesthetic learning processes: Experiences, practices and forms of knowledge].

Pippin, R. B. (2020). Filmed thought: Cinema as reflective form. University of Chicgo Press.

Rigby, S., \& Ryan, R. M. (2011). Glued to games: How video games draw us in and hold us spellbound. Praeger.

Säljö, R. (2021). The conceptualization of learning in learning research: From introspectionism and conditioned reflexes to meaning-making and performativity in situated practices. In G. Kress, S. Selander, R. Säljö, \& C. Wulf (Eds.), Learning as social practice: Beyond education as an individual enterprise (pp. 146-169). Routledge.

Selander, S. (2017). Didaktiken efter Vygotskij_design för lärande [Post-Vygotskian education: Designs for learning]. Liber.

Selander, S., \& Kress, G. (2017). Design för lärande-ett multimodalt perspektiv [Designs for learning: A multimodal perspective] (2nd ed.). Studentlitteratur. 


\title{
A semiotic and design-oriented approach to affordance
}

\author{
Fredrik Lindstrand
}

\section{Drawing a dinosaur}

A three-year-old boy is working on a drawing of a dinosaur (see Figure 3.1). The drawing is made with thick felt-tip pens on white paper. He invests his interest, knowledge, and skills as he shapes the various details that he sees as significant for the type of creature he intends to represent. At the time the typical back plates (scutes) — which he refers to as "the zigzag"- are important details to him. While the title of his drawing, "The coolest dinosaur in the world," does not give any specific details on the type of dinosaur portrayed, these scutes suggest a stegosaurus-like animal. The shape and angle of the body, the four legs, and the size of the head, in comparison with the rest of the body, all point in the same direction.

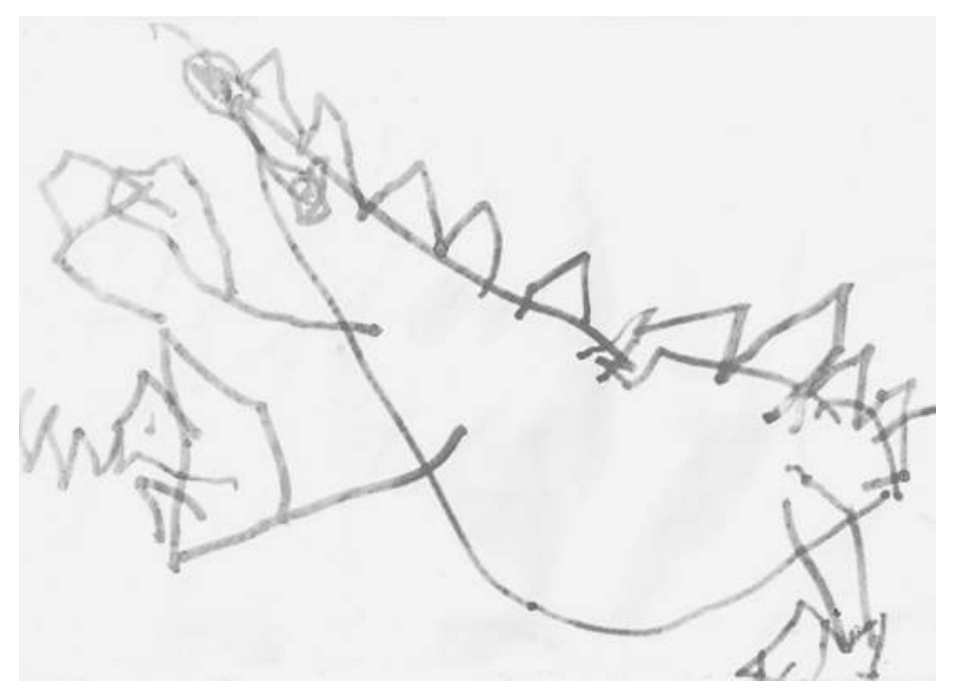

Figure 3.I Drawing titled "The coolest dinosaur in the world."

Source: Photographed by Fredrik Lindstrand 
Since dinosaurs were of great interest to him and as he liked to draw, he produced many drawings on the topic during this period. The drawings were made with a number of different technologies for inscription (see Kress \& van Leeuwen, 2001), including crayons, felt-tip pens, paint, and watercolour. However, despite this range of technologies, his drawings from this time strongly resemble each other thematically, aesthetically, and in terms of how he talked about them. Then, ten months later, a change occurred from one drawing to the next. The image below (Figure 3.2) was the first of a new way of representing dinosaurs visually. This was also accompanied by a new way of talking about the drawings. The boy (now four years old) describes the depicted situation in the following way: "It's a Triceratops attacking a Tyrannosaurus rex (!)" The exclamation mark in parentheses is there to indicate that there is something unusual and even humorous about the situation he has presented, which he indicates by smiling, lifting his shoulders a little, and raising his eyebrows while describing it.

In contrast to the previous drawing, this image represents two visually and verbally specified types of dinosaurs. The visual specification is based on some of their characteristic features such as posture, the shape of their heads, and the short arms of the T-Rex. The two dinosaurs are also set in a situation where they interact with each other, as signified by how they are placed in relation to each other and through their eye contact. This contributes to construing a social and socially dynamic scene. The visual representation of this dynamic is based on the difference in size between the two, the fact that the T-Rex is bipedal, and that it has larger and sharper teeth. The humorous aspect of the situation, apart from the differences between the two already mentioned, is

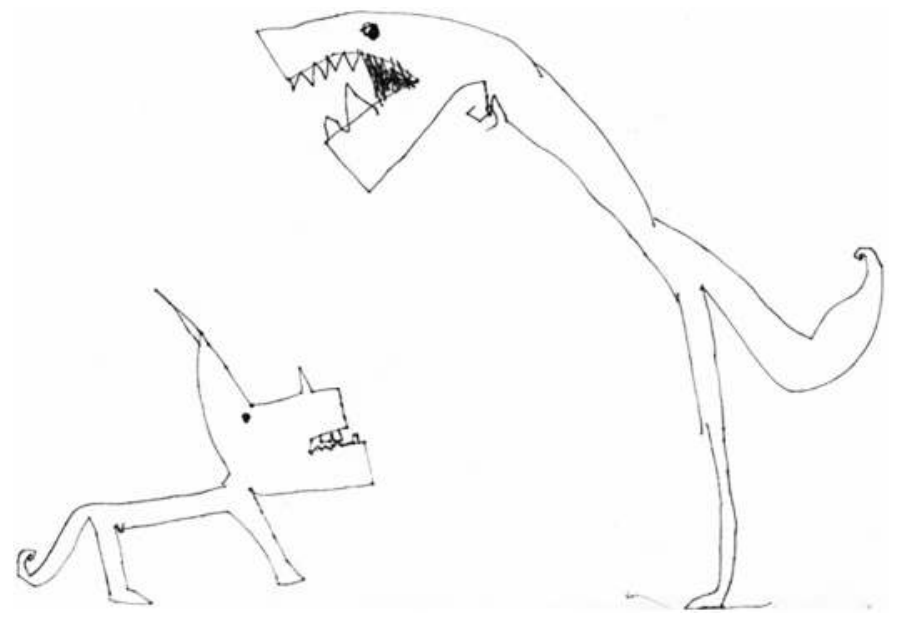

Figure 3.2 Drawing titled “Triceratops attacks Tyrannosaurus rex (!)”

Source: Photographed by Fredrik Lindstrand 
based on the boy's knowledge of the fact that the Triceratops was a peaceful herbivore, while the T-Rex was a carnivore that has often been represented as an aggressive monster. The thought of a peaceful vegetarian attacking a larger predator may indeed be seen as humorous.

Apart from the knowledge represented in the different types of dinosaurs and their relationships, we can also note differences in terms of how the drawing is constructed. It is more detailed than previous drawings, and the details are clearer and more specific. The boy has also worked from a certain perspective, but has still managed to capture the characteristics of the dinosaurs, such as the horns on the head of the Triceratops. We can also note the addition of a stylistic ingredient in the way the tails are curled.

The differences between these two representations (Figures 3.1 and 3.2) could be said to indicate that a learning process has occurred during the time that had passed between the two drawings, involving dinosaurs and drawing (among other things). However, there is also another aspect to consider regarding the difference between these two knowledge representations: The change in drawing occurred immediately after the boy was allowed to use a fine-tipped pen intended for professional drawing for the first time. The resources available for drawing thus had an important impact in terms of what knowledge could be represented and how. Different resources positioned the boy differently in relation to the subject matter, with effects on what he could draw and, in turn, what seemed possible to talk about. This points to the importance of considering the role of resources, both in Designs For Learning and in research about learning and education.

\section{A focus on resources}

Needless to say, the use of resources for various purposes is a constantly recurring feature in all kinds of processes. For researchers within the fields of education, design, and communication (to name but a few) this has become an important aspect to deal with analytically (cf. Laurillard et al., 2000; Norman, 1988). In similar ways it is important for teachers to have analytical tools for considering what the different resources could contribute in their Designs For Learning. What learners use as resources in their productive work to make meaning, and how these resources are used, also give an indication of how they (the learners) orient themselves in relation to a subject area, how they interpret the social context of their education, and so on, providing valuable insights for teachers who wish to understand their students' learning endeavours.

For us, as researchers within the Designs for Learning (DFL) perspective, the notion of affordance helps us to investigate various aspects regarding how resources are brought into play in situated meaning-making. Some of the questions that guide us are: What becomes a resource in a specific situation, to whom, how, with what social and epistemological consequences, and why? Relating to what was presented as cultures of recognition in Chapter 1 by Selander 
in this volume, we also ask what resources are recognized as valid within these situations. Our interest here is, in other words, directed towards questions about resources in relation to materiality, meaning-making, agency, and power in education, learning, and meaning-making.

The aim of this chapter is to introduce the notion of affordance as it is interpreted and applied within the DFL perspective, and to show how it is productive in the analysis of situations of learning and meaning-making in various contexts. In order to make the idea of resources and their affordances as widely applicable as possible for readers from different fields and practices, my examples stem from a number of different contexts out of school. Other chapters in this book will touch more directly upon the use of resources in educational settings.

\section{Affordance}

The notion of affordances was originally introduced by James J. Gibson as part of his theory on the ecology of visual perception (e.g., Gibson, 1950, 1966, 1977, 1979). With an interest in "agent-situation interaction," Gibson used the concept to grasp "all action possibilities latent in an environment, where the potential uses of a given object arise from its perceivable properties and always in relation to the actor's capabilities and interests" (MODE, 2012).

\section{What the environment offers}

In Gibson's own words the "affordances of the environment are what it offers the animal, what it provides or furnishes, either for good or ill" (Gibson, 1979, p. 127). In this sense-as with resources in general-there is no inherent or general value embedded in the term, as it does not say anything about the means for which it is used or the consequences of its use. It merely concludes that a certain aspect of our environment, due to its layout, lends itself to certain actions. Within the DFL perspective the notion of "environment" is extended to encompass all aspects that are part of a certain context.

The following example, which stems from a previous research project focusing on the museum as a site for learning and communication (cf. Diamantopoulou et al., 2012; Lindstrand \& Insulander, 2012), illustrates the aforementioned aspect of resources and their affordances. ${ }^{1}$ In the project we used a number of methodological approaches to investigate visitors' meaning-making in relation to three exhibitions, in Stockholm and London. One approach was to use cameras and invite visitors to take photographs of whatever they wanted to document during their engagement with the exhibition. Afterwards we used the photographs as material for discussion, in a form of photo elicitation. Apart from allowing the user to take photographs without having to make any adjustments in terms of shutter speed, aperture, and so on, the digital camera also allowed the user to scroll between the images shown on the display. 
The scrolling function worked in a circular way, as the last picture taken was followed by the first and vice versa, depending on whether the user scrolled backwards or forwards among the images. Many things could of course be said about affordances in relation to the various functions of the camera, but here I want to focus on one occasion when a participant's interaction with the scrolling function contributed to a specific meaning being made. The participant showed each image as they appeared when he scrolled, and accompanied each image with detailed verbal descriptions of what the image depicted, why he took the image, how his trajectory through the exhibition progressed, and so on. When he came to the end he realized that the scrolling function was circular and that he had scrolled his way backwards through the entire exhibition. He had made up his account of the progression through the exhibition-construed as a meaningful account of his experiences performatively and instantly in relation to the images that were screened, instead of retelling how he had actually interacted with the exhibition. In that sense, the scrolling function-as one aspect of the media specificity of the camera-had tricked him into another form of meaning-making than we had planned for. Again, "affordances of the environment are what it offers the animal, what it provides or furnishes, either for good or ill" (Gibson, 1979, p. 127). The example also indicates how resources and their affordances can play a part in framing and structuring our understanding of a subject area.

\section{Affordance as a relational notion}

To hold on to the quote from Gibson a little longer, central to the idea of affordance is that various aspects of the surrounding world lend themselves to certain actions. In the example above, the possibility to scroll between the images enables the user to find, view, and share a specific image, or to access images one by one in a certain order. However, even though most digital cameras provide a similar function, this affordance is not commonly available and attainable for all living creatures. Gibson (1979) explains that affordances:

have to be measured relative to the animal. They are unique for that animal. They are not just abstract physical properties. They have unity relative to the posture and behavior of the animal being considered. So an affordance cannot be measured as we measure in physics.

(pp. 127-128)

In this sense, affordances can be seen as pointing towards a specific and unique relationship between a being and its surroundings, based on how they both are constituted. The specific affordances of the camera referred to above relies on a user with a specific constitution-for example, a finger (or equivalent) of a certain size that can be used for pushing buttons and scrolling. The notion is thus relational, building on the specific dyad between the actual interactants. 


\section{Agency and acts of distinction}

In order to become resources for action, the potential qualities of the environment also need to be recognized by the agent as a potential for a certain action. Since recognition is an action where the agent perceives, interprets, and makes distinctions, affordances enable-and are the result of-actions. This act of making distinctions relies on the perceivable properties of the object and the agent's capabilities and interests in the situation. In line with the unique character of the relationship between a being and its surroundings, we observe differently and thus recognize different properties of the environment as possible resources. As van Leeuwen (2005) notes:

different observers might notice different affordances, depending on their needs and interests and on the specifics of the situation at hand. Perception is selective. And yet the other affordances are objectively there. Thus the meanings we find in the world, says Gibson, are both objective and subjective.

(pp. 4-5)

This is interesting from a learning perspective, since what a person recognizes as possible resources in a specific situation also says something about how that person orients herself/himself in the world and understands the issue being dealt with. These acts of making distinctions tell us something about the social and material circumstances of the interaction (the specifics of the situation at hand in the quote above). What is possible to distinguish depends on these contextual aspects, as the properties of our surroundings appear differently under different circumstances. Materially, the availability of light, for example, may have an influence on what is possible to distinguish as a resource for a certain purpose. Socially these actions point towards the social framing of the situation-what is possible to distinguish as a resource from the social position one has in a certain context. To exemplify the latter, we could think of the types of metaphors drawn on (or not drawn on) by students in their accounts of a phenomenon of some kind in class. In the process of choosing a metaphor to explain the phenomenon, some metaphors will probably seem more apt than others (for various reasons). The ones chosen may, for example, appear to be more precise in relation to some aspects of the phenomenon. There may also be other possible, and even more precise, metaphors that are not even considered. The reasons could be that they are too far away from the knowledge domain in focus, or too closely related to the students' personal realms, for example. The line between the possible and the impossible is, in this case, based on the individual's interpretation of what is appropriate or correct within the social and epistemological context of the classroom. Even if a possible resource could be perceived, we may not be able to recognize it as a possible resource due to how we are positioned socially in a certain situation. In other 
words, affordances manifest the unique relationship between an agent and its surroundings under specific contextual circumstances.

Methodologically, this calls for an approach that considers affordances in situ, rather than merely theoretically ascribing them to something based on the properties that could enable action in one form or another. As Gibson (1979, p. 129) observes: "[a]n affordance points both ways, to the environment and to the observer."

\section{Semiotic potential and meaning potential}

Theo van Leeuwen (2005) relates affordance to another notion, semiotic potential (originally from Voloshinov and later elaborated by Hodge \& Kress, 1988, as part of their social semiotic perspective). van Leeuwen (2005) explains that semiotic resources (i.e., resources for communication and meaning-making)

have a theoretical semiotic potential constituted by all their past uses and all their potential uses and an actual semiotic potential constituted by those past uses that are known to and considered relevant by the users of the resource and by such potential uses as might be uncovered by the users on the basis of their specific needs and interests.

Similar to the semiotic potentials mentioned in this quote, the notion of affordance also includes both the theoretical (the possible) potentials and the potentials that are actually brought into action. Some researchers who use the notion of affordance focus, more or less, on the theoretical affordances of, for example, certain educational technologies (cf. Kirschner et al., 2004). A manifestation of this approach is seen in the endeavour to establish taxonomies of affordances, as exemplified by Conole and Dyke (2004) who suggest a taxonomy of information and communication technology (ICT) affordances based on the aspects they see digital media contributing to in an educational context. There is a value in mapping theoretical possibilities and hindrances in a certain design, in order to see which of those possibilities users activate in their work. However, a potential problem with this type of approach is that it treats affordances as something provided by the environment regardless of whom is interacting with it. The activation part is missing, so to speak, with the consequence that the agency of learners is at risk of being left out. This, in turn, could affect the validity of the research since affordances other than those foreseen in a theoretical mapping may appear as a result of learners' performative work. While all possible affordances that could be activated in interaction with all possible agents could be included in the theoretical affordances of a certain object, it is often more interesting to look at the actual affordances that are manifested in actual encounters. 
Instead of this division between theoretical and actual affordances, the former may perhaps be substituted with the term meaning potential from Halliday's sociolinguistic theory (Halliday, 1994). Theo van Leeuwen (2005) explains that

the term 'meaning potential' focuses on meanings that have already been introduced into society, whether explicitly recognized or not, whereas 'affordance' also brings in meanings that have not yet been recognized, that lie, as it were, latent in the object, waiting to be discovered.

(pp. 4-5)

A combination of the two notions, affordance and meaning potential, contribute to the possibility of grasping the social dynamics of meaning-making. The difference between the two notions can be discerned in the following example from a preschool in the Swedish countryside.

Parents had engaged in building an outdoor environment for their children, based on their assumptions about what children like to do and play with outdoors. One of the things they built for their children was a modified shooting tower, which is a very common thing in the neighbouring forests and a symbol for the locally esteemed elk hunt (see Figure 3.3). This can be understood as the meaning potential of this building: It was built as a resource for playing elk hunting at the preschool, based on the idea that elk hunting is something interesting for children. However, once the children occupied the building it was transformed into something completely different: an outdoor

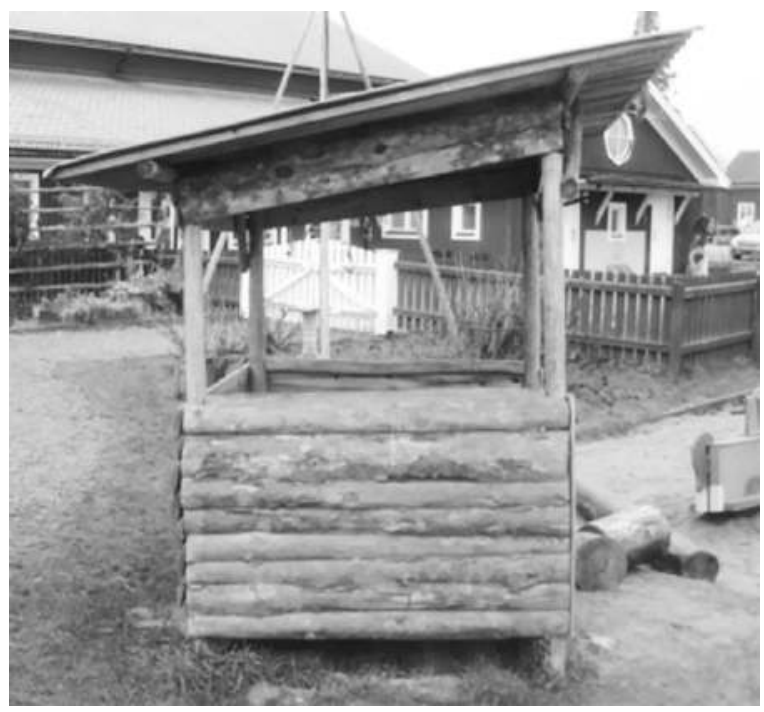

Figure 3.3 Shooting tower/outdoor kitchen.

Source: Photographed by Fredrik Lindstrand 
kitchen. They found other affordances based on their needs, interests, and perceptions. The children's interpretation and transformation of the building shows how agency is put to work.

Affordance here becomes more closely related to the specific and situated actions of the children who engage in meaningful ways as they transform the shooting tower into something that corresponds more closely to their own interests. In my interpretation, the value of identifying affordances in learners' recognition of resources, while engaging with aspects of the world, is also part of Gibson's original account above, regarding affordances as indexical of a specific and unique relationship between a being and its surroundings, based on how they both are constituted.

\section{Beyond things: semiotic and modal affordances}

Mentioning semiotic potential and meaning in my references to van Leeuwen (2005) above hints at an expansion of the reach of the term affordance, from the observable surroundings of an animal towards the somewhat more abstract qualities of the social world. This has also been commented upon by some researchers who have expressed reluctance to accept what they see as stretching Gibson's original notion too far (cf. Oliver, 2005). Thus, we need to deal with the question of what we can apply the term to.

Looking at some of the scholars who have used the notion of affordance in their research, there has been a tendency to focus on material objects and their properties (cf. Norman, 1988; Solomon, 1993). In Norman's (1988) interpretation, for example, affordance "refers to the perceived and actual properties of the thing, primarily those fundamental properties that determine just how the thing could possibly be used" (p. 9). While Gibson (1979) speaks specifically of surfaces and objects, other people (which he places within the category "detached objects") are described as providing the richest and most elaborate affordances of the environment:

The other animals afford, above all, a rich and complex set of interactions, sexual, predatory, nurturing, fighting, playing, cooperating, and communicating. What other persons afford, comprises the whole realm of social significance for human beings.

By opening the door to interactions with other human beings and to the realm of social significance that they both construe and are governed by, what van Leeuwen (2005) refers to as "semiotic resources" are already included in Gibson's approach. People, the bonds between people, and the ways in which people do things to, with, and for each other are thus included in the original account of affordances. The means for doing these things can be regarded as resources. Within the frame of a broader notion of 
text, all cultural artefacts (i.e., "things") can be regarded as text. Similarly, all texts can be approached as cultural artefacts and, as such, they have a specific materiality and material properties that, in an agent's interaction with them, can be regarded as affordances-enabling social and transformative action (cf. Björkvall \& Karlsson, 2011; Ledin \& Machin, 2018; Mosbæk Johannessen \& van Leeuwen, 2018).

As explained in Chapter 1 by Selander in this volume, DFL builds closely upon multimodal social semiotics in a number of important ways. For example, it starts with similar assumptions about communication as processes of motivated sign-making, guided by the sign-maker's interests in a given situation, and dependent on the available resources (material, modal, cognitive, and so on). Consequently, our approach to affordance stems most directly from the work of Gunther Kress (cf. Bezemer \& Kress, 2016; Kress, 2010) and Theo van Leeuwen (2005), who broadened the notion to encompass modal and semiotic affordances, and thus attend to how various modes (and the combination of modes) lend themselves to action in the form of meaning-making (see also Machin, 2016).

Kress (cf. 2010) also uses the term epistemological commitments (borrowed from Jon Ogborn ${ }^{2}$ ) in order to point out that, due to the logics of how different modes operate (e.g., composition in image and syntax in language), they lend themselves differently to us when we use them in meaning-making processes. Due to their different ways of operating, different modes provide different kinds of access to the world as they construe the world differently when used in representations. Semiotic resources are the social and cultural tools we use for communicating and making meaning. According to Bezemer and Kress (2016):

The history of semiotic use of a specific materiality produces semiotic affordances: what a sign-maker does is shaped by what other sign-makers have done before her or him, in response to similar social and semiotic needs. That prior, socially shaped, semiotic work produces socially organized sets of (material and conceptual) semiotic resources, making distinct semiotic organizational entities for meaning-making available to individual signmakers. As with material affordances, semiotic affordances are changeable and changing: sign-makers constantly expand and transform modes and their resources by making new signs.

As mentioned above, there is a strong connection between affordance and agency, in the sense that affordances both are the result of, and enable, actions. Since they are not fixed, but point towards both the agent and the environment, affordances are also in constant flux. As Bezemer and Kress (2016) point out:

Semiotic affordances are not only shaped by a social history; they are also constantly re-shaped by and in a social present of use, and furthermore 
they shape new sign-making. The units and principles of arrangement that each mode provides offer sign-makers both potentials and limitations, as well as prompts to engage with and so to see the world in certain ways - that is, to see the world through a lens shaped in specific ways (elsewhere we refer to this as 'epistemological commitment'; see Kress, 2010).

By referring to the interactional aspects of affordance we bring attention to the fact that affordances are phenomena recognized as lending themselves to our actions. In that sense they become resources for us to do something specificwhen we use a book as a tray for carrying a mug of coffee or as a racquet in a game of table tennis, or when we use images found online to explain something in a lecture. This act of distinction and recognition of what can be used as a resource for our specific intentions is also an action that points to creativity, interpretation, and learning. This is also what we refer to as (the verb) "to design" within the theoretical framework of DFL.

\section{The social affordances of discourses}

Starting from semiotic and modal affordances, the step to discourse seems logical. Similar to how different modes contribute with different takes on the world through their epistemological commitments, discourses frame knowledge in certain ways, and are articulated by means of semiotic resources. I use the term discourse here in the way Foucault (1969/1972) defined the notion, as "practices which form the objects of which they speak" (p. 49). This definition points towards the assumption that we take part in the construction of the (social) world through the ways we use semiotic and modal affordances in representations. In other words, discourse here refers to social aspects of communication and representation, in the sense that discourses affect things in the interactions between people by construing the world in a specific way. In doing so they position people in certain ways and with certain social consequences in terms of who is allowed to do what, and so on. This implies that there are always social — and ideological-aspects of representations, regardless of context. In this sense, design (here understood as the act of combining form and content) always has both epistemological and social consequences, since we cannot communicate and make representations outside of discourses (Foucault, 1969/1972). Discourses serve as resources for doing things socially-to perform social action. A certain discourse not only presupposes a certain epistemological frame but also shapes and frames representations in certain ways that affect how we understand a certain topic and, in that respect, discourses can be seen as resources for social action. As with other resources, they afford certain possibilities depending on the context and interest.

During a train journey I eavesdropped on a conversation between a twoyear-old child and her mother. The journey was long, but the mother had 
prepared a number of activities for herself and the child: They read books, watched films, made drawings, had snacks, looked at the landscape, and so on. Suddenly the atmosphere changed for a moment, as the mother raised her voice at the child: "But Lisa! Did you swallow the chewing gum?!" The girl didn't seem affected by her mother's tone at all, but answered calmly: "No, I ate it."3

By choosing to use a discourse around eating that her parents (and others with more power than her) use as imperatives in situations where eating is on the agenda (e.g., "eat your vegetables!"), Lisa challenges both the way her mother positions her and how she defines the act of swallowing the chewing gum. She uses this specific discourse as a resource and in doing so she performs a social action, thus claiming agency. The discourse she introduces has social affordances that enable her to make a certain claim. In the same way, the discourse her mother uses has other affordances that do other things socially. Lisa's response indicates an awareness of the social mechanisms of discourses.

\section{Another level-institutions and their rituals}

Before concluding this chapter, I would like to briefly mention that affordances can also be identified at other levels of analysis than the examples of meaningmaking at a micro-level in this chapter have shown. I mentioned the contextual aspects in relation to how individuals' actions of making distinctions also reflect social and material circumstances, but we could also look more directly at the institutions that shape the social and material conditions for learning. Whether we talk about institutions in daily life such as "the family," or more elaborately and deliberately developed organizations such as "the school," institutions frame certain events and relations in specific ways through rituals that fulfil certain purposes and maintain certain structures (cf. Douglas, 1986/2011; see also Insulander \& Öhman, this volume). The organization of social life as manifested in institutions provides certain possibilities and restraints, depending on what is at stake and for whom. What I am trying to say is that the technologies for organizing social life within the frames of institutions could also be analyzed in terms of affordances, to see what they contribute (for good or ill), both in relation to learners and to the institution itself. We could, for example, ask how the timetable imposes social control by structuring the school day, in terms of what to focus on and when (lessons), and how pupils' agency is distributed differently over time (e.g., lesson vs. recess). Similarly, viewed as a design for learning, we could ask how the specific combination of subjects included in the timetable and allocated in a certain pattern over the week has certain epistemological consequences. This view would also imply that the timetable is an articulation by the educational institution of what is seen as important for the children to learn. 


\section{Conclusion}

To conclude this chapter, I would like to briefly summarize the various points about affordances made above. To begin, affordances have to do with materiality (in a broad sense, including the materiality of semiotic modes such as image, language, etc.) and how materials lend themselves to actions of various kinds. How they lend themselves to action depends on the qualities of these materials and how the materials are shaped and organized-how they are designed or brought in as elements in a design for a certain purpose. While affordances are action possibilities, for good or ill, latent in an environment, yet not commonly available to all living creatures, they appear in the meeting between a specific agent and its surroundings. What becomes an affordance and for whom is based on the constitution of both the environment and the agent, and the affordance can thus be seen as a manifestation of the unique relationship between an agent and its surroundings. In order to become resources for action, the potential qualities of the environment also need to be distinguished by the agent as a potential. This act of distinction relies on the perceivable properties of "the object" (again, in a broad sense) and the agent's capabilities and interests in the situation. While enabling action, affordances are, in other words, also the result of actions. These actions of distinguishing are performed with agency, which also says something about the social framing (what is possible to distinguish as a resource from the social position one has in a certain context) and how the individual actor orients her/himself in the world. In other words, affordances manifest the unique relationship between an agent and its surroundings under specific contextual circumstances. In this sense, affordances can work as keyholes for observing how power structures are construed, for example, through the use of different discourses. Affordances make visible how agency is expressed through the activation of different resources and through the introduction of different discourses in negotiations. This points towards the social aspects of teaching, learning, and meaning-making. The resources available at a given point contribute to framing a knowledge area and what is possible to be represented in relation to this. Thereby, they also affect what can be distinguished as signs of learning/knowing.

Methodologically, the various aspects regarding affordances presented in this chapter lead me to suggest that investigations concerning resources and their affordances should be oriented towards meaning-making processes in situ, rather than theoretical mappings of potential affordances in situations of learning and meaning-making. Only then can the creative and agentive work of meaning-makers be made visible, and only then can the influence of social dynamics be presented.

The notion of affordance is valuable to a design-oriented perspective on learning, since it provides a way to grasp the qualities that resources of various kinds offer in learning (as well as other) situations. This is also typically why it 
has been used extensively in research within the more general field of designto say something about the possibilities and hindrances produced through certain ways of shaping something - as a means for mapping what a resource as a design (noun) contributes, or how it lends itself to certain modes of use. At the same time, and more importantly in relation to the DFL perspective, "affordance" also points towards the performative and transformative actions that make them resources in a specific situation. These transformative actions are what we refer to as the verb "to design." We thereby emphasize that affordance is always related to the agent that interacts with it. As Gibson (1979) notes:

affordance[s] . . . have to be measured relative to the animal. They are unique for that animal. They are not just abstract physical properties. They have unity relative to the posture and behavior of the animal being considered. So an affordance cannot be measured as we measure in physics.

(pp. 127-128)

In relation to learning, this suggests a few different directions: aspects regarding the usefulness (and perils) of resources; what learners distinguish as a resource for something that is meaningful to them; and how it is made useful by them.

\section{Notes}

1 The studies mentioned were part of a larger research project, The museum, the exhibition and the visitors. Meaning-making in a new arena for learning and communication, funded by the Swedish Research Council 2007-2010.

2 Gunther Kress, personal communication, 2005.

3 This example is also described in Elm Fristorp and Lindstrand (2012).

\section{References}

Bezemer, J., \& Kress, G. (2016). Multimodality, learning and communication: A social semiotic frame. London: Routledge.

Björkvall, A., \& Karlsson, A. (2011). The materiality of discourses and the semiotics of materials: A social perspective on the meaning potentials of written texts and furniture. Semiotica, 187(1), 141-165.

Conole, G., \& Dyke, M. (2004). What are the affordances of information and communication technologies? ALT-J, Research in Learning Technology, 12(2), 113-124.

Diamantopoulou, S., Insulander, E., \& Lindstrand, F. (2012). Making meaning in museum exhibitions: Design, agency and (re-)representation. Designs for Learning, 5(1-2), 11-29.

Douglas, M. (1986/2011). How institutions think. Routledge.

Elm Fristorp, A., \& Lindstrand, F. (2012). Design för lärande i förskolan [Designs for learning in pre-schools]. Studentlitteratur.

Foucault, M. (1969/1972). The archaeology of knowledge. Routledge.

Gibson, J. J. (1950). The perception of the visual world. Cambridge: The Riverside Press.

Gibson, J. J. (1966). The senses considered as perceptual systems. Houghton Mifflin. 
Gibson, J. J. (1977). The theory of affordances. In R. Shaw \& J. Bransford (Eds.), Perceiving, acting, and knowing: Towards and ecological psychology (pp. 67-82). Lawrence Erlbaum Associates.

Gibson, J. J. (1979). The ecological approach to visual perception. Boston: Houghton Mifflin.

Halliday, M. A. K. (1994). An introduction to functional grammar (2nd ed.). Edward Arnold.

Hodge, R., \& Kress, G. (1988). Social semiotics. Cornell University Press.

Kirschner, P. A., Martens, R. L., \& Strijbos, J. W. (2004). CSCL in higher eduation? A framework for designing multiple collaborative environments. In J. W. Strijbos, P. A. Kirschner, \& R. L. Martens (Eds.), What we know about CSCL (pp. 3-30). Kluwer Academic Publishers.

Kress, G. (2010). Literacy in the new media age. Routledge.

Kress, G., \& van Leeuwen, T. (2001). Multimodal discourse: The modes and media of contemporary communication. Arnold.

Laurillard, D., Stratfold, M., Luckin, R., Plowman, L., \& Taylor, J. (2000). Affordances for learning in a non-linear narrative medium. Journal of Interactive Media in Education, 2, 1-19.

Ledin, P., \& Machin, D. (2018). Introduction to multimodal analysis (2nd ed.). London: Bloomsbury.

Lindstrand, F., \& Insulander, E. (2012). Setting the ground for engagement: Multimodal perspectives on exhibition design. Designs for Learning, 5(1-2), 30-49.

Machin, D. (2016). The need for a social and affordance-driven multimodal critical discourse studies. Discourse \& Society, 27(3), 322-334.

MODE. (2012). Glossary of multimodal terms. https://multimodalityglossary.wordpress.com/. Retrieved 2019-08-25.

Mosbæk Johannessen, C., \& van Leeuwen, T. (Eds.). (2018). The materiality of writing: A trace-making perspective. Routledge.

Norman, D. A. (1988). The psychology of everyday things. Basic Books.

Oliver, M. (2005). The problem with affordances. E-Learning, 2(4), 402-413.

Solomon, G. (Ed.). (1993). Distributed cognition: Psychological and educational considerations. Cambridge University Press.

van Leeuwen, T. (2005). Introducing social semiotics. Routledge. 


\title{
Design and research
}

\section{Ethical considerations}

\author{
Anna Åkerfeldt and Lisa Björklund Boistrup
}

\section{Introduction}

A Designs for Learning perspective, with its close attention to the setting and the materiality of communications, is well-suited for research closely connected to the actions taken by professionals and participants. This may be research on others, where the interest is to understand how learning is supported and/or limited in a certain context, while also considering the complexities of that context. There may also be research with others, where the emphasis is on making changes in practices while investigating these changes, where researchers, professionals, and other participants collaborate. In such collaborations professionals may, for example, be working in schools as teachers and school leaders (i.e., in formal settings), or as staff working in semi-formal settings such as museums (see Chapter 8 by Insulander \& Öhman in this volume). Here, we discuss both design research on others and with others, with specific attention given to ethical considerations and aspects.

In this chapter we discuss ethical considerations, following the LDS model (Figure 4.1) from left to right; starting with the setting, which is framed by the resources at hand, and the institutional norms and regulations. This section is followed by ethical considerations in relation to the transformation units where interactions take place in different kinds of situations, constituted by transformations within and transductions between modes (e.g., pictures, body movements, speech). After this we address ethical considerations concerning participants' roles vis-à-vis a Designs for Learning framework.

\section{The setting}

When working with research that involves human beings, there are several ethical issues that need to be addressed and accounted for in different stages in the research process. As part of the setting for the research, institutional regulations are to be followed and, in many cases, there is also a need for formal ethical approval of the project. It is also the case that participants must be informed, and that they have an opportunity to ask questions, as well as being required to 


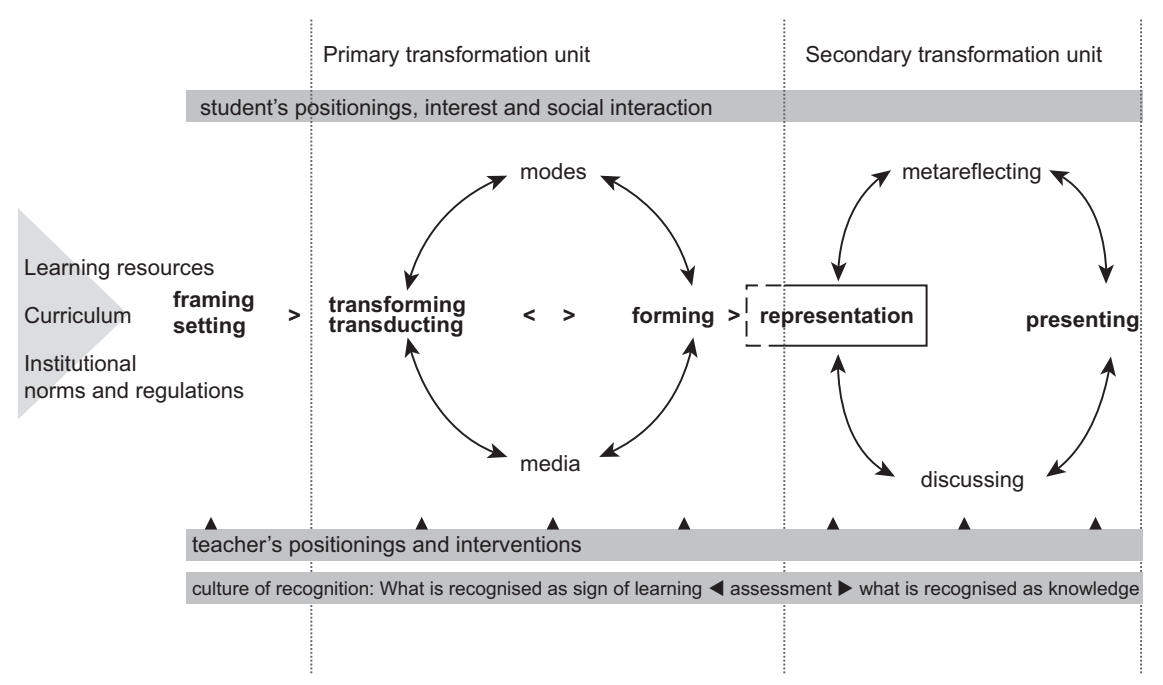

Figure 4.I Formal Learning Design Sequence.

sign a document (or to be informed verbally, depending on the research setting) where they state that they accept that a certain generation of empirical material ${ }^{1}$ is taking place. However, researchers also need to consider non-formalized, ethical questions concerning their relationship to others (e.g., unequal power relationships) and possible consequences of the research.

\section{Formal ethical protocols-an obstacle or a necessity?}

Currently, increased attention is on ethical considerations for research, where formal research approval is needed before a project begins generating empirical material. The main purpose of this is to ensure that the research is not harmful to participants, while at the same time ensuring the quality of the research. In the following we will elaborate on, and problematize, the processes around these regulations, not least in relation to research carried out together with professionals. However, even though ethical approvals are highly regulated, they differ between contexts, as they do between universities. This could mean that in one context a research project which does not include individuals' feelings and other information which might be sensitive, needs to submit a formal, and costly, ethics application to an external board, where the plan of the project is clearly articulated including empirical data and ethical considerations, whereas in another context the same project would only need a minor ethical check at the local level with, for example, a research board.

Ethical considerations also create opportunities for the researcher to reflect in depth on these before the research project starts. For example, as described 
by Selander in Chapter 1 in this volume, research in line with DFL has an interest in learning, constituted by a broad range of modes, and strongly connected to the design of the setting where humans are interacting with each other. In that sense, research in line with DFL is classified as social science research. Here we can see a tension between research in this domain and research in the domains of the natural sciences, since ethical review boards often base their understanding of regulations from declarations made within natural science research; for example, the Helsinki declaration, ${ }^{2}$ the Australian NHMRC, ${ }^{3}$ or, in the UK, ethical guidance documents from BERA $^{4}$ with ethical guidelines for educational research. The consequence is that for research in line with DFL, there is a need to adjust the narrative of the project to fit the application of ethical approval, with underlying assumptions derived from natural science research. In the following, we will examine this standpoint a little further.

In research where design approaches like DFL are adopted, there is an increased interest to work with participants in their practice rather than being the outsider doing research on others (which is mainly about collecting data from the site of the practice, then returning to the university to analyze and ultimately report on the findings in a scientific publication). For example, when carrying out research with others, one important aspect is to involve the participants in the research process since the research has its focus on the development of the practice, while simultaneously studying it. In both developing the practice and doing research on data deriving from this, researchers and professionals are each necessarily involved in a mutual, changing and dialogic process. This entails that the research project must consider the setting, not only at the beginning of the project while planning it, but also where and when the project actually takes place. This, in turn, means that there may be changes that can take a different turn from what was planned, in a way that the researchers had not foreseen when applying for ethical approval. In that sense, the standard ethical protocol required by the authority presents a challenge for researchers who wish to use a design-oriented research approach, not least because it builds upon models designed primarily for medical and natural science studies.

Of course, it is relevant to address and think about issues regarding ethical requirements beforehand, but this also means that it is often, of necessity, the researchers alone who design and make decisions regarding the research. This is likely to decrease the engagement enrolment of the participants in the practice. Should a project need to be modified, one consequence might be that the researcher would need to adjust the project to the plan, and to submit another application for ethical approval. This would normally be time-consuming (and expensive) and often requires the project to be on hold during the period the new application is processed. As we see it, this question goes beyond technical and practical issues. Rather, it has to do with a democratization of research, in line with Wood (2017) who argues: 
[G]iven the calls for universities to decolonise and democratise research, we need to question whether the ethical norms developed to cater for objective, researcher-driven enquiries are appropriate and sufficient to ensure ethical conduct for qualitative designs that are more subjective, participatory, and community-based.

(Wood, 2017, p. 1)

\section{Ethical protocols and participants in the research}

One ethical challenge for research in line with a Design for Learning perspective is that the research, and consequently ethical approvals, often need to take into consideration video data as a resource for the analysis. The reason for this is that the DFL perspective views all kinds of modes as valuable to consider (see Selander, Chapter 1 in this volume), when exploring situations where learning is taking place.

Some research inquiries with a focus on exploring classroom interaction which includes speech as well as gestures, for example, would not really be possible if multimodal data and analysis were not part of the project. An example of this is Boistrup's (2015) research, where feedback as part of classroom communication often included facial expressions and body posture. If only sound had been recorded, the findings would have been substantially different, missing out on feedback acts taking place on a day-to-day basis in mathematics classrooms; for example when the teacher has a concerned facial expression, indicating that something might be wrong with an answer. Another example is in the research by Akerfeldt (2014), where video data was supplemented with recordings of computer screen activities. The screen recordings made it possible to do an in-depth analysis of the writing process using the resource of wordprocessing software. Here also the multimodal analysis was essential so that the students' writing, editing, and pauses could be followed at a micro level and then compared to their writing with the resources of pen-and-paper. This is further elaborated in the section on Transformation units.

When the empirical material includes video-data and photographs of people, extensive additional work to gain ethical approval might be needed, not least since the rationale for ethical regulations stems from the field of natural science, as stated above. Another challenge is that it might be harder to get participants (e.g. teachers and students) to be willing to take part in the research for reasons of privacy. Previously, before the possibilities for video-data to be published and easily disseminated (e.g., through YouTube, Vimeo, or other cloud-based services), and there was no software allowing for facial recognition, this was not such a big issue. Simultaneously, this development has led to more caution in the field and by professionals, which of course can be viewed positively, since it points towards an increased awareness about recorded digital material. So, there is a tension between, on one hand, empirical material that could include video data (often needed to get a full picture of the on-going communications), and 
on the other hand, hesitation by participants (and guardians) to sign a letter of consent agreeing to take part in the research.

However, there are ways to counter this challenge. In relation to participants, one way to solve the tension is for the researcher to work on building trust prior to the research process (Nzinga et al., 2018). For example, in a school setting on some occasions the researcher may meet with the teachers and students first. If this is done, our experience is that both teachers and students become more comfortable with and positive towards video recordings and agree to participate in the research. In this process, it is of course also important to reflect upon and talk with the participant, so if there were any reason for them to leave the project and not be captured in any recordings, they would be able to communicate this without any problem. A multimodal understanding could also be relevant here, so that the participants are informed that they could use different communicative ways to indicate their unwillingness to participate, not just verbally. For instance, they could hold up a hand or shake their head. Another question is whether it is essential for the aim of the study to capture, for example, facial expressions, or not. In the research by Boistrup (2015), it was essential to also record the participants' faces, since, in this case, feedback from the teacher to students was conveyed through facial expressions, speech, and body movements, and also in writing. In the study by Åkerfeldt (2014), the research interest was on the participants' writing using the different resources at hand-in this case it was not essential to capture facial expressions; the activities on the computer screen and observations of how the students moved their hands were sufficient.

When using a design approach in research with professionals, the researcher needs to address the ethical issues at every step of the project, and not only at the beginning when filling out an ethical consent approval. We address some of these in the following sections.

\section{Capturing the institutional setting of the participants' context}

Earlier in this chapter, we addressed the ethical issues concerning the setting of the research project. There are also ethical aspects to address when taking the institutional setting of the participants' context into account, not least since institutional norms and regulations permeate the day-to-day practices within that context. The main idea here is to view the professionals in their context as part of, and affected by, the broader institutional context. In this way, the analysis involves the broader complexities of a setting, instead of solely focussing on, for example, how the individual professional manages a situation. One example is a study by Svärdemo Åberg and Åkerfeldt (2017), where analysis of students' multimodal texts was interpreted in the light of the students' social and institutional use of resources and a recognition of their knowledge through their use of different modes. In Boistrup $(2015,2017)$, feedback and assessment practices 
in mathematics classrooms were connected with institutional traces, including decisions made at the municipality and school levels affecting the classroom work. The institution was part of the setting in other ways such as through available resources, including manipulatives for mathematical explorations, and the national curriculum. The ethical aspects here concern the researcher taking this fuller setting of the participants into account, giving credit to the professionals for the complexities of the work they carry out. This makes it possible to widen the perspectives sometimes displayed in media, or by politicians, where school teachers appear to be the only ones who should bear the brunt of all kinds of criticism of school education.

The same considerations also apply to research carried out together with professionals. In such collaborations, there is the possibility to bring in the institutional setting as part of the discussions within the research group. Such discussions are summarized in Boistrup (2017), where teachers mention other actors who may support and enable developmental work in the teaching. For instance, there are many school leaders who are supportive, but there are also examples of the opposite. In the case of resources as part of the setting, teachers pointed at the new national curriculum as being supportive, while the new assessment system was described as taking too much of the teachers' time.

\section{Transformation units}

In this section we address both transformation units of the LDS model, where the primary unit reflects interactions during group and/or independent activities such as when students are working on an assignment given by the teacher. The secondary transformation unit has its focus on interactions that normally take place at the end of an activity, or period, where the whole group is gathered, and where the activities in the primary unit are discussed and reflected upon. We discuss both transformation units simultaneously, while there are other chapters in this volume where these units are addressed separately (see Chapter 5 by Boistrup \& Hällback, and Chapter 6 by Kjällander).

As mentioned above, a broad range of modes are taken into consideration in DFL research. When the researcher is an observer to interactions in transformation units and generating data which then are analyzed by the same researcher, there are different ways to include a multiplicity of modes. In the field of mathematics education, as an example, it is not uncommon for accounts from classroom activities to focus on what is being said, while other modes are brought in only when needed for a deeper understanding of what is taking place in the communication (see Boistrup, 2018). However, such an approach may at the same time miss essential parts of the communication, and consequently traces of relevant meaning-making activities.

In the first transformation unit, episodes of interactions often start with gazes and movements, such as when a teacher is watching students who are working on an assignment and then, as a next step, decides to approach them 
and engage verbally with them. Additionally, in both the first and secondary transformation units, students may present their work to peers who may react by way of body movements and/or facial expressions. These non-verbal modes constitute much of the classroom communication (see e.g. Boistrup, 2015; Svärdemo Åberg \& Åkerfeldt, 2017).

There are different ways for research to acknowledge the multimodal aspects of interactions. Examples from the field of mathematics education include research which pays attention to a certain mode, like gestures and the roles they play in classroom communication (e.g., Morgan \& Alshwaikh, 2012), or research which addresses communication inside and outside of school, as constituted by a broad range of modes, with an interest in the functions of these modes (Boistrup, 2015; O'Halloran, 2000). Such approaches are in line with DFL, and the considerations of how to include modes in research are strongly connected to ethics. For example, if one mode, such as speech, takes precedence over all others, the participants' acts could be interpreted in a more restricted way than might otherwise be the case.

The examples in the sections above relate to research that identifies how feedback acts in classrooms could be clearly captured when body movements and facial expressions are included along with words and symbols. Another example is the research by Nordin and Boistrup (2018) accounting for how young students' mathematical argumentations were construed from students describing their problem-solving in a variety of multimodal complexes (Kress, 2017), where one student mainly used drawings, while another used mainly symbols and speech. The aforementioned research provides examples of how such considerations vis-à-vis modes provide rich opportunities to do justice to the participants in complex situations such as classroom communication.

The examples above used a broad range of modes in their empirical research, which could also have ethical implications, as noted above. However, this does not mean that the most ethical approach is to capture all possible modes all the time, in every project. On the contrary, we view it as essential from an ethical perspective to reflect upon which modes should be included in the empirical material, and why. As an example, in the aforementioned research by Åkerfeldt (2014) which focussed on the writing processes, video recordings took place alongside the recordings of computer screen activities. However, the faces of the participants were not captured since they were not essential in relation to the research questions of the study. So, from an ethical point of view, it is essential that the empirical material should, wherever possible, also be part of the analysis. If not, we as researchers have intruded into the participants' lives without honouring that hospitality. It would be even worse in the case where participants were not fully informed about the researcher's intentions.

What we have emphasized above is equally relevant to research carried out together with professionals, for example, in action research. One major difference is that the decisions on what data to collect, and why, are decided jointly by researchers and professionals. However, the different 
areas of expertise in the research team can be beneficial. The professionals are the experts in the research setting with its contextual factors, including how video recordings might affect the participants, for example. Such knowledge is helpful in making ethically grounded decisions on how, why, and when to collect certain data. The researchers are the experts in ethical guidelines and should pay attention to the aspects described above and take the kind of responsibility that lies with their role. In sum, in collaborative research between researchers and professionals, both parties should be involved in the reflections concerning the ethics of the research, but it is the researcher who is responsible for both how this is done and how the results are presented (which includes checking with the professionals for accuracy or refinements, etc.).

Our examples in this section have so far been connected to classroom activities. There are of course examples of research in other kinds of settings, and consequently with other kinds of content-oriented transformation units. Here we connect to some of the chapters in this volume which do not address ethical considerations per se, but which are possible to construe. In Chapter 8 by Insulander and Öhman, museum educators collaborated with teachers and researchers. This means that the setting was mainly semi-formal, which was made clear when the activities in the workshops on programming were described as both entertainment and education. An ethical aspect here was how the authors brought in the framing of activities at both the museum and the school as part of their analysis of what was taking place in the transformation units-for example, how an "exhibit or a workshop at the museum will be designed differently from a textbook or a lesson in school, depending on different expectations and purposes" (p. xx). Another example from this volume is Chapter 6 by Kjällander, where the interactions between educators and researchers during a development project are discussed. Through the description, which followed the LDS model, reflections took place throughout the project which was planned so that it would be owned equally by educators and teachers. Essentially this was about the roles that different participants would take and have the opportunity to take. This will be discussed in the next section.

\section{Professionals' and researchers' roles}

An important issue in education (and other) research is the role of the researcher and the importance of not compromising the researcher's integrity. Distancing themselves from the field and the individuals involved in project are often mentioned as important aspects of the research. This distance is (mostly) a protection against bias and particularity (Penuel et al., 2020). However, over the years, there has been a development towards recognizing the importance of collaboration with the informants. In turn, this shift has led to referring to informants as participants in order to emphasize the collaboration which is an important principle in design research. 


\section{Principles for roles in research where participants are taken as partners}

Collaboration-where there is a shared commitment to conducting the research - is also one of the elements put forward by Penuel et al. (2020), where the collaborative partners have an equal (but not necessarily the same) involvement in the research process as well as in the co-design of solutions to specific problems. They investigated four design research approaches ${ }^{5}$ and identified eight interconnected principles: the first principles state that the participants' involvement should entail that the solutions created are with them instead of for them (Penuel et al., 2020). The second principle highlights the roles of the participants in the sense of clearly defining and describing the roles of all partners involved. Included here is the acknowledgement of professionals' expertise, which includes making it clear how that expertise was part of (and integrated into) the research. For example, statements of contribution from the different stakeholders are seen as important. It is likewise important to make material from the project available to all participants, including making adaptations when appropriate to their current workplace situation. These principles could enable design research to address criticisms about bias and particularity.

These considerations call for ethical reflections such as transparency in the research project which explicitly states what expertise the participants have contributed to the research project. Regarding the outcome, the professionals could be involved as authors of publications from the research project (see, e.g., Chapter 5 by Boistrup \& Hällback, this volume).

\section{Collaboration with professionals}

As noted above, from a DFL perspective the research is often done with and not on the professionals, which means that collaboration is a crucial ingredient in the research process. Involving professionals within a research project can be done in several different ways, from the researcher collaborating with professionals, for example, acting as a critical friend, to a more intense involvement, as mentioned above, where the participant becomes a co-author of a scientific article (Sydow et al., 2021). This raises several different questions regarding the researcher's and the professionals' respective roles. One question concerns the trustworthiness and credibility of the results from the study, for example, when the professionals are highly involved in the research process (e.g., Barab \& Squire, 2004) (for reasons discussed below). Also, in cases where the researcher has an active part in the practice, one can ask if - and how-the researchers themselves can maintain a distance and ask critical questions as well as critically discuss the results from the study. Likewise, how can a professional portray and describe the practice without these being coloured by the situation, the circumstances, and their previous experience of the context (e.g., the school 
and the pupils)? The simple answer is that they cannot. Neither the researchers nor the professionals can detach themselves from their experience and prior understanding of their practice. However, in design-oriented research we would argue that this is a strength and not a weakness or a problem. The reason is that researchers and professionals gain knowledge by working with the practice instead of only studying it. Using this knowledge opens up opportunities for broadening the analysis and considering the lived experience in relation to the institutional norms and regulations.

By this, we do not say that it is easy to work with the practice as there are challenges on different institutional levels when it comes to ethical approval (see the section above on the setting of the research) as well as in relation to project descriptions and, for example, transparency when it comes to scientific publications. Let us mention one example. In a study by Sydow et al. (2021), a researcher attended workshops that were held by another person who was the project leader. The role of the researcher was to act as a critical friend in these workshops, and this was introduced and stated in each workshop. Beside observing and following the workshop, the researcher was involved by posing questions and discussing issues that were raised in the group. The researcher took the lead and was responsible for the analysis of the empirical material. In the writing process there were specific roles, where the project leader had a more prominent role in describing the context of the study, while the researcher had a prominent role in writing up the results and discussion. The project leader (the third author of the article) was an important bridge and link to the professionals, and during the writing of the article was involved in several discussions which took place about the analysis of the material, giving insights about both the professionals' contexts and the institutional framings. Being a researcher and taking an active part in the field, such as being involved in the planning and teaching while at the same time having a critical perspective on the practice, can be questioned. Therefore, the issue of transparency regarding how the study is conducted, including critical questions, needs to be raised and discussed. As pointed out above, gaining insights into the practice, for example, can be valuable. Before entering a collaboration with professionals, the following questions may be useful as a guide:

- How do you address the power relation between the researcher and the professional?

- How can participants' different challenges and questions be taken care of?

- When doing research with professionals, how can the practice be critically examined?

\section{Discussion}

In this chapter we have discussed ethical considerations with a focus on standard ethical protocols often built on natural science research and its methodology, 
aspects related to the institutional framing of the teaching, and the roles that researcher(s) and participants (e.g., teachers and students) may play during the research. We have used the LDS model to structure and pinpoint, as we see it, some of the most challenging ethical aspects when conducting research using a DFL framework. In this section we will broaden the perspective to include a wider context as well as looking forward, and highlight some aspects that will be crucial to address in the future.

As described above, in an application for ethical approval the researcher must state their research questions before entering or contacting the field, and if this process changes the researcher's aim or questions, the researcher will then need to change their application and seek a new approval. These demands are in conflict if the researcher uses a design-based approach to the field when collaborating with professionals, as this approach builds upon professionals' inquiry rather than pre-formulated inquiries from researchers. We argue that the latter creates a gap between research and practice. Another gap could occur when findings from education research studies are mostly intended to be communicated within a research community rather than the community of the professional. Penuel et al. (2020) argue that these matters are important and that there is evidence that a design research approach in education can, when taking ethical considerations seriously, promote agency and equity in education. Wood (2017) uses the term "community research design" to indicate that it is a political stance to include and involve participants in studies, instead of "doing research 'on' them and reporting findings 'about' the issues they face” (p. 1). This calls for a change in the standard ethical approval process and we argue that this way of conducting research is a way forward in addressing professionals' challenges in real settings where there is a partnership between professionals and researchers.

We have also discussed the roles of researchers and professionals in terms of research integrity. Even though it is challenging and time consuming, we need to consider and work towards a sustainable partnership between actors in a research project. Here the researcher has a responsibility, when possible, together with professionals, to communicate research results to the research community as well as to the community of professionals. Further, we have emphasized and discussed the importance of including a wider context such as the setting in which the teaching and learning occur. This could include, for example, a policy document, regulations, or institutional framings that have an impact on classroom interactions.

In this chapter we have put forward and discussed critical issues of ethical considerations in relation to research in line with Designs for Learning. Simultaneously, we have left some issues in the background. One such issue is ownership of the empirical material constructed in a research project. As professionals and researchers enter a partnership there needs to be an agreement or a common understanding of how the empirical materials are allowed to be used, shared, and stored. Some of these issues are regulated in the ethical approval, however as 
the research process is dynamic and changes over time it needs to be discussed at all stages throughout the research process. Further, as technologies develop, new possibilities are emerging which can be used for constructing empirical material. Why, when, and how these can be used also need ethical considerations. One such area, vividly discussed in education both by researchers and professionals, is the use of artificial intelligence where there are ethical concerns such as knowing how the algorithms work and which data are used to feed the algorithms. Lack of knowledge of the data used and how it will be analyzed by AI might lead researchers or professionals to make the wrong decisions. Another issue related to the vast growth in technological development is the possibility to capture and follow students' learning processes using multiple data sources. Multimodal data, which from this perspective means empirical material collected from multiple data sources, is often used to understand a phenomenon. The ethical aspect that arises in this context is that the individuals might feel as if they are under surveillance all the time, and it might not be obvious to them that data is collected automatically when the empirical material is being constructed as part of computer activities. New technologies bring forth opportunities as well as challenges and one way to move forward is to discuss ethical aspects before but also during the research process.

\section{Notes}

1 We want to avoid the term "data collection" since it is not coherent with collaborative research, where data is said to be generated with participants.

2 www.wma.net/policies-post/wma-declaration-of-helsinki-ethical-principles-formedical-research-involving-human-subjects/

3 www.nhmrc.gov.au/research-policy/ethics-and-integrity

4 www.bera.ac.uk/resources/all-publications/resources-for-researchers

5 1) The Strategic Education Research Partnership Approach Initiated 2) Design-Based Implementation Research 3) Improvement Science in Networked Improvement Communities and 4) Community-Based Design Research.

\section{References}

Åkerfeldt, A. (2014). Re-shaping of writing in the digital age: A study of pupils' writing with different resources. Nordic Journal of Digital Literacy, 9(3), 172-193. ISSN Online: 1891-943X.

Barab, S., \& Squire, K. (2004). Design-based research: Putting a stake in the ground. The Journal of the Learning Sciences, 13(1), 1-14.

Boistrup, L. B. (2015). Governing through implicit and explicit assessment acts: Multimodality in mathematics classrooms. In M. Hamilton, R. Heydon, K. Hibbert, \& R. Stooke (Eds.), Negotiating spaces for literacy learning: Multimodality and governmentality (pp. 131-148). Bloomsbury Books.

Boistrup, L. B. (2017). Assessment in mathematics education: A gatekeeping dispositive. In H. Straehler-Pohl, N. Bohlmann, \& A. Pais (Eds.), The disorder of mathematics education: Challenging the sociopolitical dimensions of research (pp. 209-230). Springer. 
Boistrup, L. B. (2018). Multimodality and mathematisation: Different communicational resources in relation to mathematisations within and outside the mathematics classroom. Paper based on plenary at CIEAEM 69-Freie Universität Berlin, 15th-19th July 2017. Quaderni di Ricerca in Didattica (Mathematics), 27(2), 25-34.

Kress, G. (2017). Semiotic work: Design, transformation, transduction. In E. Insulander, S. Kjellander, F. Lindstrand, \& A. Åkerfeldt (Eds.), Didaktik i omvandlingens tid: Text, representation, design [Education in a time of change: Text, representation, design] (pp. 39-51). Liber.

Morgan, C., \& Alshwaikh, J. (2012). Communicating experience of 3D space: Mathematical and everyday discourse. Mathematical Thinking and Learning: An International Journal, 14(3), 199-225.

Nordin, A.-K., \& Boistrup, L. B. (2018). A framework for identifying mathematical arguments as supported claims created in day-to-day classroom interactions. Journal of Mathematical Behavior, 51, 15-27.

Nzinga, K., Rapp, D. N., Leatherwood, C., Easterday, M., Rogers, L. O., Gallagher, N., \& Medin, D. L. (2018). Should social scientists be distanced from or engaged with the people they study? Proceedings of the National Academy of Sciences of the United States of America, 115(45), 11435-11441.

O'Halloran, K. L. (2000). Classroom discourse in mathematics: A multisemiotic analysis. Linguistics and Education, 10(3), 359-388.

Penuel, W. R., Riedy, R., Barber, M. S., Peurach, D. J., LeBouef, W. A., \& Clark, T. (2020). Principles of collaborative education research with stakeholders: Toward requirements for a new research and development infrastructure. Review of Educational Research, 90(5), 627-674. https://doi.org/10.3102/0034654320938126.

Svärdemo Åberg, E. S., \& Åkerfeldt, A. (2017). Design and recognition of multimodal texts: Selection of digital tools and modes in the basis of social and material premises? Journal of Computers in Education, 4(3), 283-306. https://doi.org/10.1007/s40692-017-0088-3

Sydow, S. L., Åkerfeldt, A., \& Falk, P. (2021). Becoming a maker pedagogue: Exploring practices of making and developing a maker mindset for preschools. FabLearn Europe/MakeEd 2021 - An International Conference on Computing, Design and Making in Education, FabLearn Europe/MakeEd 2021, New York, NY. Association for Computing Machinery. https:// doi.org/10.1145/3466725.3466756.

Wood, L. (2017). The ethical implications of community-based research: A call to rethink current review board requirements. International Journal of Qualitative Methods, 16. https:// doi.org/10.1177/1609406917748276journals.sagepub.com/home/ijq. 


\section{Designing and researching vocational mathematics education}

\section{Lisa Björklund Boistrup and Matilda Hällback}

\section{Introduction}

In this chapter, we present a framework for the design of and research on collaborative teaching. We will address aspects which concern the institutional framing of teaching, as well as connections between different knowledge areas, and the modes (e.g., speech, artefacts, and body movements) in which these may be communicated. We adopt a design theoretical framework (Selander, 2008 , 2017) with the addition of a model for capturing a variety of aspects of subject knowledge (Chevallard, 2006). Our framework was developed during an action research project, with a researcher (Boistrup) and teachers (one of whom was Hällback), while drawing on both theoretical models and empirical findings. Even though the specific context of this chapter is mathematics in relation to styling (makeup and hair), the framework will offer the possibility for adoption by researchers and teachers in other areas.

We challenge the dichotomous conception where theory is viewed as something very different from practice, and where mathematics is viewed as theoretical knowledge applied to practical vocational knowledge. Rather, we view theoretical work as developed by means of a variety of resources (e.g., body movements, artefacts, speech and the like), maintained and changed over time in human practices (Selander, 2006) such as vocations and mathematics (Boistrup \& Lindberg, 2020). Rosvall et al. (2017) point to a connected tension between the workplace and so-called academic knowledge in vocational education in Sweden and Finland. This tension, as Rosvall et al. write, is exacerbated through the idea of a vocational learner as being practically oriented; using their hands instead of their heads and positioned as being in need of support. Such ideas are actually institutional norms, affecting the setting in which the teaching is designed. Through the framework presented in this chapter it is possible, in research and in teaching, to move beyond such ideas, and to strive to actively identify theoretical and practical aspects of different teaching contents (in the case of this chapter, mathematics and styling). 


\section{Other frameworks in the literature}

As described below, we argue that the framework of this chapter offers opportunities, especially vis-à-vis the design of and research on teaching in relation to how knowledge aspects are constituted by a variety of modes. In this section we make connections to perspectives in the literature of mathematics education in vocational contexts. One perspective is Bernstein's theory of pedagogic practice (2000), which has informed research on, for example, how mathematics is recontextualized into different workplace activities. One example is FitzSimons (2015), who adopted the concept of recontextualization by Bernstein when investigating vocational mathematics education taking place within an industry workplace. In this project, workers could identify unsuspected ways of mathematics being transformed in their own authentic workplace activities, while at the same time recognizing their work within its holistic context. In another study, recontextualization was adopted by Boistrup et al. (2018) in an educational setting where they identified how mathematics was relocated and transformed (i.e., recontextualized) into vocational education (viz., construction work). One conclusion, broadly speaking, is that there are at least two distinct ways to reconceptualize mathematics into vocational activities: One is the explicit use of mathematics in, for example, problem-solving, and another is that mathematical concepts and methods are integrated-and more implicitly - into the vocational activity. The framework in this chapter, which builds on Selander (2008) and Chevallard (2006), will illuminate a more nuanced version of this conclusion, with more variety in how mathematical and vocational knowledge aspects can relate to each other. The framework also addresses the roles of different modes, and the overall design of the teaching.

Another relevant theoretical perspective in the literature is Cultural Historical Activity Theory (CHAT) (e.g., Engeström, 2001). Frejd and Muhrman (2020) used CHAT to investigate the learning space available for vocational mathematics education when carried out by teams with one mathematics teacher and one vocational teacher, as was the teaching described in this chapter. Using Engeström's model, the authors investigated notions of tools, norms, division of labour, and community. They claimed that when the teaching is carried out in a vocational learning space, the setting itself facilitates students' learning of workplace mathematics. Adopting the same framework, Williams and Wake (2007) investigated mathematics as part of workplace activities. They problematized how mathematical processes have been hidden, crystallized, in what they called "black boxes," which often are instruments that carry out the mathematical algorithms needed for the work. The activity theory model contains somewhat similar notions to the learning design sequence (Selander, 2008) adopted in this chapter. The Learning Design Sequence is, however, visually and discursively outlined so that the model makes clear that notions like tools (or resources) can perform other functions in a learning setting. One 
such function is how transformations take place when knowledge is "transducted" (a term used by Kress, 2017, for changes between modes) from one mode to another. The model also distinguishes between different phases of a teaching event, which makes it relevant for the purpose of the design and analysis of teaching.

\section{The context of the chapter}

In Sweden, a large part of vocational education is included as study programs within upper secondary school, alongside study programs aiming for university studies. In these programs, the curriculum covers both knowledge specified for the vocation in question, including periods of practicum, and general knowledge areas, for example, English and Mathematics. In some schools, the vocational teacher and the mathematics teacher teach one lesson together each week, with the first year students at least. The data for this chapter stem from these lessons.

In the two lessons described and analyzed here, the styling teacher (Divo) and the mathematics teacher (Matilda) collaborated. These lessons were part of an action research project at the school where the first author of this chapter, Boistrup, was the researcher, and the second author (Hällback) was one of the teachers, and a project leaders at the school. Both authors have been engaged in the detailed analysis and the writing of this chapter. Hällback had the responsibility for transcriptions and Boistrup for how the theories were adopted when the project was carried out. The teachers took responsibility for planning and carrying out the teaching, even though the researcher (Boistrup) was able to interact during the lessons from which the data was collected. Divo Racheed (the styling teacher) was part of the initial analysis. He has read the chapter and agrees with our detailed analysis and writing. All steps in the research followed ethical guidelines, and the research was equally "owned" by the researcher and participating teachers (as described by Boistrup \& Samuelsson, 2019). Since the focus of this chapter is on the proposed framework, we will not elaborate further on these methodological aspects.

Both lessons were filmed, and photos were also taken. In the first lesson, the overall assignment was to carry out makeup (highlighting and contouring), through the adoption of triangles, drawn on a face chart (Figure 5.1a), and in the face (Figure 5.1b).

The origin of the assignment reflected by Figures $5.1 \mathrm{a}$ and $5.1 \mathrm{~b}$ was a series of lessons, taught by Divo (D) and Matilda (M), which had a focus on symmetry, both from a mathematical and a vocational point of view, where one aim of highlighting and contouring is to create an impression of a symmetrical face.

The other lesson concerned hair styling, with the overall assignment to make different types of hair curls which are created mainly by the angle between the hair and the surface of the skull (Figures 5.2a \& 2b). 


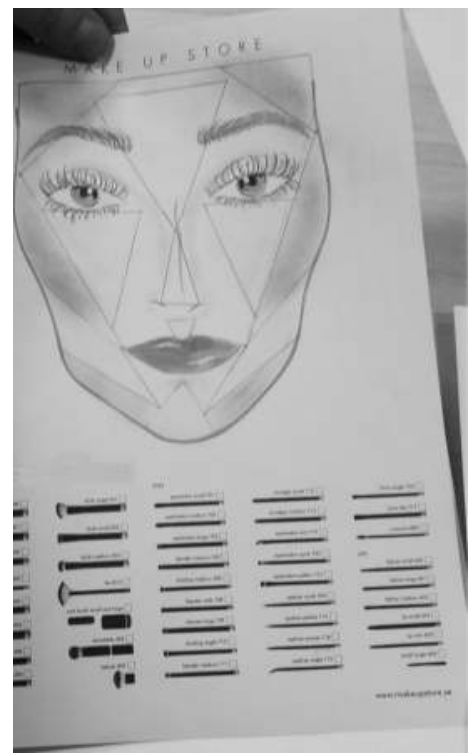

Figure 5. I a Student's face chart.

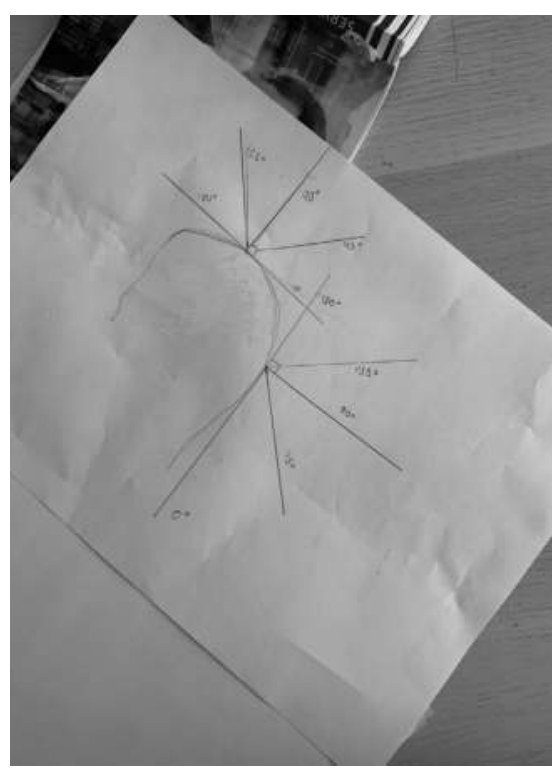

Figure 5.2a A student sheet with angles.

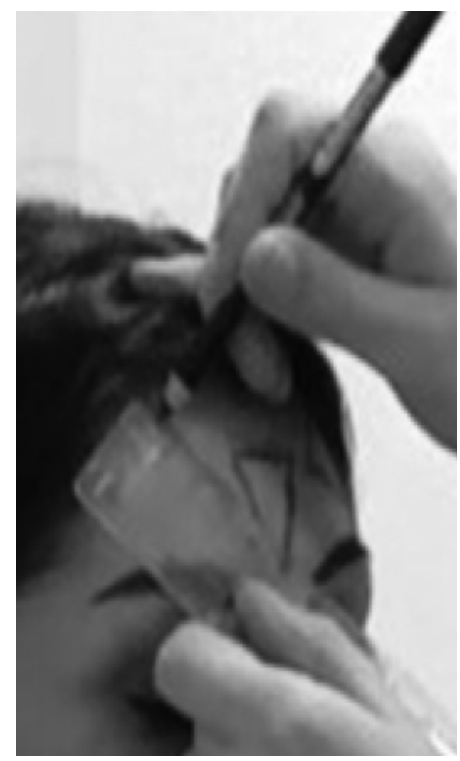

Figure 5. Ib Clip from film with a student drawing triangles.

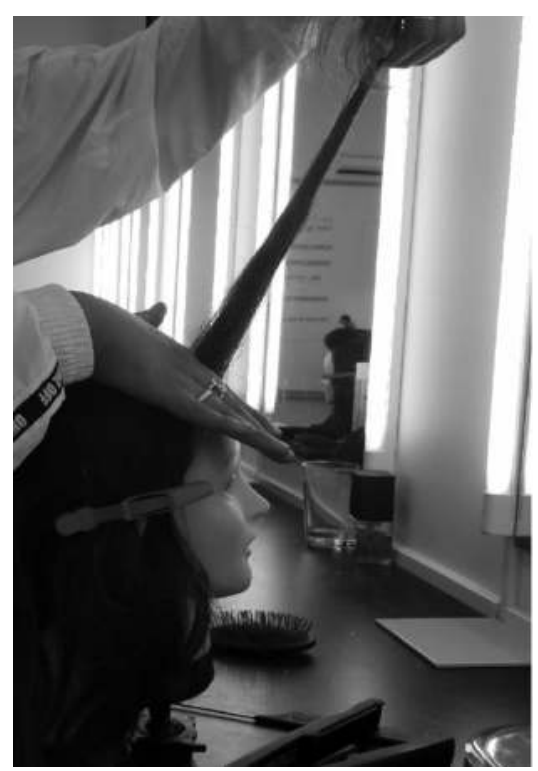

Figure 5.2b Student clarifies an angle of 90 degrees. 
In order to successfully create a certain hair style, it is essential to curl all parts of the hair at the same angle-90 degrees as in Figure 5.2, between the loop of hair and the surface of the skull.

\section{Designing teaching}

As described elsewhere in this book, Selander (2008, see also Chapter 1) presents a model for studying processes in teaching with an interest in "the formation and transformation of knowledge when people (visitors, students, etc.) engage in different processes of problem-solving, information-seeking and sign-producing activities" (p. 17) (see Figure 5.3).

On the left side in Figure 5.3, the setting is defined in terms of how a lesson, or series of lessons, starts out. The curriculum may derive from both the national level of the school system, and the local. When it comes to the national level of this chapter, the national curriculum of mathematics for vocational programs clearly states that the mathematics taught in these programs should connect to, and be affected by, respective directions of the vocation of the program. This institutional norm means that a program such as "building and construction" will have a different mathematical emphasis from a crafts-oriented program such as "styling." The curriculum at the local school level of this study expects that the mathematics teachers and vocational teachers should find connections between their respective knowledge areas, when teaching together for one lesson each week. Also, the learning resources are institutionally affected by, for example, the

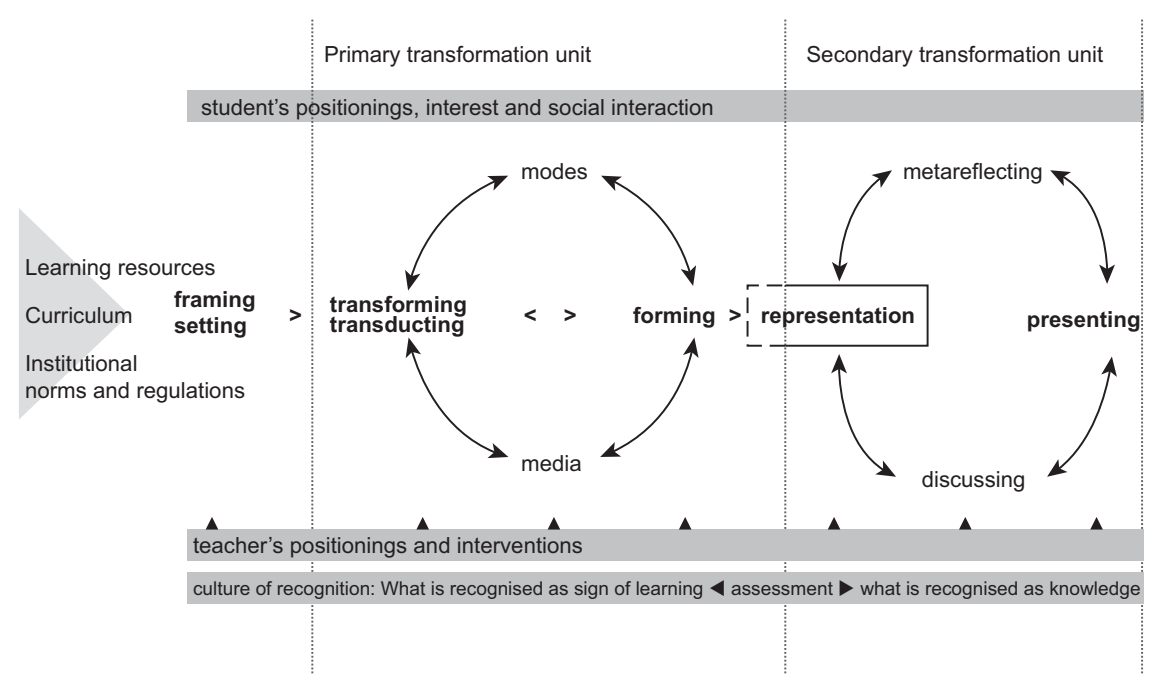

Figure 5.3 A Learning Design Sequence.

Source: (A revised version of the model in Selander, 2008, p. 17) 
organization of the teaching at a school. In this study, this concerns the location of the collaborative teaching used for vocational teaching. An institutional norm at this school is that mathematics is essential, and hence this was the chosen teaching content for the collaboration with vocational teaching.

The primary transformation unit takes place during the lesson, and here the knowledge is formed through different forms of expressions, or modes. The modes derive, implicitly or explicitly, from the interest of students and teachers in the social interaction to communicate a certain knowledge aspect at a certain moment. The expressed knowledge is also transformed within modes and transducted between different modes. One example from the hair styling lesson of this chapter is how the angles in the student sketches (see Figure 5.2a) were transducted into the activity of curling with certain angles between hair loops and the surface of the skull (as in Figure 5.2b). During the primary transformation units, teacher interventions occur when the teacher interacts with students and provides feedback (which may be viewed as part of formative assessment).

The secondary transformation unit often, but not always, takes place at the end of a lesson when the teacher and students discuss and metareflect on the teaching content of the lesson. This clearly took place in the hair styling lesson, where the styling teacher led the summarized metareflection of knowledge connected to the relation between the angle of the hair loop and the hair style. There may also be occasions where a teacher is interacting with a few students during the lesson that also have the characteristics of a secondary transformation unit, as exemplified in a following section. The knowledge in the secondary transformation unit is represented by different modes, deriving from the interest by teacher and students to make it comprehensible, and possible to present to others. Sometimes students' presentations are part of a summative assessment, in the sense that students demonstrate they have accomplished aspects of the required knowledge-for example, mathematical concepts, or overarching knowledge about styling.

The learning design sequence captures essential aspects of the design of, and research on teaching. It helps in understanding the processes of teaching and learning, not the least in the attention paid to the affordances of various modes (see Chapter 3 by Lindstrand).

\section{Theoretical and practical aspects of knowledge: praxeology}

In our action research project, we took great interest in understanding vocational knowledge aspects in relation to mathematics, and we chose to add the model of praxeology to the learning design sequence. Praxeology is a model addressing the characteristics of knowledge and is part of Chevallard's (2006) "Anthropology of the didactics" (ATD). As Castela (2015) describes it, "ATD is interested in the processes and products of what we may consider as the 
institutional cognition, that is to say, in how institutions develop their socially acknowledged capitals of practices and knowledge" (p. 8). Through ATD's interest in knowledge as constituted by institutionally framed practices, the model of praxeology is theoretically coherent with a design theory perspective.

Praxeology is constituted by praxis and logos, and offers us a foundation for addressing practical and theoretical aspects in, and the connections between, mathematics and vocational knowledge (Chevallard, 2006). Praxis (know-how) concerns tasks (types of assignments) and techniques (procedures with which the task type can be carried out). An example of a vocational task in the project was the curling of hair with three different kinds of curls, while a mathematical task was to identify the angles of 45, 90, and 180 degrees between the loop of hair and the surface of the skull. When curling the hair, aspects of vocational technique concern, for example, how to capture a loop of hair with the curling iron in a functional way. A mathematical technique could concern directing the loop of hair in the proper direction in order for the angle to be as intended. Logos (know-why) concerns technologies (why a procedure works in the way it does) and theories (overarching structures on a general level). An example of a technology connected mainly to styling was why the curling iron needs to be handled in a certain way in relation to how it affects the hair, while a mathematical technology was an explanation of why the direction of a hair loop creates a 90 degree angle and not one of 180 degrees. The main function of theory is then to provide a basis for the technology (Bosch \& Gascón, 2014). This basis may be constituted by axioms, traditions, research findings, or theoretical assumptions. An example of a theory connected to the vocational knowledge from the data was the overarching knowledge about hair styles, where curling all hair loops with the same angle creates a hair style similar to what Marilyn Monroe had, for example. Examples of theoretical aspects more connected to mathematics were what constitutes the concept of an angle, including the mathematical terminology.

Through the framework, we identified praxis and logos of both vocational and mathematical knowledge. The four Ts in the model (task, technique, technology, and theory), are intertwined and constituted by each other. Analytically, we identified them in data from the collaborative teaching in styling and mathematics.

For the analysis of knowledge aspects, we developed the analytical model in Table 5.1. The model is inspired by Boistrup et al. (2018), with an interest not

Table 5.I An analytical model for the analysis of praxis and logos, where the columns reflect a continuum between Styling and Mathematics. In the middle column there is an equal mixture of Styling and Mathematics.

\begin{tabular}{|l|l|l|l|l|l|}
\hline & \multicolumn{2}{|l|}{ Styling } & \multicolumn{3}{r|}{ Mathematics } \\
\hline Task & & & & & \\
\hline Technique & & & & & \\
\hline Technology & & & & & \\
\hline Theory & & & & & \\
\hline
\end{tabular}


only in vocational knowledge on one hand, and mathematical knowledge on the other, but also in the interfaces between the two knowledge areas.

The analytical model in Table 5.1 provides the opportunity to identify knowledge aspects that mix styling and mathematics, as well as aspects "belonging" more to either of the two knowledge areas, while at the same time identifying aspects of praxis (task and technique) and logos (technology and theory).

\section{A framework for the analysis of collaborative teaching}

In this section we coordinate the learning design sequence with the praxeology analysis model from the previous sections into a revised version of the learning design sequence. We illuminate on the one hand, the design of the teaching in terms of what modes are activated and, on the other hand, how the knowledge of mathematics and/or vocations might develop during teaching. Subsequently, we present the foundation for a framework built on the above, which may be adopted for researchers and teachers involved in questions concerning how mathematical knowledge is connected to vocational activities.

\section{A revised version of the learning design sequence}

With an interest in foregrounding knowledge aspects in relation to the learning design sequence, we added a ribbon addressing praxis and logos knowledge aspects into the model by Selander (2008) (see Figure 5.4). This is in line with the argument by Selander (2018).

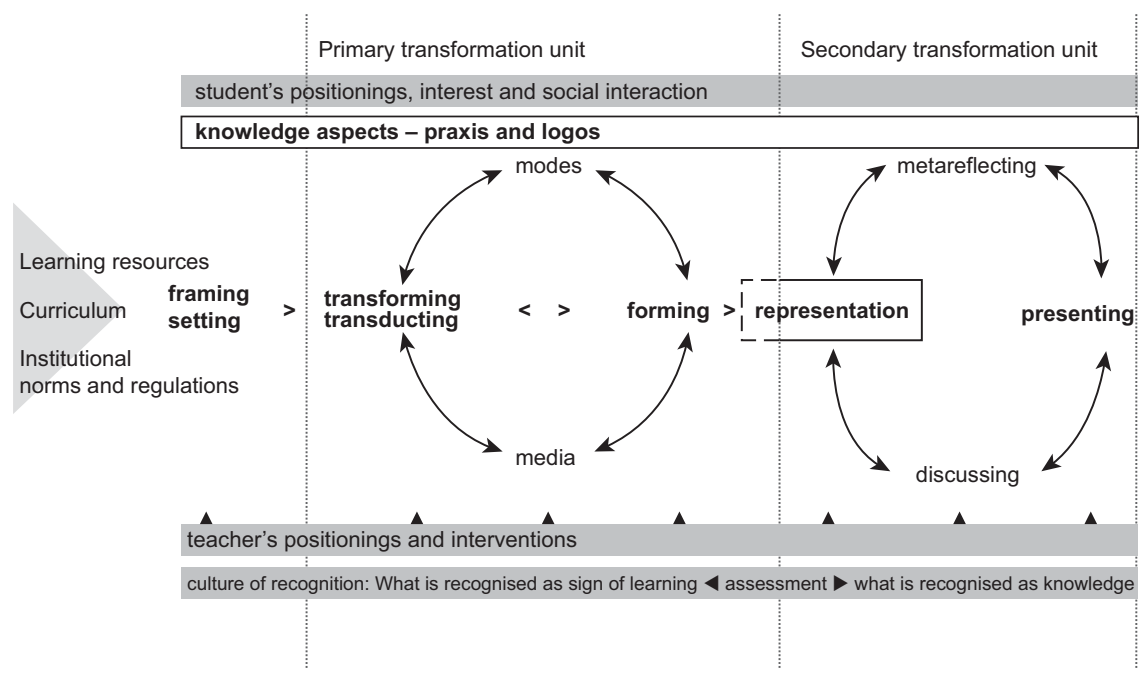

Figure 5.4 A revised version of the Learning Design Sequence, with aspects of praxeology included. 
The knowledge aspects, in terms of praxis and logos, are part of the setting (curriculum) and both transformation units. This is why the ribbon stretches sideways over the whole sequence. In the following, we provide examples of the two lessons, while illuminating the revised version of the learning design sequence. For the makeup lesson, we provide four examples, each mainly connected to one of the four Ts: task, technique, technology, and theory. All examples derive from situations where there is an interaction between a teacher or researcher and a few students. One of the examples is considered to reflect the secondary transformation unit, while the other three illuminate the primary transformation unit. For the hair styling lesson, we provide one example which takes place in the end of the lesson including all students and both teachers, and it illuminates a typical case of the secondary transformation unit.

\section{Four examples from the makeup lesson}

When it comes to the setting of the makeup lesson, the location was the styling teaching rooms, with the consequence that the learning resources connected to styling were there, with mirrors, makeup material, and so on. The mathematics teacher added learning resources to the teaching as well, which will be shown below. The curriculum in the sense of teaching content was derived from both styling and mathematics, with knowledge aspects concerning applying makeup through highlighting and contouring, and handling triangles from a mathematical perspective. The institutional norm - that there is value in drawing on vocational knowledge in the teaching of mathematics - was very much present. The overarching assignment of the lesson was a combination of these knowledge areas: to carry out facial makeup through the use of triangles. This overarching assignment consisted of task types, for example, knowing which parts of the face to highlight, and which parts to make darker through contouring. In order to make modes and resources clear, the video episode is transcribed multimodally, with columns addressing various modes (see Excerpt 5.1).

\section{The task of identifying triangles in the face during makeup (primary transformation unit)}

At the beginning of the lesson, and as part of the primary transformation unit, $M$ (the maths teacher) discusses a task type with a student: the procedure of identifying triangles in the face during makeup. $M$ starts by telling the student that she needs to make a face chart with triangles because that is what the task is about (see Figure 5.1a). She says: "The important thing now is. . that . . you:"

In Excerpt 5.1, $\mathrm{M}$ communicates with $\mathrm{S}$ through the modes of speech and body movements, and the resource of a face chart. Through this communication $\mathrm{M}$ forms the knowledge aspects in her description of the task to the student. The description mostly concerns knowledge from styling with the 


\section{Excerpt 5.I $M$ talks to a student about using a face chart. $M=$ Mathematics teacher (Matilda), $\mathbf{S}$ = Student.}

\begin{tabular}{|c|c|c|}
\hline Time & Speech & Body movements and resources \\
\hline $15: 33$ & M: ... make one with triangles & Points at a blank face chart \\
\hline $15: 35$ & S: Okay & $\begin{array}{l}\text { Holds a pencil in her hand } \\
\text { and the tip of her thumb } \\
\text { in her mouth. Looks like } \\
\text { she is pondering }\end{array}$ \\
\hline $15: 38$ & $\begin{array}{l}\text { M: And make it up, because } \\
\text { that's what's important now }\end{array}$ & $\begin{array}{l}\text { Sitting next to and looking } \\
\text { at the student and at the } \\
\text { table }\end{array}$ \\
\hline \multirow[t]{2}{*}{$15: 42$} & S: Can I put that makeup on? & $\begin{array}{l}\text { Points at the table and the } \\
\text { papers }\end{array}$ \\
\hline & $\ldots$ & \\
\hline $15: 55$ & $\begin{array}{l}\text { M: But it's really good, because } \\
\text { you usually put ... }\end{array}$ & $\begin{array}{l}\text { Points at the cheek on the } \\
\text { paper where makeup is } \\
\text { shown }\end{array}$ \\
\hline $15: 57$ & M: ... concealer here, lighter & $\begin{array}{l}\text { Shows a triangle in an area } \\
\text { under the eye of the } \\
\text { cheek on the paper }\end{array}$ \\
\hline
\end{tabular}

additional element of mathematics because the conversation in Excerpt 5.1 clearly includes the value of triangles as part of the learning of this particular type of makeup ("do one with triangles," pointing at an empty face chart). At $15: 42$, S starts to transform the content to actually doing the makeup when

\begin{tabular}{|l|l|l|l|l|l|}
\hline & \multicolumn{2}{|l}{ Styling } & \multicolumn{3}{l|}{ Mathematics } \\
\hline Task & & & & & \\
\hline Technique & & & & & \\
\hline Technology & & & & & \\
\hline Theory & & & & & \\
\hline
\end{tabular}

Figure 5.5 Matilda (M) talks to a student about using a face chart. 
she points at the resources, for example, the makeup brush on the table. $\mathrm{M}$ follows up on this when she points at the cheek of the face in the chart, and emphasizes where to put the concealer, while showing a triangle in the area under the eye. The event received the following placement in the praxeology analysis model:

The position in Figure 5.5 displays that the task content (first row) of the communication above has a clear focus on styling, but also with some mathematics. Hence, the position in the second column.

The technique of placing triangles in the face (primary transformation unit)

In the following event, which is considered part of the primary transformation unit, the styling teacher (D) discusses how the students should proceed to place triangles in the face (see Figure 5.1b). Normally, a stylist does not draw triangles on a person's face with clear lines, but during this lesson students would do this to emphasize the moment of seeing triangles in the face while applying makeup. To see triangles facilitates, among other things, the work of making a face more symmetrical through makeup (which is a theoretical aspect, not highlighted by the teacher during this event). Before this event, $\mathrm{D}$ has asked some students where they can find relevant triangles on the face and had them point to such a place:

\section{Excerpt 5.2 D discusses how students should place triangles in the face. $D$ = Styling teacher (Divo), $\mathrm{S}=$ Student.}

\begin{tabular}{|c|c|c|}
\hline Time & Speech & Body movements and resources \\
\hline 20:07 & $\begin{array}{l}\text { D: You are really good; you } \\
\text { know exactly where on the } \\
\text { face the triangles should be. }\end{array}$ & $\begin{array}{l}\text { Dips his makeup brush on } \\
\text { the back of the hand, } \\
\text { stands slightly forward } \\
\text { leaning }\end{array}$ \\
\hline 20:08 & & $\begin{array}{l}\text { Carries out makeup on } \\
\text { a student under the } \\
\text { eyebrows with light } \\
\text { strokes }\end{array}$ \\
\hline $20: 16$ & $\begin{array}{l}\text { D: Here, here we should have } \\
\text { light, right? And then we take } \\
\text { all that }\end{array}$ & $\begin{array}{l}\text { D puts a lot of makeup on } \\
\text { the student's jawbone } \\
\text { and tries to show a clear } \\
\text { triangle }\end{array}$ \\
\hline
\end{tabular}


In comparison to the previously described events, the focus in Excerpt 5.2 is more on the actual technique of doing makeup with the support of triangles, than a clarification of what the task was. D articulates this in words ("you know exactly where on the face the triangles should be") in coordination with body movements and resources. The word triangle communicated through speech is transformed by $\mathrm{D}$ into body movements when he shows triangles as part of carrying out the technique of makeup. This transformation is part of making the technique clear to the students. This event is depicted in the following position in the praxeology analysis model:

\begin{tabular}{|l|l|l|l|l|l|}
\hline & \multicolumn{2}{|l}{ Styling } & \multicolumn{3}{l|}{ Mathematics } \\
\hline Task & & & & & \\
\hline Technique & & & & & \\
\hline Technology & & & & & \\
\hline Theory & & & & & \\
\hline
\end{tabular}

Figure 5.6 Divo (D) discusses how students should place triangles in the face.

The placement in the middle column in Figure 5.6 is due to the fact that D largely directs the students' attention to the triangles of the face (part of mathematical knowledge), at the same time as he does this from a styling perspective.

\section{The technology behind seeing triangles in the face when doing makeup (secondary transformation unit)}

In the following event a student $(\mathrm{S})$ is doing the makeup on the mathematics teacher $(\mathrm{M})$. The researcher $(\mathrm{L})$ comes by and asks the student some questions. The fact that $\mathrm{L}$ is posing questions to $\mathrm{S}$, and thereby makes her metareflect and present how and why to adopt triangles when doing makeup, made us consider this to be mainly within the secondary transformation unit.

Initially, in the event of Excerpt 5.3, S indicates a number of triangles in M's face to $\mathrm{L}$ and, by the modes of speech and body movements, and resources like brush and makeup powder, she presents the makeup she applies. When doing this, she explains the techniques of contouring and highlighting through the use 


\section{Excerpt 5.3 $L$ asks $S$ about the benefits of triangles. $L=$ Researcher (Lisa), $M=$ Mathematics teacher $($ Matilda), $\mathbf{S}=$ Student.}

\begin{tabular}{|c|c|c|}
\hline Time & Speech & Body movements and resources \\
\hline $35: 00$ & $\begin{array}{l}\text { L: Well, what are you doing } \\
\text { now? }\end{array}$ & $\begin{array}{l}\text { S does makeup on M. Holds } \\
\text { a brush. Smiles }\end{array}$ \\
\hline 35:03 & $\begin{array}{l}\text { S: Yes, now I lay out the light } \\
\text { triangles in the face }\end{array}$ & $\begin{array}{l}\text { S does makeup on M's } \\
\text { forehead. M closes her } \\
\text { eyes. A student in the } \\
\text { background is watching. }\end{array}$ \\
\hline
\end{tabular}

[ $S$ continues to point out triangles, and then uses makeup to create a clear triangle under one of the eyes, while also describing this orally]

$35: 23$

L: But, but, when you ... to think in triangles...

$S$ focuses on $M$ with her gaze.

L: ... does it help? Does it facilitate, do you think?

S turns away to get more makeup on her brush.

[S explains that she can carry out the makeup anyhow, since she had learnt how to do it. The she adds that she imagines that they are helpful for someone who is learning]

35:35 S: And to think like this, well yes, look here, what I mean, look in the sense of triangles at the face.

$S$ takes new makeup on the brush and then continues to do makeup on M's cheek

$35: 53$ $\cdots$

S: It becomes easier to get it

S: What is bringing a part of the face out, and what ...

$M$ blinks with her eyes and $S$ puts makeup on M's other cheek

Puts makeup on M's cheek, body is turned to that side of $M$.

$35: 56$

M: Yes

$35: 59$

S: Yes, but, since, there are many people who put contour on all the way down here, and then it looks just wrong

Continues to put makeup on M's cheek.

Points at the lower part of M's cheek.

of triangles. Hence, this is considered technology. Our analysis of this is that the student sees an explanatory value when triangles are also emphasized from a mathematical perspective which justifies the placement to the right of centre (see Figure 5.7). 


\begin{tabular}{|l|l|l|l|l|l|}
\hline & \multicolumn{2}{|l|}{ Styling } & \multicolumn{3}{l|}{ Mathematics } \\
\hline Task & & & & & \\
\hline Technique & & & & & \\
\hline Technology & & & & & \\
\hline Theory & & & & & \\
\hline
\end{tabular}

Figure 5.7 Lisa (L) asks a student about the benefits of triangles.

\section{Theory aspects of triangles (primary transformation unit)}

Theory, in praxeology by Chevallard (2006), is about overall knowledge and ideas which form the basis as to why technologies can explain certain techniques. The event that we present here was interpreted to display knowledge reflecting different areas of the praxeology analysis model (see Figure 5.8).

The event analyzed in Figure 5.8 is that $M$ and a student were looking for triangles in a face chart, as a basis for the makeup to be done. The aspects of the interaction, where they looked for triangles of the face, led to the middle box in the line of technology since they were justifying how and why to use triangles when doing makeup. At the same time, they discussed the properties of the different triangles found, and this was inferred to concern theoretical aspects of mathematics:

Excerpt 5.4 shows that $M$ emphasizes that triangles can look very different. She also uses various terms that are relevant to descriptions of triangles, such as the word "base." This belongs to overall mathematical knowledge, which justifies the placement in the box in the lower right corner of Figure 5.9.

\begin{tabular}{|l|l|l|l|l|l|}
\hline & \multicolumn{2}{|l|}{ Styling } & \multicolumn{3}{|c|}{ Mathematics } \\
\hline Task & & & & & \\
\hline Technique & & & & & \\
\hline Technology & & & & & \\
\hline Theory & & & & & \\
\hline
\end{tabular}

Figure 5.8 Matilda (M) and a student are looking for triangles in the face. 


\section{Excerpt 5.4 $M$ and a student are looking for triangles in the face. $M$ = Mathematics teacher (Matilda), S = Student.}

\begin{tabular}{|c|c|c|}
\hline Time & Speech & Body movements and resources \\
\hline 23:01 & $\begin{array}{l}\text { M: Exactly } \mathrm{mm} . . . \text { and then you } \\
\text { can imagine that you have } \\
\text { a triangle kind of like this } \\
\ldots \text {. or? }\end{array}$ & $\begin{array}{l}\text { Is squatting beside S. S looks } \\
\text { at } M \text {, who makes a triangle } \\
\text { in the forehead with her } \\
\text { fingers }\end{array}$ \\
\hline \multirow[t]{2}{*}{ 23:04 } & M: Or you want it so that it ... & $\begin{array}{l}\text { Shows with her fingers in the } \\
\text { opposite direction. }\end{array}$ \\
\hline & . & \\
\hline \multirow[t]{2}{*}{$23: 24$} & $\begin{array}{l}\text { M: Hey, look at you! You can } \\
\text { really find many triangles. }\end{array}$ & Looks at the student. \\
\hline & $\ldots$ & \\
\hline $23: 32$ & $\begin{array}{l}\text { M: Here we can make rather } \\
\text { small triangles. Like this, } \\
\text { right? }\end{array}$ & $\begin{array}{l}\text { Shows with her thumb and } \\
\text { index finger how thin the } \\
\text { triangle may be. }\end{array}$ \\
\hline $23: 34$ & M: Which has a small base. & $\begin{array}{l}\text { Shows with both index } \\
\text { fingers in the air, how small } \\
\text { it may be. }\end{array}$ \\
\hline $23: 26$ & $\begin{array}{l}\text { M: But with higher sides, kind } \\
\text { of. }\end{array}$ & $\begin{array}{l}\text { Draws upwards with the } \\
\text { index fingers. } S \text { nods. }\end{array}$ \\
\hline $23: 29$ & $\begin{array}{l}\text { M: So ... there, right? Right } \\
\text { under ... }\end{array}$ & $\begin{array}{l}\text { Points at the cheek of the } \\
\text { face of the student's paper. } \\
\text { S nods. }\end{array}$ \\
\hline
\end{tabular}

\section{One example from the hair styling lesson}

For the hair styling lesson, the setting, in the sense of location, was the styling teaching rooms. The learning resources connected to styling were there, with mirrors, curling irons, and model heads to practice on (see Figure 5.2b). Also present were worksheets from a previous exercise, led by the mathematics teacher, with marked angles between the hair loop and the skull (see Figure 5.2a). The curricular knowledge was from styling, with the curling of hair, and mathematics, with the mathematical knowledge of angles. The overall assignment was to make different kinds of hair curls. This overarching assignment consisted of task types, where one was to do the three different curling loops of hair with the angles 45 , 90 , or 180 degrees, and one was to know about the three angles as mathematical objects. During the lesson these task types were present, and intertwined, in various interactions, reflecting aspects of techniques, technologies, and theory. 


\section{Technology and theory aspects of hair curling (secondary} transformation unit)

The event in this section takes place at the end of the hair styling lesson when everybody was gathered together, teachers and students, and is an example of the secondary transformation unit. $\mathrm{D}$ is summarizing, mainly through posing questions to the students, while drawing on overarching styling knowledge, how different hairstyles derive from different angles:

\section{Excerpt 5.5 Divo poses questions about what signifies different hairstyles. D = Styling teacher (Divo), S = Student.}

\begin{tabular}{ll}
\hline Time & Speech \\
\hline I8:3। & $\begin{array}{l}\text { D: So, if we want to have the } \\
\text { Hollywood hairstyle ... }\end{array}$
\end{tabular}

$18: 32$

18:35

18:36

$18: 38$

18:39

18:40

18:54

D: Marilyn Monroe ...?

\section{Hollywood hairstyle ...}
D: ... and a hairline that moves backwards like this.
D: What technique should we adopt then?

$$
\text { S: Well ... }
$$

D: If the curls are meant to go backwards like this, "wavy"
D: Which method should we use then?
D: Is it 45,90 , or 180 [degrees]?

Body movements and resources

D "forms waves" with his hands to illuminate Hollywood curls, smiles, and look at some students. $M$ stands behind, slightly on the side, with her hands in her pockets, and looks at the students.

D moves his hands along the hair, and "forms waves" with his hands. Continues to smile.

Holds hands still up in the air, where the "formingwaves" move ended

[Not visible]

Shows with his hands again,

Puts his hand on his waist.

Holds I, 2, and 3 fingers to clarify the three methods.

[One student answers 90 degrees and the next says 45 , which $D$ answers is correct. D makes connections again between the angle and the hairstyle that is created ("They go backwards, they go from the side," Shows with the hand from the forehead and backwards, "shape waves"). Then, D asks the next question:]

Moves his hands above the head to show much volume. 


\begin{tabular}{|c|c|c|}
\hline Time & Speech & Body movements and resources \\
\hline 18:55 & D: Big curls & $\begin{array}{l}\text { Shows big curls with his } \\
\text { hands. }\end{array}$ \\
\hline 18:55 & S: Right ... & $\begin{array}{l}\text { D still shows curls with his } \\
\text { hands }\end{array}$ \\
\hline 18:56 & $\begin{array}{l}\text { D: And volume, the } 60 \text { s, } \\
\text { Hairspray? }\end{array}$ & $\begin{array}{l}\text { Shows volume with his hands } \\
\text { above his head. }\end{array}$ \\
\hline \multirow[t]{2}{*}{$18: 58$} & $\begin{array}{l}\text { D: How many degrees would } \\
\text { that be? }\end{array}$ & Looks at the students. \\
\hline & \multicolumn{2}{|c|}{$\begin{array}{l}\text { [A student answers I } 80 \text { degrees and D confirms that this is true. } \\
\text { He ends the event by saying that the students "are in control"] }\end{array}$} \\
\hline
\end{tabular}

The overall knowledge (theory) that D emphasizes in the event of Excerpt 5.5 is about what characterizes different hairstyles. This is knowledge that forms the basis for the explanations that D also gives (technology), which in itself affects the methods, with different angles, that were used during other events in the lesson (techniques). This is reflected in Figure 10:

There is a certain emphasis on the three angles in these events, but they are really a detail in relation to D's rich description of the different hairstyles, which is why we chose the boxes at the far left of the praxeology analysis model. The fact that aspects belonging to theory are found in parallel with aspects belonging to technology is not so surprising. Our interpretation is based on the fact that an overall knowledge aspect (theory) in a teaching situation is motivated by a teacher or student wanting to explain something, which often reflects technology.

\begin{tabular}{|l|l|l|l|l|l|}
\hline & \multicolumn{2}{|l|}{ Styling } & \multicolumn{3}{l|}{ Mathematics } \\
\hline Task & & & & & \\
\hline Technique & & & & & \\
\hline Technology & & & & & \\
\hline Theory & & & & & \\
\hline
\end{tabular}

Figure 5.9 Divo (D) poses questions about what signifies different hairstyles. 


\section{Conclusions}

In this chapter, we have illuminated how it is possible to carry out detailed analysis of data from collaborative teaching, with attention to design aspects concerning, for example, transformations between modes/resources, and practical and theoretical aspects of knowledge. We have drawn on the frequently adopted learning design sequence, while also adding an elaborate focus on aspects of knowledge. With the attention to how such aspects can be understood as part of practices, we have contributed with a framework which adopts the assumptions from the original learning design sequence. The perspectives of this chapter can be viewed as a didactic model possible to adopt for teachers and researchers with a specific knowledge interest, such as collaborative teaching in, for example, mathematics and vocational subjects.

From a design theoretical perspective, this chapter illuminates the setting of the teaching in terms of the institutional norms of the school where it was promoted that mathematics should be integrated with vocational teaching for one lesson a week. Another setting aspect concerns resources, where the chapter describes how the styling classroom had many authentic artefacts which helped to strengthen knowledge aspects of styling and mathematics. This is similar to the findings of Frejd and Muhrman (2020), although the framework of this chapter extended the multimodal focus of the analysis which also deepened the understanding of the meaning-making that was afforded through the teaching. One example in the form of an artefact was the face chart, which is normally used in styling practices, but was now used with a focus on mathematical aspects such as symmetry and triangles as well. This focus, in turn, helped the styling content to be more clearly articulated. Through the transformation units of the learning design sequence, it was possible to identify how knowledge aspects were transformed between modes, and how this affected the extent to which the knowledge aspects reflected mathematics and styling, and also whether it was mainly about praxis or logos.

In this chapter, the two content areas were mathematics and styling. As described in the introduction, other studies with an interest in knowledge aspects of mathematics in vocational contexts have adopted recontextualization by Bernstein (2000) (see, e.g., Boistrup et al., 2018; FitzSimons, 2015). Similarly to these studies, this chapter aimed to take these contexts seriously and not take for granted that mathematics in vocational activities is simply materialized as school mathematics (see also FitzSimons, 2002). The framework of this chapter adds new ways of capturing the character of the mathematical and vocational knowledge in an educational setting, and how these knowledge areas can relate to each other in many different ways, through a variety of modes.

In order to develop a fruitful collaborative teaching setting between knowledge areas such as mathematics and vocational education, as in the case of this 
chapter, the teachers within the collaboration need to be willing to challenge their taken-for-granted assumptions and, hence, to go beyond the traditional discourse of the content to be taught. An open-minded view of the subjects, mathematics and styling, was consequently taken as a condition for the development of a rewarding collaborative teaching and research project. This facilitated the research, since more opportunities were created for understanding design theoretical aspects of mathematics and vocational knowledge in relation to each other. The teachers together, and sometimes with the researcher, explored what (undetected) content was "hiding" within both subjects, in a variety of modes. Also included here is the need to take both subjects' contents and resources seriously, and to look at both knowledge areas as equally relevant. Furthermore, this was a way to handle the tension, described by Rosvall et al. (2017), between workplace and so-called academic knowledge in vocational education.

For a teacher in upper secondary school, specializing in one or maybe two subjects, it is easy to highlight and to put one's personal teaching subject in the first room and not see the other subjects taught in school as equally important. In order to find new ways of capturing their own subject's content, the teachers found the framework developed in this action research project, and described in this chapter, as a helpful tool supporting them in exploring and elaborating design aspects with an emphasis on teaching content, not least in planning and evaluating the lessons. When analyzing the lessons afterwards, both teachers realized that they had helped each other with maintaining the other's subject knowledge. Also, when approaching the teaching content from a design sequence and a praxeology perspective, they realized what was actually taking place in the lessons and the actual content the students came into contact with. They could, therefore, use the framework as a guiding tool when carrying out subsequent lessons. If, for example, they realized, when evaluating and analyzing a specific lesson, that the technology for a specific technique was missing, they could keep that in mind before and during the next lesson, while also making well-founded decisions on which modes could be part of the transformation units of the teaching. Hence, the teachers not only developed the lessons consisting of collaborative teaching, but also subsequent lessons where mathematics and styling were taught independently.

Based on how the framework of this chapter was adopted, it is also possible to adopt in relation to other educational knowledge areas (than mathematics and vocational content, as in this chapter), not least when different school subjects are taught together. The ideas of the Learning Design Sequence are not bound to any specific context or content, and nor is praxeology. Our hope is that the version of the Learning Design Sequence in Figure 5.4 along with the analytical model for the analysis of praxis and logos (Table 5.1), may constitute a framework for the research and design of collaborative teaching, with an interest in a variety of knowledge aspects. 


\section{Acknowledgements}

This research was funded by AcadeMedia Inc. Additionally, we are thankful to the teachers and students at Praktiska gymnasiet Liljeholmen who participated in the project, which was the basis for this chapter, especially Divo Racheed.

\section{References}

Bernstein, B. (2000). Pedagogy, symbolic control and identity: Theory, research, critique (Rev. ed.). Rowman \& Littlefield.

Boistrup, L. B., Bellander, E., \& Blaesild, M. (2018). Mathematics in pre-vocational education: A model for interfaces between two different teaching contents. In A. Rogers, B. Street, K. Yasukawa, \& K. Jackson (Eds.), Numeracy as social practice: Global and local perspectives (pp. 76-98). Routledge.

Boistrup, L. B., \& Lindberg, V. (2020). Challenging theory versus practice: Connections between mathematics and vocational education. In Proceedings of CIEAEM71. QRDM, 7, 475-481.

Boistrup, L. B., \& Samuelsson, J. (2019). Power-relations in participatory action research projects in mathematics education. In Proceedings of CIEAEM 70, 15th-19th July 2018, University of Mostaganem, Algeria. Quaderni di Ricerca in Didattica Mathematics, 2(3).

Bosch, M., \& Gascón, J. (2014). Introduction to the Anthropological Theory of the Didactic (ATD). In A. Bikner-Ahsbahs \& S. Prediger (Eds.), Networking of theories in mathematics education (pp. 67-83). Springer.

Castela, C. (2015). When praxeologies move from an institution to another one: The transpositive effects. Mathematics, Science and Technology Education for Empowerment and Equity, 23rd Annual Meeting of the SAARMSTE (Southern African Association for Research in Mathematics, Science and Technology Education), (pp. 6-19).

Chevallard, Y. (2006). Steps towards a new epistemology in mathematics education. In M. Bosch (Ed.), Proceedings of the 4th conference of the European society for research in mathematics education (pp. 21-30). CERME 4.

Engeström, Y. (2001). Expansive learning at work: Toward an activity theoretical reconceptualization. Journal of Education and Work, 14(1), 133-156.

FitzSimons, G. E. (2002). What counts as mathematics? Technologies of power in adult and vocational education. Kluwer Academic Publishers.

FitzSimons, G. E. (2015). Learning mathematics in and out of school: A workplace education perspective. In U. Gellert, J. Giménez Rodríguez, C. Hahn, \& S. Kafoussi (Eds.), Educational paths to mathematics: A C.I.E.A.E.M. sourcebook (pp. 99-115). Springer. https://doi.org/ 10.1007/978-3-319-15410-7-5

Frejd, P., \& Muhrman, K. (2020). Is the mathematics classroom a suitable learning space for making workplace mathematics visible? An analysis of a subject integrated team-teaching approach applied in different learning spaces. Journal of Vocational Education \& Training. https://doi.org/10.1080/13636820.2020.1760337

Kress, G. (2017). Semiotic work: Design, transformation, transduction. In E. Insulander, S. Kjellander, F. Lindstrand, \& A. Åkerfeldt (Eds.), Didaktik i omvandlingens tid: Text, representation, design (pp. 39-51). Liber.

Rosvall, P.-A., Hjelmér, C., \& Lappalainen, S. (2017). Staying in the comfort zones: Low expectations in vocational education and training mathematics teaching in Sweden and 
Finland. European Educational Research Journal, 16(4), 425-439. https://doi.org/10.1177/ 1474904116669154

Selander, S. (2006). Kunskapsformer, topiskt tänkande och tolkningspraktiker [Forms of knowledge, topical thinking and practices of interpretation]. In A. Bronäs \& S. Selander (Eds.), Verklighet verklighet: Teori och praktik i lärarutbildning (pp. 25-40). Norstedts.

Selander, S. (2008). Designs for learning: A theoretical perspective. Designs for Learning, 1(1). Selander, S. (2017). Didaktiken efter Vygotskij-design för lärande [Post-Vygotskian education: Designs for learning]. Liber.

Selander, S. (2018). Can a sign reveal its meaning? On the question of interpretation and epistemic context. In S. Zhao, E. Djonov, A. Björkvall, \& M. Boeriis (Eds.), Advancing multimodal and critical discourse studies (pp. 67-79). Routledge.

Williams, J., \& Wake, G. (2007). Black boxes in workplace mathematics. Educational Studies in Mathematics, 64(3), 317-343. 


\title{
Design workshops to develop a digital educator's tool
}

\author{
Susanne Kjällander
}

\section{Introduction}

This chapter will focus on Designs for Learning (Selander, 2008, 2017; Selander \& Kress, 2017) by means of analyzing the building of digital tools for use in preschools. It will also discuss what it means to do research with preschool teachers in an intervention project where the research questions were asked by the educators themselves; something embraced by the notion of designs in learning (Selander \& Kress, 2017; see also Chapter 2 by Lindstrand \& Selander in this volume). Empirical material from the project DigiTaktik-Digital Tools as a Method for Learning and Formative Feedback in the Context of Number Sense and Early Math Skills will illustrate how educators and researchers in collaboration design for and in learning while developing a digital tool. In this chapter, illustrative empirical examples from the design process will be followed by interview quotes from the workshops. The chapter will conclude by highlighting the importance of collaboration across disciplines as well as professions.

\section{Aim and research question}

This project was preceded by an existing collaboration between preschools and Stockholm University. In earlier research projects where the mathematics learning game Magical Garden ${ }^{1}$ had been used, educators indicated that they were concerned by their lack of insight into children's mathematical knowledge. They asked for a device to visualize children's design in learning which led to a new research project arising from the needs expressed by the educators.

During two years of collaborative work, the teachers and the researchers developed an educator's tool that could be used to support children's individual learning in the context of group-oriented practice. The theoretical perspective Designs for Learning (Selander, 2008; Selander \& Kress, 2017; also see Chapters 1 (Selander) \& 2 (Lindstrand \& Selander)) was used, and this chapter deals with methodological issues concerning how a workshop series could collect and analyze empirical material. It will also discuss how teachers and researchers, within the frame of a workshop series, can develop and design a 
new, digital, and multimodal, educator's tool. A central question in this project and chapter is:

- How was the model Learning Design Sequence (LDS) used as a theoretical perspective for analyzing a two-year workshop series, with the aim to develop a functional educator's tool, in order to help preschool teachers to intervene in children's early mathematics learning?

The findings of the research question were developed through analysis of data from a series of workshops. The design was planned and executed in collaboration with two preschool teachers (who are part of the project group) and five researchers from interdisciplinary fields: didactic science, cognitive science, psychology, and neuroscience. The tool was designed together with approximately 30 educators. This chapter shows the use of LDS as a resource in designing and analyzing the workshops in relation to the educator's tool.

\section{Digital tools to support children's learning and teacher's professions}

Magical Garden (Gulz et al., 2020b; Husain et al., 2015) is the name of a research based digital mathematics learning game that is used and further developed within the project DigiTaktik. The game use is adaptive in the sense that it continuously adapts to the individual child - by means of a weighted historical success rate, the number of times a particular task has been practiced, and how fast the child advances through the game. The game is based on the pedagogical principle of learning-by-teaching, with the child taking on the instructor's role and helping a digital tutee-a teachable agent-solve tasks of progressive difficulty (Biswas et al., 2001).

Earlier research (Moreno-Ger et al., 2008) suggests that it is not especially hard to create a digital tool for educational purposes. What is hard, according to the authors, is making sure that the digital tool, app, or game is both educational and entertaining. This means that the testing process, evaluation, and re-design are expensive and result in many designs or developments being rejected or even failing, sometimes almost immediately.

However, the subsequent development and use of Artificial Intelligence (AI) offers new possibilities. AI could, for example, make a difference in the development of digital resources for education, since the metadata can create programs where teachers can see what children know and what they are struggling with. In this way, the subject content can be individualized, making it possible for children to learn at their own pace. When preschool children's' groups are large, it is hard for the individual preschool teacher in their daily work to follow each child's individual mathematics learning (Kjällander, 2019). 


\section{Workshop as a research method}

In a literature review, Ørngreen and Levinsen (2017) characterize the workshop format, highlighting some common features in the massive body of research workshops. They are arranged events with limited duration, and the participants have things in common and often work in the same professional field. Workshops have shared agendas, such as participatory design, and they are often conducted by people with experience; they promote genuine participation, often in small participant groups where they allow personal attention and where everyone can be heard. Active participation is required and participants may influence the workshop's direction. During the workshop it is expected that the participants practice the relevant techniques, skills, and situations. These findings have guided our workshop series in the project DigiTaktik. Much of what has been discussed above is embraced by our "workshop model." Calkins and Tolan (2010) indicate that all workshops should be designed to guide participation and engagement, which are considered dynamically linked to learning (also see Chapter 9 by Insulander \& Svärdemo Åberg in this volume).

Ciampa (2016), who has planned, designed, analyzed, and evaluated workshops in a research project, concluded that: "Teachers cannot just read about Web-based and digital resources; they must begin exploring these resources for themselves" (p. 305). In launching the Technology Professional Development Workshop, the researchers concerned highlighted the workshop as a method where the professional learning would be responsive to the teachers' identified needs, as a result of a "preworkshop needs assessment" (p. 296) that the teachers completed. During the workshops, individualization and feedback were crucial: "We also need to visualize new ways to take advantage of the Web-based and digital resources that are available to disciplinary literacy educators that allow for individualization and immediate and personalized feedback" (p. 305). This chapter takes up that challenge.

Workshops can, according to Ørngreen and Levinsen (2017), be divided into three different categories: (a) workshops as means, (b) workshops as practice, and (c) workshops as research methodology. The category "Workshops as means" came to be the category most relevant to this chapter. It is also a category with much published literature, and is explained as authentic workshops having the aim of achieving specific goals. These goals can have to do with outcomes that result from participating in the workshop, such as teachers' transformed practices, new competencies, new ideas, or even new knowledge. In our workshop series we aimed to achieve all such outcomes.

\section{Designs for learning and the learning design sequences}

To design a collaborative process of the development of the digital educator's tool in a workshop series, a theoretical model, Learning Designs Sequence (LDS) (see Figure 6.1), was adopted and used for analysis. 


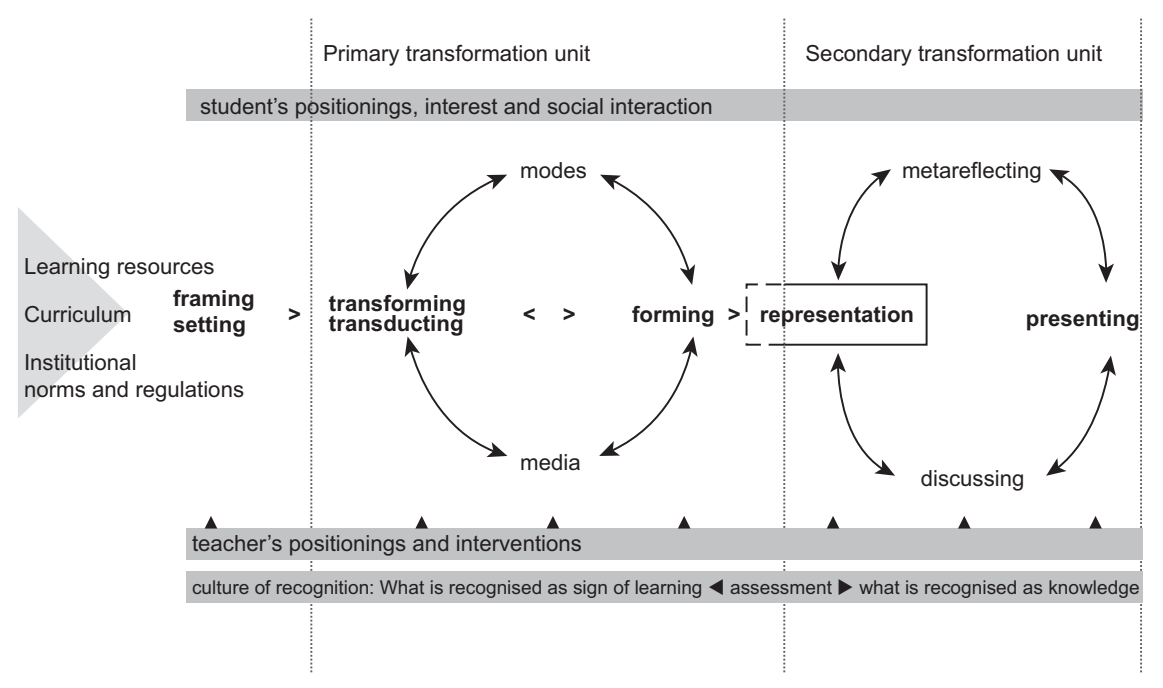

Figure 6.I The Learning Design Sequence.

Source: (a revised version of the model in Selander, 2008, p. 17; Revision by Selander and Boistrup, designed by Routledge)

The model in Figure 6.1 can be used to design and analyze teaching in a classroom (see also Chapter 5 by Boistrup \& Hällback in this volume), learning at a museum or, as in this chapter, the design and analysis of a workshop series. Different parts of the model can be important according to which questions are central for each particular project. In this chapter, the following categories were central: the setting (which is the research group's planning), the transforming (which is the educators' and researchers' process of creating the educator's tool), the forming (which is the formation of the tool), and the representation (which is the way the participants' understanding has been reflected in the design).

In the communication between researchers, educators, and resources, meaning is made by different modes such as speech, gestures, mimic, texts, and body position, as well as through colour, photo, symbols, sound effects, music, layout, and moving image (Kress \& van Leeuwen, 2001). The LDS model is used here to establish an environment where educators and researchers, working in cooperation, can develop and analyze an educators' tool. Different modes are of different importance in different situations (Kress et al., 2001), and the workshop participants choose the media (e.g., paper, pens, cello tape) and the modes that seem to fit the situation best. Their choices are illustrated in this workshop series where the tool is designed multimodally in a transformative process (Selander, 2009, p. 21).

The workshop series took place over slightly more than two years. The project can be read as a series of three sequences, initiated in the setting, and 
then transformed, and formed anew. The workshop series can also be understood as one whole sequence, with an introduction (setting), work (transforming and forming), and a presentation of the work (representation). The educator's tool was also to be used to strengthen children's individual early mathematics learning in the context of group-oriented practices by inviting educators to intervene in a child's learning processes, thereby gaining a view of their progress in the game-perhaps seeing that they seem to struggle at some point and are not moving forward - and on the basis of this having the possibility to gather a small group of children to play a related physical game to practice what seems difficult for the child, for example.

\section{Methodological and ethical considerations}

All empirical material was created within the frames of the multidisciplinary and mixed methods research project DigiTaktik_Digital Tools as a Method for Learning and Formative Feedback in the Context of Number Sense and Early Math Skills. The research project strictly followed the Swedish Research Council's ethical guidelines for research on human persons and was granted clearance by the ethics committee of the Karolinska Institute. Special attention was paid to participants' body language, including gestures and posture.

In this section, I will present illustrative empirical examples from the design process, complemented by educators' and researchers' quotes from the praxisbased research workshops. The ethical considerations in this project were very challenging since the Covid-19 pandemic broke out in the middle of it. We struggled to make the right ethical decisions, but it happened that the most ethical approach was not always the safest.

\section{Design of the workshop series}

The workshop series was designed and analyzed within the theoretical framework of Designs for Learning (DFL) (Selander, 2008), using the theoretical concepts (shown in italics) from the model Learning Design Sequence-[LDS] (Selander, 2008). According to Orngreen and Levinsen (2017), workshops can be designed as both singular and successive events. In this project, five multimodal (Kress, 2010; Selander \& Kress, 2017; van Leeuwen, 2005) workshops were designed, executed, documented, and analyzed in collaborative processes of social interaction between the field and the academy. The number of participants during the five workshops ranged from 9 to 23, and caregivers, preschool teachers, preschool headmasters/mistresses, teachers, and researchers all took part. Long before the first workshop, an informational letter was sent to all teachers who had been working with the game Magical Garden in an earlier research project and to all teachers who are now part of the project DigiTaktik. At the end of 2018 the workshop series was initiated with an invitation to a day of presentations, workshops, discussions, and aesthetic work, with food and 
coffee-breaks. The following events were included in the workshop series over two years, a whole LDS, and divided into different stages of the LDS model:

x Pre-workshop (2018) (setting).

1 WS1 (December 2018) Paper prototype informed by the game designers and formed by groups of 20 educators with paper, pens, scissors, and glue (setting).

2 WS2 (June 2019) Digital prototype1 presented to about 20 participants. The prototype was tested and revised while instruction videos were recorded, texts were written, and images designed, and a lecture about digital tools in preschool was held (transforming ).

3 WS3 (November 2019) Digital prototype2 tested and modified in cooperation with approximately 20 educators (transforming ).

4 WS4 (April 2020) Digital prototype3 tested and modified with a few participants online via Zoom due to the Covid-19 pandemic; therefore, two more WS4s were executed at two different preschools (forming ).

5 WS5 (September 2020) the Digital prototype4 of the tool was presented to about 15 participants and tested and modified just before the research pilot study (representation).

Magnus Haake designed and lead the whole workshop series, supported by the DigiTaktik research team. Also, all workshops can be understood as having completed one LDS each. Some of the researchers ${ }^{2}$ had extensive experience of working with workshops as a research method, while others were more used to video ethnography. ${ }^{3}$ Thus, a two-folded method was used where field notes and photos were taken and where some parts were video documented.

Ørngreen and Levinsen (2017, p. 79) also underline that "In a workshop, issues can be presented, experimented with, played out, and discussed. Thus, when workshops are applied as part of a research design, the researcher opts for an immersive and collaborative environment where meaning is negotiated." The research team was well prepared to design for genuine cooperation, not least since we were financed by an authority for praxis-based research. Based on Selander (2017), we were keen to design the workshop so that educators would "be able to process, transform, and use information as well as develop [an] action repertoire and assessment abilities—and thus be able to participate in a meaningful way in a knowledge domain" (p. 37, my translation).

\section{Design of the workshops-analysis and results}

The series of praxis-based research workshops was planned in close relation to and cooperation between (a) two stakeholders (i.e., two preschool teachers who are part of the project group) and (b) five researchers from interdisciplinary fields: didactic science, cognitive science, psychology, and neuroscience. In the following, the different workshops will be presented in chronological order, 
with empirical excerpts. They will be briefly analyzed using design theoretical notions and conclude with a list of functions implemented in the educator's tool prototype. For transparency, the first workshop [WS1] will be illustrated and explained, whereas WSs $2-5$ will be presentenced in less detail.

\section{Pre-workshops-autumn 2018}

In the LDS model the pre-WS can be placed before the setting (as shown in Figure 6.2), where environmental issues such as resources, curriculum, and norms are important.

The LDS model shows that the setting has a prominent impact on the whole transformative process in the two transformation units. Earlier research indicates that it is important to have a "pre-workshop" (Ciampa, 2016) where the teachers' identified needs are highlighted and worked out as a starting point. Before the first workshop we had several pre-workshops within the research team with the two preschool teachers, where relevant information was given about what was possible to expect from educators' experiences, attitudes and knowledge of digital resources, digital games and possibly also other digital teacher's tools. The two stakeholders then had meetings with educators to identify their experience, expectations, and needs (Ciampa, 2016). Half of the invited educators had previously been part of one of our earlier research projects in the same area, and the other half were working in the same area as the two stakeholders who are part of the research team. From the very first meeting we were thus a cohesive group with things in common, working in the same field, and with shared agendas (Ørngreen \& Levinsen, 2017).

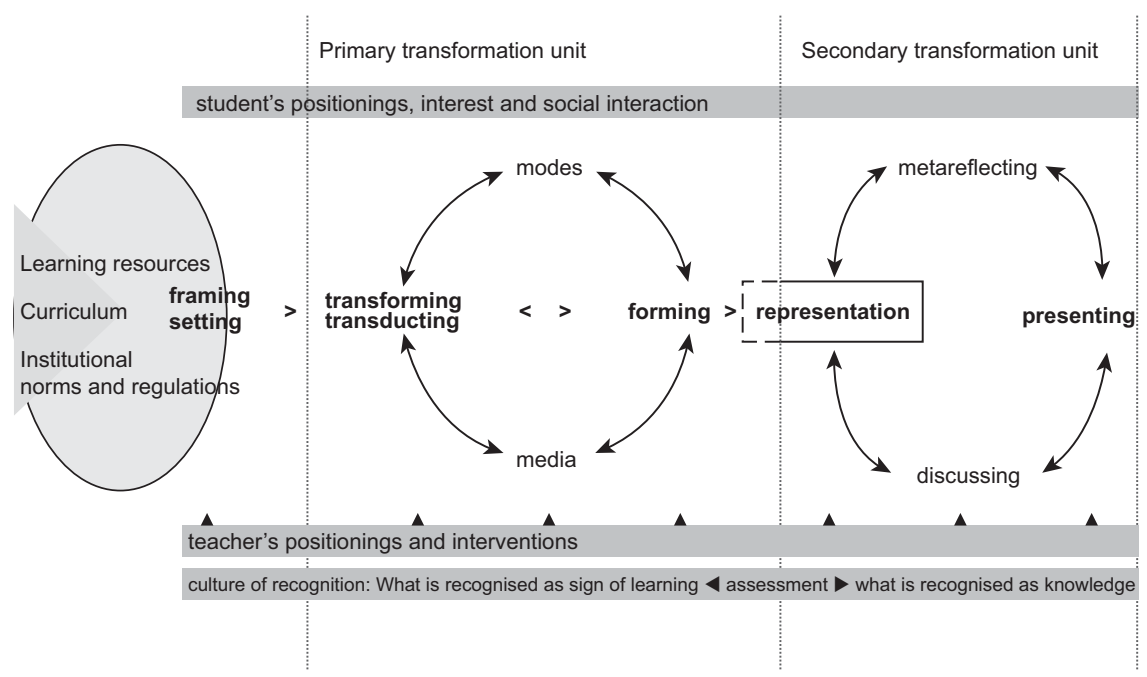

Figure 6.2 The LDS setting. 


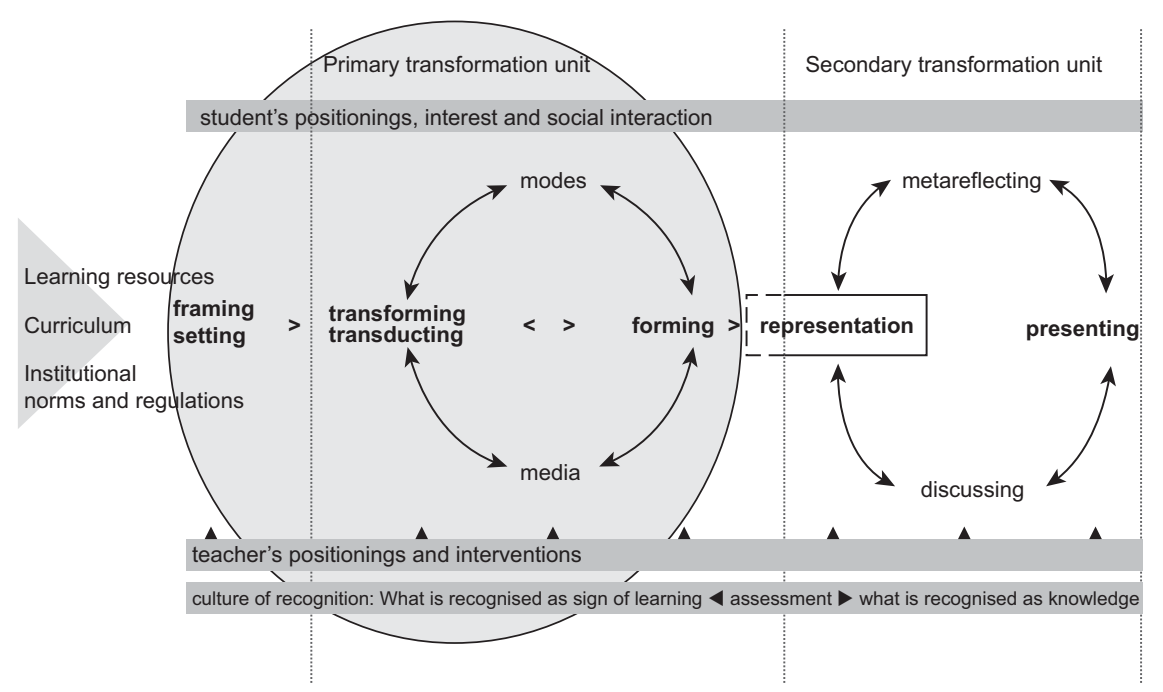

Figure 6.3 The LDS primary transformation unit.

\section{WSI-empirical example}

In the LDS, comprising all of the workshops during the 2 years, WS1 (201812-03) can be placed in the setting section, where environmental issues such as resources, curriculum, and norms are important, along with the educators, as well as in in the primary transformation unit (see Figure 6.3).

Our research project was introduced by the municipality school operations manager via newsletters, platforms, and workplace meetings. For some educators who had taken part in an earlier research project with some of the researchers, the following letter was not unexpected.

\section{WSI The setting}

An invitation letter (Figure 6.4) was sent to possible workshop members. In the setting, the norms, expectations, preschool mathematics curriculum, project problem, aim and research questions, the game Magical Garden, and finally the resources (modes and media) were thoroughly introduced. Informed consent forms were handed out and signed by all educators.

\section{WSI The primary transformation unit}

This first workshop (WS1) was arranged with a strict structure and designed to comprise the whole Learning Design Sequence in six steps, out of which the first five were part of the first transformation unit. 
Hi! You receive this invitation for being a xx teacher in the project .xx or since you will participate in the research project DigiTaktik. Stockholm and Lund University received funding from the Swedish Institute of Educational Research for the new research project DigiTaktik on mathematics in preschool. In the first step of the project we would like to invite you to participate in a workshop where you can share your experiences about working with or supervising work with Magical Garden. Together we will have a workshop on how a digital pedagogic tool in mathematics could be designed. The project group will organize the workshop led by xx. This workshop is the first in a mumber of occasions where some are about developing the pedagogic tool and others about in-service training by us and other researchers talking about, among other things, digitization in preschool.

Where? $x x$

When? Dec 3rd, 15-19

How? Bring your own devise if you have one.

We offer a simpler meal.

RSVP: To $x x$ no later than Oct $31^{\text {tt }}$

More info: You will get more information when you register or if you contact project leader $x x$

A warm welcome! wishes from $x x$

Figure 6.4 Invitation letter to educators introducing the setting and the aim of the project.

Source: (Photographed and owned by Susanne Kjällander)

In this first part of the LDS, the educators and researchers were supposed to transform and form an idea and a physical prototype with different modes (e.g., text, images, symbols, colours) and media (physical resources such as scissors, paper, pencils, and also an intended website, a platform, a social media group, an app, etc.).

The workshop was introduced by an experienced researcher giving instructions on a few points, describing the modes and media that could be used (see Figure 6.5). The other researchers paid extra attention to the interests as expressed by the educators and the social interaction going on among them. The researchers intervened at the beginning of the primary transformation unit by introducing the assignment and supporting the educators' social interaction.

1 Welcome, introduction, division into groups (approximately four persons per group).

2 Brief walk through/repetition of Magical Garden + introduction to what is behind the game in Magical Garden (e.g., what data is "logged" and what information can be accessed).

3 Present a ready-made booklet about Magical Garden. This material could/ should be used during the design process.

4 Discussion (see below) in groups for 10-15 minutes.

5 The discussions are also a "warm up" for the design process in the next step. A set of questions was presented on the whiteboard: What was it like working with Magical Garden? How can you use this type of game in a better way? What does the preschool teacher need in order to use Magical Garden in the best way? (e.g., a question bank, tutorials, digital platform, teacher tutorial, educational material, other teaching tools?) Do you need (or want) knowledge of mathematics or knowledge of how children learn 


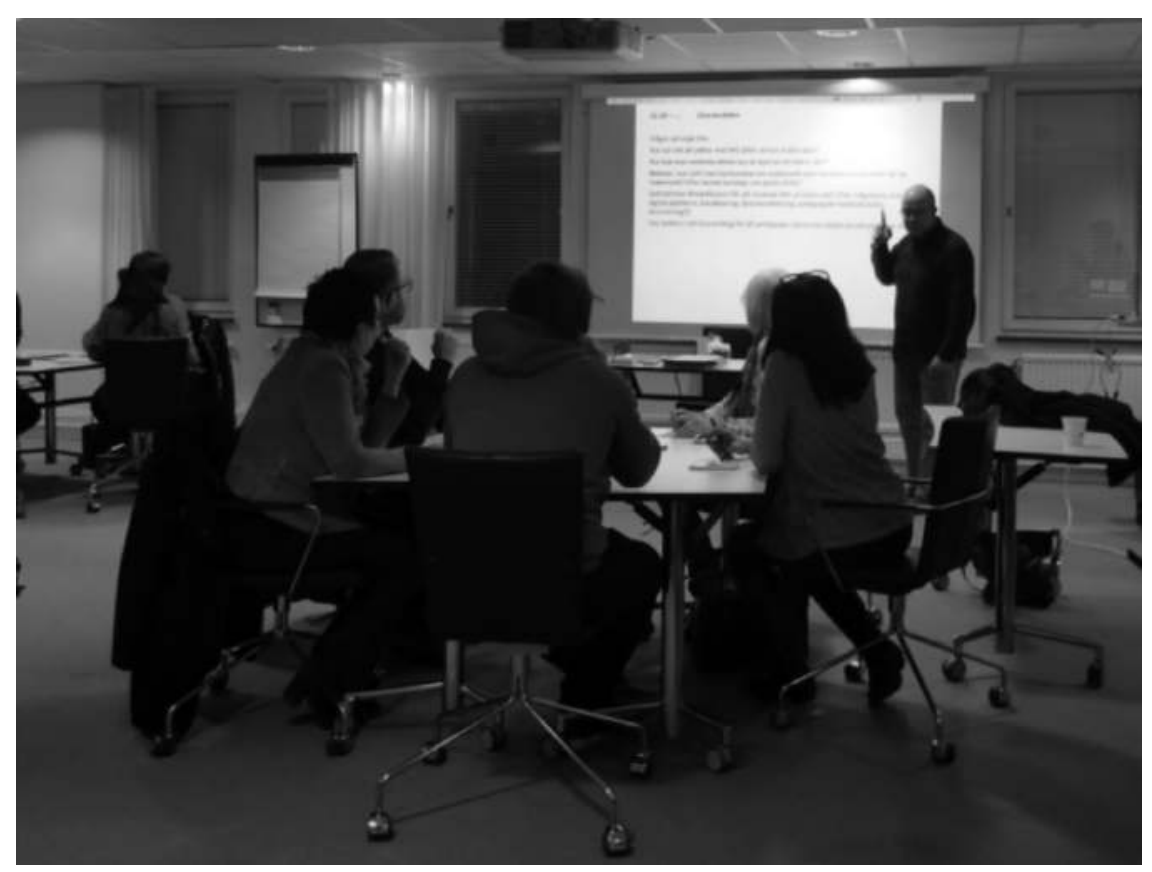

Figure 6.5 Photo:The interests and social interaction and the researcher's intervention at the beginning of the first transformation unit.

Source: (Photographed and owned by Susanne Kjällander)

mathematics? Or maybe knowledge of the game Magical Garden? This part of the transformative work ended with a gathering of the big group in a joint summary and review process.

In this gathering, questions and discussions took place during the first part of the primary transformation unit where the educators were engaged in transforming. In Excerpt 6.1, a few selected quotes from the educators are displayed:

\section{Excerpt 6.I This excerpt illustrates a discussion when no one knows what kind of tool will be developed.}

- What shall we call what is to be developed? Learning Tools, Teacher's Guide, Teacher Module? 
- It is important that educators have the early mathematics understanding, so that they can understand the children's learning processes. Today, some educators in Swedish preschool are lacking basic knowledge. How could the learning tool develop the educator's own approach to math?

- To go back and see what the children need to work more with, would be a good idea. Can you see the curves, the progression, in the game? The children who have come a very long way: how do we challenge them?

- The teaching tool can deal with both digital and analogue parts.

In this excerpt, ideas about the educators making the tool an educative one for themselves are initiated, and the curriculum-based idea of using a digital tool along with physical tools is introduced. The work of the design process aiming at producing proposals for an educator's tool took place during approximately 2.5 hours: a fast but powerful design process. The assignment was to develop a so-called Lo Fi prototype for an educator module. The Lo Fi prototype can be described as a visual representation of a digital product that will have little resemblance in appearance, but not in function, to the final digital design.

A prototype can take different forms, and in this case it was most likely to take a physical form since we handed out physical materials. On the other hand, since "bring your own device" was mentioned in the invitation, many digital tablets were laying on the tables as well and used in some groups. The workflow designed by the researchers and presented to the educators during the first part of the primary transformation unit had the aim of engaging educators in the process of transforming by following instructions in the steps (a)-(d) (see Excerpt 6.2).

\section{Excerpt 6.2 Instructions given to the educators in the primary transformation unit.}

a) Structured brainstorming. Generate suggestions for features and services in an educator module. Use the questions: "What did you miss in Magical Garden as an educator?", "What kind of educator support would you have wanted in Magical Garden?" Structured brainstorming involves loading pieces of paper with suggestions into a common pile; a minimum five pieces 
per educator, but the goal is to accumulate as many pieces (suggestions) as possible. During the so-called structured brainstorming, you should not talk to each other-and it is especially forbidden to comment on each other's suggestions;

b) Function analysis. Review the suggestions and sort them (and now you get to talk) based on the I) necessary, 2) desirable or 3) excluded/removed functions and services. The proposals sorted under "a) necessary" shall be commented on/clarified;

c) Prototyping: Sketch (visual) interfaces with paper, scissors and coloured pencils —or use digital prototyping support;

d) Presentation $\&$ walkthrough: Present your thoughts to the rest of the educators and researchers in the workshop.

The instructions in this excerpt were structured since the researchers were keen to keep the educators' interest focused on the tool. In the following, a selection of the educators' questions and discussions during the second part of the primary transformation unit is presented. The educators were engaged in forming and said:

\section{Excerpt 6.3 Educators' ideas about the educator's tool have developed and are in this part of the LDS more concrete with innovative suggestions on design, content, and functions.}

- Do you have to work with analogue first and digitally then? Can you go directly on the digital?

A discussion takes place about a well-known teaching resource, "Favourite mathematics," which is a program with a teacher's guide. It is concrete material in a digital form. The educators want the app to clearly visualize the mathematics areas in focus. There are also some ideas on tool content such as: subject headings and instructional film/suggestions for analogue activities.

The educators suggest an activity fill-in-box about who has worked today, on which page, as well as attendance list, statistics and progression. They would like the tool to enable them to log in and choose an alias/picture of each child and click, for example, "active" or "not active." They want to identify inactive 
children and identify areas where children get stuck, as suggested, with notifications/alerts to the educator. They ask for a forum to share experiences with others and a tool with instructional videos rather than text-they want inspirational educational films for both children and adults. They highlight that the learning tool must be suitable for educators with different skills, both trained and untrained.

In the primary transformation unit, as seen in this excerpt, a design process was accomplished and visualized in the educator's exploration, learning, and transformative multimodal work that took place in different modes and media such as spoken ideas, written notes, paper models, and symbols. By the end of the primary transformation unit the educators formed the very first prototypes for the educator's tool. Discussions were made both in a large group and in smaller constellations (see Figure 6.6).

\section{WSI Secondary transformation unit}

The last step in the design process of WS1 took place in the secondary transformation unit: Collection and walkthrough of all groups' multimodal representations. In this part, three different kinds of physical representations were formed and designed out of paper, pens, and cello tape, but referring to a digital tool: the very first prototypes of the educator's tool, which can be seen in Figure 6.7.

Each group of five educators presented their prototype, as seen in Figure 6.7. A researcher guided the metareflection and discussion in the whole WS group. Since all the prototypes must be transformed into one digital prototype, common

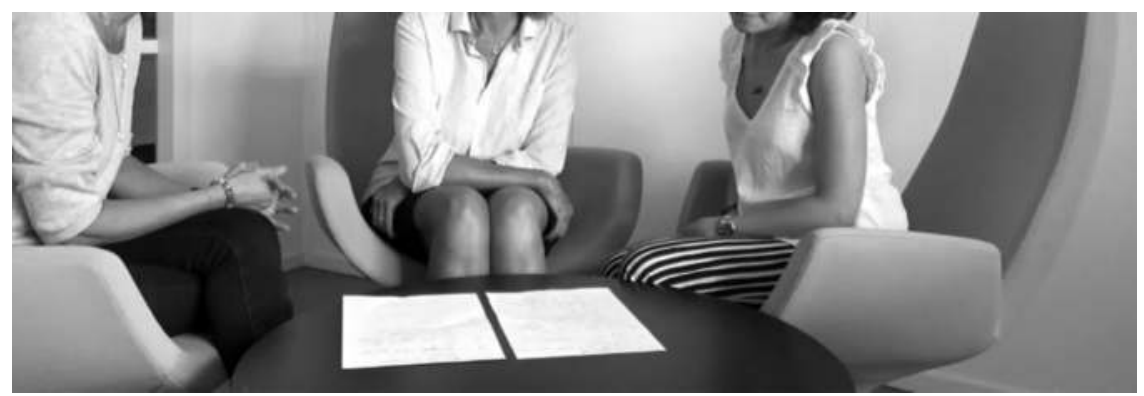

Figure 6.6 The oral brainstorm in one group is transducted to written text on paper.

Source: (Photographed and owned by Susanne Kjällander) 


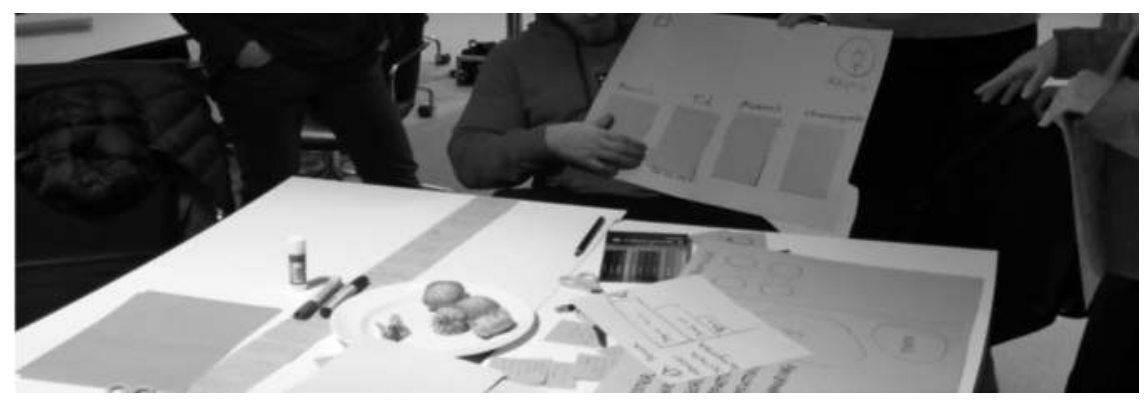

Figure 6.7 The very first prototype of the educator's tool formed by the educators in WSI. Source: (Photographed and owned by Susanne Kjällander)

features were gathered and displayed by a researcher on the whiteboard. Below are examples of quotes made by the educators during the secondary transformation unit:

\section{Excerpt 6.4 Discussions in this part of the LDS focus on the educators' everyday teaching at the preschool. The subject of mathematics is also discussed, what is embraced, and how it should be inclusive as well as physical.}

- Mathematical patterns are important - how can they be visualized and trained? Can the tool ease ... support ... encourage talking mathematics with children? Physical exercises should be included, for example, brain training, since the human encounter and the analogue material are important.

- $\quad$ Forum for collegial sharing and learning (both for educators and programmers). The tool must be able to enter and use with only a few minutes of preparation time. It may be important not only to do extra tasks with the children who really need to, but not to single out any child.

- Is there a risk with too much information or too much documentation?

In this excerpt, educators express more elaborated suggestions since they had time to metareflect on the possible content and functions of the tool, and since their quotes come from a discussion in the whole group, when an utterance can be understood as a motivated sign in a presenting mode. 


\section{WSI Analysis of the primary and the secondary transformation unit}

In the first WS we strove to design an accommodating social interaction where all educators could participate (regardless of digital competence) and we encouraged their multimodal transforming and forming processes. Our interventions in the discussions at all times implied that everything was possible and that their representations did not have to be realistic or feasible at this stage. This approach — or didactic design — was appreciated as an affordance by the educators who came up with ideas of children's aliases, and the idea that the tool should include physical matters such as "Brain train" (Neville et al., 2013). In all groups transduction (Kress, 2010; Newfield, 2014) took place where a brainstorm, with modes such as words and gestures, was transducted to the mode of written text, which was again transducted into the mode of colour, text, and symbols on a poster.

\section{Examples of results from WSI implemented in the prototype}

Some crucial parts of the tool were invented during WS1 and later incorporated into the final tool:

- The importance of using the same notions for learning, early mathematics, preschool didactics, digital resources, and the teacher's assignment, preferably with references to the National curriculum (National Agency for Education, 2018).

- Early mathematics - the realization that early mathematics must be learned, and does not develop automatically, must be presented in the tool

- The tool must be simple to navigate and there should be different tabs for different content (e.g., mathematical games, Brain Train, and educational films)

- Both physical and digital resources should be used together, according to the National curriculum for Swedish preschool. This standpoint is incorporated in the extended digital interface, and in the classroom with physical exercises, games with blocks, bean bags, and other physical objects connected to the mathematical content in the educator's tool.

- Visibility of children's progression within the game

\section{WS2-empirical example}

In the whole LDS, WS2 (June 18, 2019) can be placed in the primary transformation unit where transforming occurs and the educator's role is important.

\section{WS2 setting}

The setting for WS2 was explained as follows in the invitation: "With support in the material from Workshop1, a first prototype of a digital teacher's tool in mathematics, has now been created." The learning resources had, at this point, 
already been transformed from the physical to the digital (by programmers at Lund University), and the institutional norms (such as the aim of the research project and the invitation) indicated that the workshop would focus on the digital prototype.

\section{WS2 primary transformation unit}

One of the researchers went through the game on the projector. The first prototypes on the educator's tool were presented: The different tabs, and what is supposed to be visible under each tab, were displayed. One of the tabs was explored together in the group and a recorded film clip was viewed and discussed collaboratively. Participants all agreed that they wanted all available information: the game, the films, and the information to be displayed on the same page/platform/resource. WS2 was organized in three groups, but educators were allowed to try all activities and to go between the groups where they were supposed to transform and form their preferences by: (a) writing texts; (b) drawing models; and (c) recording film clips. The researchers walked through the groups and intervened by supporting, asking questions, answering questions, handing out material, and assisting with cameras and other techniques. In all three groups a common theme arose: the importance of a common language between the tool and everyday life in preschool. That was also the case for the discussion about what the tool should be called, as presented below in Excerpt 6.5:

\section{Excerpt 6.5 Suggestions on what the tool can be called. \\ - "Platform" \\ - "Module" \\ - "Teacher's guide" \\ - "Teacher's tool" \\ - "Educator's tool" \\ Most participants vote for "Teacher's tool”.}

There are many different views of what the tool could be called, as seen in Excerpt 6.5, and over many months it was called "teacher's tool" until it was evident that such a word would exclude professions other than educated preschool teachers. 


\section{WS2 secondary transformation unit}

During the last part of WS2, all groups presented the products of their work which were much appreciated by the audience. Following this, a metareflection was guided by the researchers and different suggestions were assessed on their feasibility for designing into the tool. Some important discussions and decisions took place about both children's early mathematics and educators' own mathematical knowledge.

\section{WS2 analysis of the primary and secondary transformation unit}

The didactic design in WS2 was to engage the educators in the physical production of multimodal parts of the tool. It is a simple task to come up with amazing ideas and visions during a WS, but a difficult business to transform them into a representation. The educators were productive during the WS and transformed their ideas into an assembly of texts, films, and models. Possibly the multimodal assignment with a focus on image was appreciated as a prompt (van Leeuwen, 2005) to visualize children's learning in the tool. When they were viewing the prototype in the WS setting, no-one reacted to the words used, but when they were engaged in transforming and producing (e.g., recording a staged interview with each other about early mathematics) they used the same language as in the curricular texts they were familiar with. This was discussed with a lot of interest and engagement, and the researchers realized how important it was for the tool to be trusted by educators. This is related to the discussion that the tool must be called something that would be deemed trustworthy. It must appeal to everyone, yet not exclude anyone. In preschool, people with different educational backgrounds work together, and almost no-one is a teacher, still they chose the name "teachers' tool." Later, after the metareflective round, they reconsidered and chose "educator's tool" ("pedagogverktyg") to include everyone. Since the Swedish expression (pedagogical tool) would give the wrong connotation in English, in this chapter we call it "educator's tool."

\section{Examples of results from WS2 implemented in the prototype}

The game Magical Garden was discussed a lot during WS2. The different levels/worlds/tracks (such as the "Bumblebee Humfrid," "The Bird Rescue," and "The Crane," as well as a set of additional games such as "The Birthday Party" and "The Labyrinth") were the main focus. The following are a few examples of results from WS2 that were implemented in the prototype:

- Notions from the national curriculum, such as "room" and "form" instead of "spatial perception"

- The possibility of making the game cooperative by means of the tool, so that children can play one or two levels/worlds/tracks together or show each other the plants that are growing in their Magical Garden 
- The importance of visibility of children's mathematics knowledge in, for example, diagrams to visualize if the child is practising subtraction in the number range of $0-4$

- The importance of a display of all 9 levels/worlds/tracks and an indicator of where the child is playing currently

- Aims with the different levels/worlds/tracks must be pronounced so that the educator will know that "The Bumblebee Humfrid" is mainly training position while "The Crane" is mainly training number sense.

\section{WS3-empirical example}

WS3 (November 14, 2019) can be placed in the LDS model's primary transformation unit, where the educators are in the transformative process.

\section{WS3 setting}

In the setting of WS3 the prototype and its modes and media were set as "homework" for educators to prepare beforehand. A set of questions was sent out beforehand:

1 Think through what kind of information about children's learning you would like the system to give you. Be concrete and specific. Be prepared to explain how you could know that about a child.

2 Consider situations when you would like to use the educator's tool to find out more information about one or more children's learning. Is it inside or outside a children's group, as part of another activity, or as a separate activity in itself? Be concrete and specific. Be prepared to explain what would be required of the system for it to work in that situation.

This was a new didactic design - the two earlier WSs had not asked for any preparation, meaning that the setting started at the WS, but in this case the setting was initiated prior to the WS, at home.

\section{WS3 primary transformation unit}

In the primary transformation unit a preliminary version of the developed educator's tool was displayed. The tool's affordances (Gibson, 1979, Kress, 2010, see also Chapter 3 by Lindstrand, this volume), such as links to in-depth text for the user to choose, were presented. For example, the automatic linear presentation of the game and the tool with images and narrators caught the educators' interests. Small group discussions were focused on what else could be solved by the game. A masters student presented her prototype of a "follow-up tool" as invented in WS2. The educators showed great interest in this aspect of the tool and came up with many suggestions for development. Below, in Excerpt 6.6, are examples of questions and discussions by the educators during the primary transformation unit: 


\section{Excerpt 6.6 A summary of questions and discussions in focus in the primary transformation unit.}

- How can I as an educator help a child with difficulties? Can you get a profile on how the child learns best? Advice on what instructions you can give the child, how best to help the child. Why do the kids get stuck when they get stuck? Suggestions on what to do physically to practice this. How can the child get over the threshold? Can you visually see what happened to the child over time during the semester?

- If you get notifications, you can get your eyes on what a child needs to practice. There should be a visual presentation of the child's development. Two versions: one for the educator and one for guardians/children. Something one can show at parental meetings.

- How can you make sure that educators don't just "tick off" math without getting involved, since the game is self-instructive?

At this point of the LDS the educators seem to be imagining using the tool in their teaching, with different suggestions on how it should, and should not, be used-as illustrated in Excerpt 6.6. During the WS they explore how it could be used to target specific children (and also how it can be used when in contact with guardians). The educators begin to be critical of their own creations and to discuss possible negative effects.

\section{WS3 secondary transformation unit}

Several themes were initiated in the secondary transformation unit. In WS3 part of the educator's tool was discussed where the educators could create and make their own mathematical content. This was not initiated in the two earlier WSs, nor followed up in the last two. Two more tracks were suggested here: one for the most advanced learners, and one for children who are less advanced learners. This was not discussed previously, nor was it followed up. In the educator's tool it could be possible to access this kind of information about a child since children's mathematical advancements are logged-yet, preschool is not about ranking children so there will be no such function. In the final large group discussion, the educators highlighted that the analogue and the digital must go hand in hand; they also suggested the use of a tab for physical mathematics. 
Some examples of results from WS3 implemented in the prototype are:

- visual representations of children's progress, learning, and struggles in early mathematics;

- links from a child's level in Magical Garden to the educator's tool where suitable physical mathematics games at the same level are presented;

- the opportunity for the educator to choose the path through Magical Garden and to all the different levels;

- the need for a more mature/professional address, such as font size \& type and layout, in the educator's tool than in the game.

\section{WS3 analysis of the primary and secondary transformation unit}

The discussion in the primary transformation unit was led by the masters student who had not been a central part of the WS series before. There is a chance that this challenged the institutional norms we had built up, because many new suggestions were raised, including inviting guardians to become familiar with the educator's tool to take part in monitoring the child's progress and learning (and possible difficulties) in mathematics. This is not aligned with the preschool mission and curriculum and so would never be designed into the tool. WS3 was the first WS where we intended to initiate the setting before the LDS, and the WS was thus preceded by the "homework" (as mentioned above). This kind of didactic design did not work well, since the educators did not find time to engage in it beforehand as intended, and accordingly this didactic design was not used again.

\section{WS4-empirical example}

All events in WS4 (2020-04-02; 2020-05-03; 2020-06-01; and 2020-06-03) can be placed in the LDS model's primary transformation unit where educators are in a formative process.

\section{WS4 setting}

In the fourth WS the most prominent resource was the educator's tool and, since this took place during the pandemic crisis, Zoom was used. The institutional norms were challenged again since we were used to meeting physically in a room, but now had to design the WS differently. The WS was planned to be in person, but was first cancelled, then postponed, and in the end held via Zoom. The WS was designed as a prototype testing session where the research group members played the game Magical Garden to create several different game logs at different levels. The educator's tool could thus be tested when the educators used the visualized logs to intervene in learning to support mathematical learning. Unfortunately, only one educator came to this WS via Zoom, so we added two more workshops 
held by the stakeholders (the two project members who are also working as preschool teachers) in their respective preschools with their colleagues. Many ethical discussions took place in the project group concerning the ethical correctness of inviting preschool teachers to digital workshops while they were in the middle of the pandemic crisis. After postponing the WS a few times, we sent out an invitation, but were keen to make clear that participants would not feel forced to join us: "The workshop is optional so just say yes if you feel you have time to spend a few hours on preparation the week before the workshop. We know that you are struggling with all the anxiety and extra work that these new times mean, so we do not want to burden you any further."

\section{WS4 primary transformation unit}

The WS outline, as presented at the beginning of the WS, was divided into five parts:

1 Three introduction videos were displayed.

2 The follow-up tool was set up for exploration.

3 The website was improved and set up for review.

4 A special tab on the website called "Preschool mathematics" and the heading "Why is preschool mathematics so important?" was made the basis for discussion.

5 Independent explorative work with the material was carried out.

Examples of questions asked by the educators about the educator's tool and the follow-up tool include:

\section{Excerpt 6.7 The educators' questions about the different parts of the educator's tool.}

\section{The educator's tool}

Is it easy to understand? Is something missing? Is something superfluous/unnecessary? Should it be presented in some other way? Should the language itself be changed? Is more help/support needed to download (and then print)? Can you think of a better heading than "Game in the Room"?

\section{The follow-up support}

Do you understand everything? How should we proceed? 
Excerpt 6.7 illustrates the WS leader's questions, prompting a metareflective discussion between the educators about the educator's tool. One part of the tool was the new "Follow-up support," which the educators seemed thrilled about.

\section{WS4 secondary transformation unit}

The educators at the preschools discussed three highlights from the educator's tool:

1 Instructional films: They liked the mode $\&$ media of a multimodal film and they appreciated the content as it is considered important to be aware of mathematics and to pronounce and highlight the mathematical terms.

2 The site: They liked the site with the suggestions on physical mathematical games in the extended digital interface (Kjällander, 2011) and the suggestions to bring Magical Garden out into the physical room, so called extensions (Gulz et al., 2020a), but did not see the difference between the two.

3 The follow-up tool: The tool was hard to use for intervening in children's learning, but the details in which the children's information could be visualized were appreciated.

The following are examples of findings from WS4 implemented in the prototype:

- There is a need for printable material.

- There must be better evaluated and grounded use of colours in the tool.

- There need not necessarily be a visible actor in the film clips.

- The connection between the different parts of the different tabs in the tool must be visualized.

- The widespread misconception that preschool mathematics is only a preparation for school must not be promoted.

- Examples of extensions from the digital into the physical should be illustrated.

- Connections between the follow-up tool and the suggested games must be more clear.

\section{WS4 analysis of the primary and secondary transformation unit}

The Covid-19 pandemic challenged the project, and the research group felt it was ethically questionable to invite educators to participate in the WS when they were struggling with absent colleagues and worries about personnel, children, and parents. Our stakeholders let us know that life in preschool went on just as normal, but we decided not to arrange a WS requiring physical attendance. We do not know whether the educators did not attend the WS4 because of the factors listed above, or whether it was just because they did not want to attend a WS via Zoom. We think it was probably the latter since they were positive about an alternative, a face-to-face WS with the stakeholders. 


\section{WS5-empirical example}

WS5 (2020-09-14) can be placed in the LDS model's secondary transformation unit where the representation is a focal point along with metareflective discussions and assessment.

\section{WS5 setting}

Once again, the institutional norms and curricular matters were changed, since the pandemic circumstance at this time meant that we could now meet, but keeping at all times a two-meter physical distance. The two stakeholders made sure there would only be a few participants in the room, with the rest on Zoom, and we had a large table where we could all keep a suitable distance apart. The learning resources were therefore Zoom, some computers and tablets, and a large TV screen on which the educator's tool was displayed. The aim of this last WS was thus two-fold: to conduct a last-minute-review of the tool, and to "give something back" to the WS participants-namely, to pre-release the tool to them.

\section{WS5 primary transformation unit}

This workshop was not as strictly designed as the others, since the educator's tool was almost complete, and would be presented and debugged for final alterations before the pilot study the week after. WS5 had three parts, of which two are in the first transformation unit: (1) the presentation of the almost finalized educator's tool, and (2) the time for participants to try the tool on their own iPads (i.e., group children, watch the videos, try the mathematics games). Some of the participants had viewed and tried out the educator's tool beforehand, but we presented it carefully to all at the beginning. They tried the educator's tool on their own iPads before engaging in a workshop with the following questions to structure their discussions:

\section{Excerpt 6.8 Questions asked by the researchers to intervene in the educators' discussion of the educator's tool.}

Is it easy and understandable to navigate the follow-up support?

Is there any information/data you would like to get more of in the follow-up support?

Is it clear enough if a child has problems and what the problems might be?

How would you use the information about an individual child, or for a group of children, to do activities outside the game? 
The discussions in this WS were clearly based on the educators' professions. The questions from the WS leader, as illustrated in Excerpt 6.8, afforded them the possibility to imagine using the tool with specific children in their preschool group.

During this WS's Body \& Mind activities, Brain Train (Neville et al., 2013) was finally incorporated into the educator's tool, after being introduced at the beginning of the WS series and discussed from time to time during the workshops. The package's position was discussed and the following was decided: There must be a clear idea on how, when, and how often the activities should be carried out. The connection between early mathematics and Body \& Mind must be clear.

\section{WS5 secondary transformation unit}

The third and final part of WS5 was: (3) the discussion, with participants in the room and via Zoom. As the tool was almost ready for piloting, the discussion was focused on headings, button design, chronological order, and symbols (which could all be updated before the pilot). Crucially, it was also necessary to pay attention to the children's many spoken languages, and to the children's different mental and physical functional variations, in the production of the tool. Examples of findings from WS5 implemented in the prototype are:

- Some diagrams had the wrong order of "history" buttons.

- The list needed to be reversed-with newer on top and older at the bottom.

- Change the name of the tab "Hints \& games" to a more professional heading, for example, use a title such as "teacher guide," "support," or "handbook."

\section{WS5 analysis of the primary and secondary transformation unit}

The importance of choosing the right notions to legitimate preschool educators' professionalism was prominent in this WS. This was invoked in earlier WSs, but the reason for this standpoint was not explained. WS5 presented an ethical dilemma and we questioned ourselves on what was worse: meeting physically but at a distance yet still risking infection; or failing to give back some competence, information, and/or in-service-training. We communicated with the operations manager, head teachers, educators, the university, and The Public Health Agency of Sweden (www.folkhalsomyndigheten. se/the-public-health-agency-of-sweden/). Based on their joint request we decided that, since we had already promised in the first information letters about the project that they would be the first to see results and products, we wanted to have the final WS as a physical meeting in a room, rather than a virtual WS. By the end of the primary transformation unit, the educators no longer described their participation in the workshop series as only "helping the researchers." Rather, they appreciated their participation as in-service training for their own professional learning, and their discussions and metareflections 
were highlighted as valuable representations for their own benefit as well as for that of the researchers.

\section{Concluding discussion}

This chapter has cast light on workshops as a multimodal research method (Kress, 2010; Selander, 2008; van Leeuwen, 2005)—an area that, according to Orngreen \& Levinsen (2017), is not so common in research within this theoretical field. It contributes to knowledge on how a workshop series with interdisciplinary researchers and educators with different educational backgrounds (i.e., caregivers, preschool teachers, and head teachers) can be used to design a digital, multimodal tool for education. Compared to earlier research it can be concluded that the DigiTaktik workshop series has many common features with many research workshops (Ørngreen \& Levinsen, 2017) in that we had arranged events with participants who work in the same field.

The WSs were conducted by researchers and experienced educators, and even if we expected an outcome in the form of a tool, this tool was indeed built on new insights, innovation, and suggestions by the participants. We designed for a small participant group where everyone could be active and could be heard, in order to promote genuine participation and social interaction, and to allow personal attention. We also continuously practiced the relevant techniques, skills, and situations while designing the tool. Individualization and feedback, highlighted as the most crucial in a WS, according to Ciampa (2016), went both ways in the WS series. I would argue that the DigiTaktik WS could be understood as a "Technology Professional Development Workshop," as expressed by Ciampa (2016). The workshop series represents a longitudinal workshop series of over almost two years. Orngreen and Levinsen (2017) stated that no studies in their literature review discussed how workshops could be used as a method for enlightening a domain over long periods of time.

This chapter has presented an account of how the model LDS was used as a design and analysis resource with the aim of developing a functional educator's tool to help preschool educators to intervene in children's learning. During the first WS, the institutional norms of the setting in the LDS were appreciated by the teachers as though the aim was to help and support research. During the WS series, this was transformed and they began to form a new aim-to acknowledge their own signs of learning during the period of time. By the time of the final WS, it was obvious that they appreciated the WS series as in-service-training for themselves. In the first workshop educators were already aware of new knowledge, and their utterances often vividly illustrated that they developed their professional learning by means of signs of learning in the interaction with the researchers - and vice versa.

It is complex to ask didactic questions in an environment of distributed resources where the textbook is no longer in use, but there are instead a vast 
number of digital resources (Selander, 2017). Selander highlights the relations between the goal, curriculum, resources, and the teacher/student, when a concrete artefact such as an educator's tool is being formed in social interaction. The importance of a having common language in the workshop series was highlighted. The common language developed in social interaction, using the same words in the educator's tool as in the preschool curriculum in order to support and dignify the use of the tool. Even if educators began using theoretical notions, the largest language transformation was made by the researchers who realized how much the educators knew and valued their curricular texts and concepts.

During the two years, educators asked for (and then sometimes dismissed) the possibility of having summative assessment with notifications to their emails, and the possibility of displaying an individual child's mathematical processes to both children and guardians. This kind of summative assessment of individual children was not supported by the preschool national curriculum and was therefore not built into the tool. Both researchers and educators experienced a transformed and formed representation of knowledge. For the research team, Signs of learning were that the educators, even if they really wanted to, did not have time to read or prepare between the workshops.

It was obvious that the educators kept the project in mind in between the WSs and had discussed their thoughts since they presented elaborated reasoning that made connections between the different WSs. We learned that they were extremely effective, engaged, and productive during the three hour WSs, and came to appreciate every single moment together. Also, it turned out to be very fruitful to "give back" to the participant during each WS, with food and engaging informative discussions and, on some occasions, a bit more with lectures, free books, and invitations to exciting events. We created good relationships that hopefully will last, and we know the participants valued this since they participated over and over again (except during the pandemic), regardless of the immense workload they were experiencing in preschool.

The researchers had limited experience about this kind of formative assessment and participated reluctantly, but the educators were eager to have children's design in learning visualized and displayed. In preschool, educators have limited time for planning. Researchers are well aware of this, and designed the tool accordingly, with short films and text, for example, implemented in every tab of the educator's tool. All films, texts, and other instructions or information are brief, with a maximum of five minutes to watch a video, learn a game, or prepare for an exercise. Everything is illustrative and multimodal with images, moving images, sounds, voice, symbols, colours, and diagrams, with the aim that even a quick glance should make sense to the educator. We hold that the LDS model could be used to plan, design, and implement workshops as a research method, and we believe that the tool that we designed and built together can be used in preschool. 


\section{Final remarks on the methodology}

The design and the implementation and the analysis of a workshop series as a research methodology making use of the Learning Design Sequence worked out well. The different transformation units and their notions helped us to analyze one WS, transform and update the tool, and prepare for the next WS. Initially, during the research application process, we were more focused on designing, what Ørngreen and Levinsen (2017) would call "Workshops as research methodology" to inform our own design of the educator's tool. During the process our pre-understanding was transformed and we became increasingly involved with the WS participants, with the result that the design of the WS series transformed more into the category of "Workshops as a means," as we actually built the tool and learned together. The didactic design during the WS series transformed depending on the transformation unit of the whole two-year LDS in which the specific WS was situated. In the first workshops we designed an open environment with social interaction and brainstorming where everything was possible - it did not have to be realistic at that point. In the following WS the didactic design implied representation and production, therefore many creative but unrealistic suggestions were assessed and dismissed. Instead, the educators strove to build the tool with a professional language that was common and familiar, and closely connected to the curriculum; a tool that can be trusted by the educators when learning is distributed (Selander, 2017). I would like to finish with a quote from Ørngreen and Levinsen (2017):

The workshop co-constructs a place for collaborative negotiation of meaningnot only between participants, but also between facilitators (the researchers) and participants, who both during and after the workshop adopt and adapt to what is being discussed, performed, and learned. Through this, workshops bring us close to practice without being in practice.

\section{Acknowledgements}

I would like to thank all educators who have participated in the workshop series, Magnus Haake who designed the workshop series, and the Swedish Institute of Educational Research for funding this research. I also want to thank Frankenberg, Gulz, Haake, Pakulak, Yildirimdemir, Ring, Hagås and Koniakowski.

\section{Notes}

1 Developed by Educational Technology Group, Lund University.

2 Cognitive Science, Lund University

3 Didactic Science and Developmental Psychology, Stockholm University 
4 For a more conclusive presentation of modality and coding orientation, see Kress and van Leeuwen (2006).

\section{References}

Biswas, G., Katzlberger, T., Bransford, J., Schwartz, D. L., \& TAG-V. (2001). Extending intelligent learning environments with teachable agents to enhance learning. In J. D. Moore, C. L. Redfield, \& W. L. Johnson (Eds.), Artificial intelligence in education (pp. 389397). IOS Press.

Calkins, L., \& Tolan, K. (2010). A guide to the reading workshop. FirstHand \& Heinemann.

Ciampa, K. (2016). Implementing a digital reading and writing workshop model for content literacy instruction in an urban elementary $(\mathrm{K}-8)$ school. The Reading Teacher, 70(3), 295-306.

Gibson, J. J. (1979). The ecological approach to visual perception. Houghton Mifflin.

Gulz, A., Kjällander, S., Frankenberg, S., \& Haake, M. (2020a). Early math in a preschool context: Spontaneous extension of the digital into the physical. IxDEA: Interaction Design $\mathcal{E}$ Architecture, (44), 129-154.

Gulz, A., Londos, L., \& Haake, M. (2020b). Preschoolers' understanding of a teachable agentbased game in early mathematics as reflected in their gaze behaviors-an experimental study. International Journal of Artificial Intelligence in Education, 30(1), 38-73.

Husain, L., Gulz, A., \& Haake, M. (2015). Supporting early math-rationales and requirements for high quality software. Journal of Computers in Mathematics and Science Teaching, 34(4), 409-429.

Kjällander, S. (2011). Designs for learning in an extended digital environment. Case studies of social interaction in the social science classroom. Diss.

Kjällander, S. (2019). Övergripande aspekter av digitalisering i förskolan. In S. Kjällander, \& B. Riddersporre (Eds.), Digitalisering i en förskola på vetenskaplig grund (pp. 21-40). Natur \& Kultur.

Kress, G. (2010). Multimodality: A social semiotic approach to contemporary communication. Routledge.

Kress, G., Jewitt, C., Ogborn, J., \& Tsatsarelis, C. (2001). Multimodal teaching and learning the rhetorics of the science classroom. Continuum.

Kress, G., \& van Leeuwen, T. (2001). Multimodal discourse: The modes and media of contemporary communication. Arnold.

Moreno-Ger, P., Burgos, D., Martínez-Ortiz, I., Sierra, J. L., \& Fernándes-Manjón, B. (2008). Educational game design for online education. Computers in Human Behaviour, 24(6), 2530-2540.

National Agency for Education. (2018). Curriculum for the preschool, Lpfö 18. Skolverket. www. skolverket.se/publikationsserier/styrdokument/2019/curriculum-for-the-preschoollpfo-18

Neville, H., Stevens, C., Pakulak, E., Bell, T. A., Fanning, J., Klein, S., \& Isbell, E. (2013). Family-based training program improves brain function, cognition and behavior in lower socioeconomic status preschoolers. In PNAS. Early Edition.

Newfield, D. (2014). Transformation, transduction and the transmodal moment. In C. E. Jewitt (Ed.), The Routledge handbook of multimodal analysis (pp. 100-113). Routledge.

Ørngreen, R., \& Levinsen, K. (2017). Workshops as a research methodology. Electronic Journal of E-Learning, 15(1), 70-81. 
The Public Health Agency of Sweden. www.folkhalsomyndigheten.se/the-public-healthagency-of-sweden/

Selander, S. (2008). Designs for learning: A theoretical perspective. Designs for Learning, 1(1), 4-22.

Selander, S. (2009). Didaktisk Design [Didactic design]. In S. Selander \& E. Svärdemo-Åber (Eds.), Didaktisk design i digital miljö—nya möjligheter för lärande [Didactic design in digital environments: New opportunities for learning]. Liber.

Selander, S. (2017). Didaktiken efter Vygotskij-design för lärande [Post-Vygotskian education: Designs for learning]. Liber.

Selander, S., \& Kress, G. (2017). Design för lärande-ett multimodalt perspektiv [Designs for learning: A multimodal perspective] (2nd ed.). Studentlitteratur.

van Leeuwen, T. (2005). Introducing social semiotics. Routledge. 


\title{
Sites for learning and knowledge representations- the Middle Ages
}

\author{
Eva Insulander, Fredrik Lindstrand \\ and Staffan Selander
}

\section{The Middle Ages in our (European) society}

The term "Middle Ages" was defined during the Renaissance. It was seen as the time between the glorious, classical antique societies and the (then) glorious and new, modern era. In Europe, this period is often delimited as the period between the fall of the Western Roman Empire, 476 AD, until the end of the 15 th century (with the discovery of America in 1492). However, in Sweden the Middle Ages came later, from the 11th century when the Viking Age ended and Scandinavia was Christianized. It ended at the beginning of the 16th century (when Gustav Vasa, who led the unification of Sweden, was crowned king in 1523).

During the medieval period (until Copernicus' work on a heliocentric universe was published in 1543), the Earth was seen as the centre of the universe. The idea of harmony dominated; heaven and earth, like body and soul, good and evil spirits, as well as visible and invisible phenomena, should be in harmony and balance. It was an ongoing dualistic fight between the good forces (God and the angels) and the bad ones (the Devil and the demons). Also, the idea of a hierarchical order was central-God was responsible for the world, and the (household) father for the family, and everyone had his or her "natural" place in society. Religion could explain everything in this world, from the development of the planet Earth to angels and devils. A sophisticated system was created for the hierarchy of angels (with three main categories, each of them with three subcategories).

Obviously, we cannot look back at this time as though seeing it from a "time helicopter." Many other things and ideas which did not exist at that time influence our thinking today. This is also the case with ideas of meritocracy and social travels, the idea that we are not masters in our own house (the psyche, Freud), the idea of economic and class imbalance (Marx), the idea of a (historically seen) very old Earth which was not created during six days, or the idea of a late-modern "liquid" society compared to earlier, more stable and hierarchical societies (Bauman, 2012). Today, we also use network models rather than hierarchical models to illustrate how things (or ideas) are connected 
to each other (Lima, 2011). What we see of the Middle Ages today is a rather clean, polished, and romantic picture - a period of time to escape to or to play around with.

\section{The ubiquity of the Middle Ages in our late-modern society}

The Middle Ages is used as a frame, a background, or a theme in many modern and late-modern stories and fantasies. We can see this time period represented in books, toys, and games, in popular science, in music, and in films, festivals and re-enactments, and, for example, in museums and monasteries. In these representations, we can notice different "emblematic" or epistemic organizing principles-for example, the Stockholm Medieval Museum (in Swedish: Medeltidsmuseet i Stockholm) has the "town" in focus, whilst the Museum of National Antiquities (in. Swedish: Historiska museet i Stockholm) focuses on religion. Likewise, when it concerns toys or films or digital games, we often find the knight and the castle as emblematic, and handicrafts and tournaments as emblematic in contemporary "medieval" festivals, for example. Of course, beside these emblematic representations, we also find different sub-themes of other aspects of life, war, or production during the Middle Ages.

All in all, the Middle Ages is represented in many different ways. Taken together, these knowledge representations offer a variety of aspects of what the Middle Ages "is" about. When children come to school, they already have ideas about the Middle Ages. As a consequence, we can ask how learning outside schools differs from learning in schools, as well as what is seen and recognized as knowledge and signs of learning about the Middle Ages in these different contexts.

As we will show in the following, different formal, semi-formal, and nonformal framings support different kinds of learning resources: for example, toys and games, school textbooks, and digital supportive resources, films, and TV programs, as well as visits to historical places and the making of artefacts. The use of resources is framed by such things as tradition, habit, and knowledge, as well as by timeframes, technological equipment, and standardized procedures to measure knowledge and learning. It seems that in our contemporary hybrid society, there is a growing interest in using, for example, digital artefacts and maker-spaces in the school context, which also will affect ideas about what could be seen as the central knowledge areas within a particular school subject (also see Insulander et al., 2016, 2019; Lindstrand et al., 2016a, 2016b).

\section{Gaming the Middle Ages-examples of designs for learning in non-formal settings}

With an estimated 2.7 billion gamers across the world in 2020 (Gough, 2020) and an incessantly multiplying number of streamed gaming sequences, vlog 
episodes, comments, and online discussions related to games, video games are an important part of contemporary (media) culture. Since gaming is an activity that for most people is related to free time, away from work or school, and since most of the games people choose to engage in have been designed primarily for purposes other than learning, we will approach them in this chapter as examples of how we think about learning and designs for learning in non-formal settings (see Selander, this volume; see also Selander, 2008, 2015, 2017). Our starting point here assumes that learning takes place in all parts of life and that signs of learning (or at least signs of knowing) - in the form of multimodal knowledge representations - are produced in all kinds of activities. In the case of video games such knowledge representations are produced by producers of games, who have made numerous choices and selections in their designs of the narrative frame, the game world, game play, and so on; and also by gamers through their ways of approaching various aspects of the games. Since we use representations of the Middle Ages as our thematic frame in this chapter, this section will focus on video games and gaming related to this specific historical period. We will begin by presenting a selection of video games that somehow represent a Medieval world, and we will then elaborate on issues regarding learning in relation to playing one of these games.

Similar to texts in other media (films, books, TV series, podcasts, and so on), there is a big variation in terms of how different games relate to a common theme, such as the Middle Ages in this case. They could, for example, be said to vary in terms of modality - the degree of truth claim they makeand what coding orientation (e.g., "realism" or "fantasy") ${ }^{1}$ they activate, as there is a range between more fact-based representations of historical events and contexts on the one hand, and more fantasy-based representations that host mythical creatures and magical phenomena on the other. We will here touch upon a few genres and themes among these games, with emphasis on which aspects of the idea of the Middle Ages they incorporate. A common feature, despite their individual differences, is that most of the games we mention share a focus on war, battle, and/or other forms of power struggle. Common to them all, in other words, is an idea of the Middle Ages as a site for violence and struggle.

Some examples of games that claim to be historically correct are Assassin's Creed (Ubisoft, 2007), with the sequels Assassin's Creed: Altaïrs Chronicles (Ubisoft, 2008) and Assassin's Creed: Bloodlines (Ubisoft, 2009a). The stories in these games are set in present day USA and during the third crusade in Jerusalem in 1191. The producers claim that the digital representation of Jerusalem, some of the events that take place in the game, and some of the characters, were carefully crafted in accordance with historical documents. The game is categorized within the genres "sneak 'em up," or "stealth," where the world within the game is viewed from the player's character's perspective. A difference from so-called "first-person-shooter-games" is that the emphasis in this type of game is not to confront other players in combat, but to move quietly, save 
ammunition, and avoid conflicts. Nevertheless, violence and power struggle are still central features since the player's mission -in the role of an assassin-is to hinder the Temple Knights in their ambition to take control of the world.

Another game that emphasizes the Middle Ages as an arena for war and battle is Chivalry: Medieval Warfare (Torn Banner Studios, 2012)—a multiplayergame in the so-called "hack and slash" genre. The focus here is to control one's character in battles against other players and handle different kinds of weapons in order to defeat the other players.

However, not all games set in medieval environments are as obviously oriented towards fighting and action, even though battle remains a central theme. Several games within this field are categorized as "strategy games," where the aim is to expand one's province or realm by gradually building up the prerequisites for winning power battles of various kinds. An example of this is the provincial development game Crusader Kings II (Paradox Interactive, 2012), where the player needs to develop conditions for maintaining troops in order to expand her or his realm. Apart from political aspects, religion and family relations also play a role in the diplomatic negotiations that take place. Other games, such as Medieval II: Total War (Sega, 2006), combine strategic elements with more direct battles where the players control their troops in encounters with other players' armies.

An example of games that offer other possible ways of expanding one's power is Anno 1404 (Ubisoft, 2009b). The aim of this strategy game is to build an economic empire, which is pursued through initial foundation and development of cities "at home" and subsequently through the colonization of countries abroad.

Finally, a strategy game that is quite different from the others mentioned here is Banished (Shining Rock Software, 2014), which does not contain any battles at all. The mission here is instead to build a village from start and to develop the prerequisites for handling difficult circumstances such as starvation and deadly diseases.

All of these games use medieval worlds as context for the narrative and as visual themes in the design of what Bogost (2007) refers to as the "skin" of the game (i.e., the world within the game as it is presented to the player by means of different modes). If we regard them as possible resources for learning, it would be interesting to look more closely at how the Middle Ages is represented more specifically. What aspects are made salient thematically and visually/multimodally? What characters are introduced as inhabitants of this world and what are their roles within the game?

It is also of interest to reflect on how the player is positioned in relation to these represented worlds. In terms of perspective, we could ask whether the player encounters events and gains information through the limited visual and audial scope of a specific character, or whether the world is presented from above with an overview and instant information about different occurrences happening simultaneously in different regions. Is the role of the player to act 
and react to events presented instantaneously, or to plan ahead and use the resources at hand to control future developments? These two stances invite two different forms of information, experiences, and processes, and are related to what Bogost (2007) refers to as the "procedural rhetoric" of the game.

\section{Learning about the Middle Ages}

Similar to other forms of engagement in a knowledge domain, such as creative processes of various kinds, we argue that, as a result of the player's choices, ways of approaching tasks and situations, handling of the controls, and so on, aspects of what happens on the screen while playing a video game can be understood as performative expressions of knowing.

To a large extent this knowledge is of course largely related to media-specific capabilities like handling the controls, using available information in different ways within the game, and following (and predicting) the development and dramaturgy of the underlying story as the game proceeds.

Besides these, there are also other aspects of performative expressions of knowing that are more closely connected with specific circumstances within the frames of a game. These can still be argued to be connected to aspects regarding gameplay, but they can also be seen as related to the themes and subject content that the narrative activates.

In Assassin's Creed (Ubisoft, 2007), which is claimed to have been thoroughly designed in accordance with historical documents, the protagonist moves through the city of Jerusalem in the year 1191. The mission is to gather information in order to retrieve certain valuable objects and to kill a number of central characters in order to stop the Temple Knights from gaining the power to rule the world.

With regard to performative expressions of knowing, an interesting aspect is that this game can be described as being interactive. Different scenes in the game change depending on how the player acts. Altair can, for example, move through crowds without attracting the attention of the villagers if the player allows him to move carefully, but he attracts attention and hostile guards if acting violently. In a similar way it can be risky to arouse the villagers' attention by moving in ways that do not correspond to the social and cultural norms of the medieval cities, for example, by climbing walls when others can see. This aspect of the game implies that the gamer can control the gaming experience and thereby also influence the representational aspects of the Middle Ages presented in the game. A greater degree of familiarity with the cultural and social aspects of the contexts presented in the game can imply that the gamer will face fewer problems along the way and vice versa. In that sense the game's staging of environments and events can be seen as indications that the gamer shows signs of knowing. Interesting in relation to this aspect is that this knowledge is largely corporal, as it has to do with how to move one's body properly in a certain historical, social, and cultural context. This embodied side of the game 
also affords the possibility of exploring the city, and thus inviting perspectives of the city that are unique to each player. Of relevance to learning, and in addition to the performative aspects of playing, the choices brought about through these interactive and embodied functions of the game increase the players' agency.

At a different level, related to our digital time, many gamers chose to stream (i.e., broadcast) their playing live via sites like twitch.tv and/or record their playing for later publication on YouTube. In these situations, the gaming is made public on social media where others can comment, share tricks and hints, ask questions, and so on. These conversations can work as resources for learning, and what is posted can be viewed as expressions of knowing that are related to the subject of history generally and the Middle Ages and medieval local culture specifically. While being non-formal communities, with no shared curricula, it would probably be possible to discern elements that would indicate a certain culture of recognition in terms of who comments, what the comments regard, how the player is positioned through the comments, the tone in discussions, and so on.

\section{The Middle Ages in museums-examples of designs for learning in a semi-formal setting}

Our second example takes place within the semi-formal setting of the museum. Museums differ in some respects from the non-formal setting at home. The definition of the site as being semi-formal focuses our attention on the affordances (see Lindstrand, this volume) and the conditions for learning, while at the same time attending to the role of the visitors. Using the semi-formal model of Learning Design Sequences, we discuss how framing influences the choice of resources, the design of knowledge representations, and affordances for meaning-making.

In a museum exhibition, knowledge is often framed differently when compared to a school textbook (Insulander et al., 2017). In this case, different aspects of the Middle Ages will be emphasized, and different understandings of meaning-making and learning are taken for granted. In comparison with the school (see our third example below), a museum may be described as a place for free-choice learning. Visitors may engage with aspects of the exhibition that they find the most interesting, in an order they decide for themselves, and without the requirement to be assessed afterwards. However, an exhibition has also been deliberately designed. It is the result of choices and arrangements that correspond to the producer's understanding of the particular knowledge area and theme to be displayed. Selections have been made with a particular audience in mind, arranged and adjusted to the conditions of learning. An exhibition has its own organizing principles, which function something like a curriculum.

The semi-formal Learning Design Sequence (see p. 3, this publication) guides our view when we examine the museum space as a design for learning. 
The design for learning entails an orchestration of modes and media into knowledge representations. The selection of objects and the design of labels and text panels as well as images are examples of learning resources which have been coordinated and arranged by a producer into an exhibition. The purpose may be to disseminate information about a specific era and at the same time arouse visitors' interest. The institutional norms in a museum often include walking slowly and talking quietly. Usually, you cannot touch museum objects, but study or admire them inside a showcase or from a distance.

Designs for learning focus on design, with regards to both the organization of the setting and the process where learners make choices and selections-how they frame the exhibition, and thereby create their own understanding of the content presented. If we then look at the primary transformation unit-design in learning-we observe how visitors engage in an exhibition as they walk through the galleries, transforming and forming signs. The second transformation unit may involve talking about their experience with peers, sharing it with others on social media-or if it's part of a research study-reflecting on their visit to a researcher in an interview.

An example of a museum that produces theme exhibitions with a medieval emphasis is the Stockholm Medieval Museum. It was built in 1986 around the ancient monuments that were unearthed during the excavations of the island Helgeandsholmen in 1878-80. The city wall from the 1530 s, a cemetery that belonged to Helgeandshuset, and a secret corridor that ran from the castle to the courthouse are today incorporated in the exhibition space. The museum has a permanent basic exhibition that depicts different parts of medieval Stockholm with a building cabin, a church and monastery, a gallows hill, a square, and so on. Wax dolls and reconstructions as well as different kinds of scenarios are mixed with authentic artefacts in environments that help visitors to feel that they are getting closer to the Middle Ages. The exhibition covers social, cultural, and economic history, and focuses on authenticity and on how historical knowledge is gained. Guided tours are offered by museum educators. The orchestration of modes and resources is used to highlight what is seen as the core element of this particular semiotic context: life in a medieval town, and at the same time, authenticity and reflection on historical knowledge.

A different example is the Kalmar County Museum. The museum arranges "time travels" for children and students who can participate in life in the city, in the castle, or on a farm. There they meet, for example, monks and nuns, get to try out handicrafts, and participate in a medieval feast. Another example of a museum that offers activities related to the Middle Ages is the Sancta Birgitta Monastery Museum in Vadstena, which was originally built in the 13th century as a royal palace, and was fortified in the 14 th century. The museum offers guided tours and dramatized hikes. Visitors can try on clothes in the dressing room, and book a children's party with a treasure hunt where they will look for clues: "The Queen's jewel box." For adults, there is a medieval detective story in the form of "In the Name of the Rose" (after Umberto Eco's novel of the same name). Compared to the Stockholm Medieval Museum, the 
orchestration of resources in these two cases is used to create interest and to invite visitors to participate in storytelling.

Another monastery museum is located in Gudhem in Västergötland, between Lake Vänern and Lake Vättern. During the Middle Ages, Gudhem's monastery was an important spiritual, political, and cultural centre. The monastery was damaged by fire and abandoned in 1529, and in 1928 excavations of the monastery ruins began. Today, the museum offers lectures and you can visit the monastery garden or learn to paint icons, for example. Pilgrimages to and from Gudhem are also arranged. In the Stone Hall, which opened in 2008, visitors can see finds from excavations of Gudhem's monastery and scenery from the films about Arn Magnusson, based on Jan Guillou's novels (Guillou, 1998, 1999, 2000). These books are about a fictional crusader whose beloved Cecilia was at Gudhem for 20 years. While presenting facts about the monastery and the role of religion in the medieval society, the orchestration of resources also acknowledges "medievalism" in popular culture. These museums thus support different kinds of learning resources, and in Gudhem we may also notice performative expressions of visitors' knowing, for instance in the museums' guestbook on their website, where visitors have posted images and written messages in Latin. If we compare the museum with the school, what activities, resources, and content are recognized as important?

\section{The Middle Ages in schools-examples of designs for learning in a formal setting}

Our third example places emphasis on history in a school context where we use the concepts of agency and cultures of recognition to discuss how the Middle Ages is represented. History as a school subject is framed differently from history in a museum. The syllabus strongly determines what should be selected, presented, and taught in each classroom. Even though teachers have a certain degree of agency in terms of what to focus on, they are obliged to follow the curriculum. The Swedish education system is decentralized, but the government sets standardized goals and objectives for Swedish localities to follow. According to the Swedish curriculum for the compulsory school, each subject has an aim and core content which is decisive for classroom work. Assessment also creates conditions for what is to be taught and learned. The knowledge requirements demonstrate what knowledge and skills pupils should develop. So, compared to the museum where visitors can attend to what they find interesting, interest in a school context might be more connected with a wish to succeed with the task, to get good grades, or to do what is expected. Thus, cultures of recognition are different in the two institutions.

History as a school subject often requires several linguistic abilities from pupils. These include the ability to critically read and examine different types of sources and texts, to make value judgements, and to compare facts. Thus, textbooks have long been considered of great importance in history education. 
Textbooks can be seen as the link between the governing documents and the teachers' teaching, and at the same time as an interface between the curricula and students' learning in school. We will now look at the design and meaning potential of a school textbook as a learning resource. For teachers, as didactic designers, it is essential to be aware of how textbooks represent knowledge in terms of content and modal configuration. Here we will take a closer look at the Book of History 1 (Andersson \& Ivansson, 2012). Of the book's 160 pages, just over 50 pages are about "The Middle Ages in Sweden" and "The Middle Ages outside Sweden." It is mentioned that the Middle Ages in Sweden lasted from 1050 to 1520. Various aspects of the Middle Ages are addressed, such as politics, religion, social aspects, and nutrition, as well as fairy tales and legends. "The Middle Ages outside Sweden" deals with the Hanseatic era, how barter developed, coins and banknotes, crusades, cathedral buildings, and Jeanne d'Arc. In this way, the Middle Ages become strikingly "Swedish" in the textbook, although the Hanseatic influence was significant and that, in principle, it was the German language that dominated in Stockholm. We can compare the book's emphasis on the Middle Ages in Sweden with the central content of the syllabus that instead strongly emphasizes the Nordic region and the rest of Europe. The knowledge requirements emphasize cultural encounters, which could justify a clearer focus on this also in the textbook that would help to clarify the purpose and central content of the governing documents. The orchestration of modes is used here to establish norms for the kind of knowledge accepted as such in the school context.

Pupils also need to be able to represent their knowing about the Middle Ages in some kind of narrative. In school, students can represent their understanding in several ways - as talk during the lessons and in how they work with tasks of various kinds. Students may transform the information and work with different resources to write a story, with a course of events and several personal descriptions. Other tasks may involve the production of multimodal texts that in their layout combine several modes: font, image, and colour. The different tasks will have consequences for assessment, where the teacher can recognize students' selection according to their interest and how pupils compose different units of the text. In the school context, it is seen as essential that the pupil knows how to use some subject-specific concepts in a relevant context. With both tasks, the student is given the opportunity to express interest and choice, but what differs are the resources they are permitted to use.

\section{Concluding remarks}

We can see that the Middle Ages_as a knowledge domain-is delimited in different ways in different contexts. It can also be noted that certain themes are unmentioned in all three contexts, like the roles of women and children, or, for example, more profound discussions about the medieval understanding of the world, based on religion as it was then. 
In this chapter, we have focused on areas like the non-formal digital game, the semi-formal museum visit, and the formal school setting. These different sites of learning have somewhat different logics concerning knowledge focus, the use of material and semiotic resources, as well as what is valued as knowledge. Let us in Table 7.1 show some of the main differences between institutional framings, material resources, agency, and learning in these three contexts: playing a game, visiting a museum, or learning in a school context.

From our analysis, it seems clear that not only the knowledge focus but also views of what learning is about differ between the three (formal, semiformal, and non-formal) contexts: They highlight different knowledge foci and different (material and semiotic) resources, they give space for different kinds of agency, and they use different assessment standards. Consequently, these have an impact on how individuals or groups (more or less consciously) design their own action spaces and learning paths in different sites for learning.

There is much to learn about the Middle Ages, but there are also many ways to frame this historical period. In other words, each of the sites focuses on specific aspects for engagement and learning. Those aspects that actually count as learning in the school context depend first and foremost on the curriculum, the existing school traditions, and tools for assessment. This emphasis might lead to certain kinds of relevant knowledge "not being seen" in the school context,

Table 7.I Learning in non-formal, semi-formal, and formal learning sites.

\begin{tabular}{|c|c|c|c|}
\hline & $\begin{array}{l}\text { Learning in non-for- } \\
\text { mal settings-gaming }\end{array}$ & $\begin{array}{l}\text { Learning in semi-formal } \\
\text { settings - museums }\end{array}$ & $\begin{array}{l}\text { Learning formal } \\
\text { settings - in schools }\end{array}$ \\
\hline $\begin{array}{l}\text { Information } \\
\text { structure }\end{array}$ & $\begin{array}{l}\text { Architecture of the } \\
\text { game }\end{array}$ & $\begin{array}{l}\text { Architecture of the } \\
\text { exhibition }\end{array}$ & Curriculum \\
\hline $\begin{array}{l}\text { Background } \\
\text { for activity }\end{array}$ & $\begin{array}{l}\text { Goals and possible } \\
\text { actions in the } \\
\text { game }\end{array}$ & $\begin{array}{l}\text { Artefacts (real objects) } \\
\text { and possible actions } \\
\text { in the exhibition } \\
\text { room }\end{array}$ & $\begin{array}{l}\text { The teacher's planning } \\
\text { and the assessment; } \\
\text { possible actions in } \\
\text { the classroom }\end{array}$ \\
\hline Activity & $\begin{array}{l}\text { The play steers the } \\
\text { possibilities }\end{array}$ & $\begin{array}{l}\text { Follow the } \\
\text { presentation line }\end{array}$ & Follow the teacher's line \\
\hline Feedback & Instant feedback & No feedback & Postponed feedback \\
\hline $\begin{array}{l}\text { Sites of } \\
\text { assessments }\end{array}$ & The gaming & $\begin{array}{l}\text { No testing (sometimes } \\
\text { a general evaluation/ } \\
\text { questionnaire) }\end{array}$ & The formal assessment \\
\hline $\begin{array}{l}\text { Assessment } \\
\text { rationale }\end{array}$ & $\begin{array}{l}\text { Competence to } \\
\text { use adequate } \\
\text { knowledge } \\
\text { (and semiotic } \\
\text { resources) in the } \\
\text { game context; fun }\end{array}$ & Experience; have fun & $\begin{array}{l}\text { Abstract, formal goals; } \\
\text { competence in } \\
\text { using the school- } \\
\text { relevant (material and } \\
\text { semiotic) resources }\end{array}$ \\
\hline
\end{tabular}


which compels new questions about possible future learning sites, school contexts, and assessment standards. It might also be possible that we see more collaborative work between schools, museums, game makers, and other interested parties. In our hybrid society, the old brick walls that delimited schoolwork from outside society are no longer absolute borders. Already, we can notice a new engagement from different professionals to take part in schoolwork and developmental projects, we can see a new role for maker-spaces and studios in schoolwork, and so on. All this might also change our understanding of what characterizes non-formal, semi-formal, and formal learning sites.

Our focus on different knowledge representations could also be seen as an attempt to focus on content aspects in a new way, including the role of material and semiotic resources. In a world of multimodal and digitally distributed learning resources, the school textbook is no longer "the heart of serious learning." We learn in new and interactive ways, not only by reading printed texts. Consequently, individuals can use digitally distributed and open channels to demonstrate their learning and their new knowledge.

Finally, it is our hope that this chapter could also function as a model for the analysis of knowledge representations and learning in other knowledge areas and school subjects. As we see it, learning is first and foremost not an act of reproduction, but of meaning-making and re-design. The design perspective can be used not only for the analysis of how things are framed and what takes place, but also for expanding the thinking on how things could be different.

\section{References}

Andersson, S., \& Ivansson, E. (2012). Boken om historia 1. Vikingatiden, Medeltiden, Sverige för 100 år sedan [The book of History 1]. Liber.

Bauman, Z. (2012). Liquid modernity. Polity Press.

Bogost, I. (2007). Persuasive games: The expressive power of videogames. The MIT Press.

Gough, C. (2020). Numbers of video gamers worldwide 2020, by region. statista.com/statistics/ 293304/number-video-gamers/. Retrieved 2020-08-12.

Guillou, J. (1998). Vigen till Jerusalem [The road to Jerusalem]. Norstedts.

Guillou, J., (1999). Tempelriddaren [The Knights Templar]. Norstedts.

Guillou, J. (2000). Riket vid vägens slut [The land at the end of the road]. Norstedts.

Insulander, E., Lindstrand, F., \& Selander, S. (2016). Designing the Middle Ages: Knowledge emphasis and designs for learning in the history classroom. Historical Encounters: A Journal of Historical Consciousness, Historical Cultures, and History Education, 3(1), 31-42.

Insulander, E., Lindstrand, F., \& Selander, S. (2017). The design of knowledge representations in different multimodal texts about the Middle Ages. Journal of Educational Media, Memory and Society, 9(2), 1-14.

Insulander, E., Lindstrand, F., \& Selander, S. (2019). Design för lärande-Historia. Medeltiden som exempel [Designs for learning: History: The Middle Ages as an example]. Liber.

Kress, G., \& van Leeuwen, T. (2006). Reading images: The grammar of visual design (2nd ed.). Routledge.

Lima, M. (2011). Visual complexity: Mapping patterns of information. Princeton Architectural Press. 
Lindstrand, F., Insulander, E., \& Selander, S. (2016a). Multimodal representations of gender in young children's popular culture. Mediekultur, 61, 16-25.

Lindstrand, F., Insulander, E., \& Selander, S. (2016b). Mike the knight in the neo-liberal era: A multimodal approach to children's multi-media entertainment. Journal of Language and Politics, 15(3), 337-351.

Selander, S. (2008). Designs for learning and the formation and transformation of knowledge in an era of globalization. Studies in Philosophy and Education, Springer, 27(4), 267-281.

Selander, S. (2015). Conceptualization of multimodal and distributed designs for learning. In B. Gros, Kinshuk, \& M. Maina (Eds.), The futures of ubiquitous learning: Learning designs for emerging pedagogies (pp. 97-113). Springer.

Selander, S. (2017). Didaktiken efter Vygotskij-Design för lärande [Post-Vygotskian education: Designs for learning]. Liber.

\section{Games and web-sites}

Paradox Interactive. (2012). "Crusader Kings II". Video game.

Sega. (2006). "Medieval II: Total War”. Video game.

Shining Rock Software. (2014). "Banished". Video game.

Torn Banner Studios. (2012). "Chivalry: Medieval Warfare”. Video game.

Ubisoft. (2007). "Assassin's Creed”. Videogame. Montreal: Ubisoft.

Ubisoft. (2008). “Assassin's Creed: Altärs Chronicles". Video game. Montreal: Ubisoft.

Ubisoft. (2009a). “Assassin's Creed: Bloodlines”. Video game. Montreal: Ubisoft.

Ubisoft. (2009b). “Anno 1404”. Video game. Montreal: Ubisoft. 


\section{The Touring Science Centre- an example of collaboration between a museum and a school}

\section{Eva Insulander and Elisabeth Öhman}

\section{Museum and school partnerships}

The semi-formal environment of the museum has as its mission, among other things, to collect, preserve, and exhibit the heritage of humanity for the purposes of education and enjoyment. The formal environment of the school, on the other hand, has as its purpose to create the best conditions for children's development and learning and to help improve pupils'learning outcomes. When Sweden moved from a rule-governed system to a goal-governed system, ${ }^{1}$ information about the quality of schools became essential. Schools - and teachers - are now held accountable for providing a good education for all. In line with this reform, learning outcomes and assessments have become of increasing importance at national, regional, and individual levels. The differences between the two institutions (school and museum) often result in different strategies and agendas regarding field trips and programs. Museums in general are set up to develop broader knowledge and understanding. However, as they also focus on attracting schools, in many cases they try to provide for the curriculum and make sure that a field trip will support the curriculum standards. As teachers search for museum programs, they want to know that their pupils will be able to meet specific learning objectives.

Previous studies on relations between museums and schools have shown difficulties regarding power relations; often, museum educators have a dominant role during visits while the school teachers have an ill-defined educational role (Mathewson \& McKeon, 2002). There are differences in how each group sees the purposes of a visit. Whereas museum educators consider a successful visit to be one where the pupils find personal relevance in the exhibition and feel comfortable, teachers, on the other hand, focus on the relevance of the visit in relation to the curriculum and the practical schoolwork. It is not unusual for museum educators to be critical of teachers' lack of involvement and lack of knowledge in relation to the subject area represented in the museum (Griffin, 2007). Allen (2004) claimed that science museums can be difficult learning environments simply because they offer a myriad of choices and lack the clear goals of a curriculum. Teachers are not usually aware of how to gain maximum benefit from science centres (Cox-Petersen et al., 2003). 
Genuine collaboration between the school and the museum seems rare. Cigdemoglu and Köseoğlu (2019) see the need for professional development models that can integrate informal and formal learning framings. Professional development programs provided by science centres and museums are often offered to schools, but they take place at the museum and rarely offer support or coaching at the participating schools' sites (Phillips et al., 2007). In order for the partnership to succeed, Griffin (2007) claims that museum educators and school teachers need a better understanding of each other's pedagogical contexts and strategies.

The Designs for Learning (DFL) framework emphasizes, among other things, the importance of understanding how institutional norms and power relations frame learning. This chapter explores some of the challenges and opportunities for teaching and learning in the collaboration between a science and technology museum (a semi-formal framing) and an elementary school-a formal framing; also see Chapters 1 (Selander), 7 (Insulander, Lindstrand \& Selander) and 9 (Insulander \& Svärdemo-Åberg), in this volume. We will show how differences between these two institutional framings have consequences for both teachers and museum educators as they meet in collaboration. This study is a critical reflection on the possible strengths and weaknesses, with the intention of using the findings as a basis for the development of improved relations and understandings between the two groups.

\section{A partnership focussing on digital resources}

In Sweden, the government recently decided to strengthen the national curriculum regarding digital skills (Swedish National Agency for Education, 2011), and computer programming and computational thinking are now being introduced in both formal and informal learning environments. However, many teachers lack any knowledge about programming, and a majority of the teachers are not familiar with basic programming concepts (Nouri et al., 2020). As science museums wish to increase school students' interest in science and technology, and to develop their competence in programming, there is an incentive for collaboration with the schools that really need support. Previous research has shown that science museums, through their exhibits, resources, and established maker spaces, can introduce a contextualized use of computational thinking that complements the work of the formal school framing (Bowler \& Champagne, 2016; Mesiti et al., 2019; Moore et al., 2020). Kjällander et al. (2016) point out that programming can be approached by using physical materials, such as robots and various applications, where pupils can use visual programming.

The initiative to engage in the development of new competencies came from a Swedish science and technology museum, as a response to the Swedish national curriculum regarding digital competences and programming. Observations of activities and interviews with museum educators and school teachers 
provided information about the teaching and learning interactions and cooperative practices at both sites. The purpose of the study was to illuminate and to discuss how the site-specific resources and practices of the museum's semiformal framing contributed to the school's formal goal-oriented work. Our questions were:

1 How is programming designed?

2 How is programming represented and transformed in the program across the framings of school and museum?

3 What do museum educators and teachers recognize as significant when working with programming?

Using a design-theoretic perspective allowed us to investigate how the institutional frames influence both teaching and learning. This research has also allowed us to demonstrate how museums may contribute to the curricular aims of the school by offering solutions and a place and space that expands the idea of where learning takes place.

\section{Context of the study and research design}

The "Touring Science Centre — programming in school" was a non-profit educational program for middle schools (for students aged 10 to 12 years) located in socially vulnerable areas of Sweden. It was produced by a Swedish science and technology museum involving a mobile platform that focussed on programming and aiming to motivate the interest of children and young people in technology and science through creative processes and collaborative problemsolving. In total, three museum educators were responsible for carrying out activities at different schools. They arrived at the schools in a van filled with resources for programming activities: digital tablets with coding software, and LEGO robots.

The school and the four different classes chosen for this particular study were selected due to their availability and the fact that they had already scheduled bookings. The data were collected during two months of field work, and consisted of observations from the activities included in the educational program, which included: (a) one introductory workshop with teachers at the school, (b) $4 \times 1$ workshops with pupils at the school, (c) $4 \times 1$ workshops with pupils at the museum, and (d) one follow-up workshop with teachers at the school (see Table 8.1). Our data included field notes, photographs of work processes (without identifying data), documentation of educational material, and interviews with the teachers and museum educators. All teachers gave informed consent to observation, and four teachers agreed to share their thoughts about the educational program in interviews.

The three museum educators involved in the program also attended an interview. These interviews were semi-structured and followed three themes: 
programming, schools in vulnerable areas, and the collaboration between the school and the museum. The interviews were transcribed and a thematic content analysis involving a reflexive movement between data collection and analysis was conducted. We focussed on the analytical concepts of framing, design, and transformation as a filter, through which the material was interpreted. The museum educators were once again informed about the purpose and aim of the study, and were given the opportunity to ask questions about the study and to cease their participation without having to give any specific reason. An informed consent form was signed by the participants. The schools' and the participants' names were anonymized. In Table 8.1, the documented activities are summarised.

\section{Analytical approach}

The thematic content analysis of the teaching and learning in a cooperative practice was carried out using some of the central concepts from the Designs for Learning framework, described in Chapter 1 by Selander of this book. In the context of this study, framing operates on two levels. It refers both to the institutional and organizational principles of the school vs. the museum, and to the individual framing and interpretation of a representation, based on individual preferences, cultural values, and so on (see also Lindstrand on affordances, Chapter 3, this volume). Different, institutionally based expectations of how communication and learning will occur in a museum or in a school can be observed through, for example, focussing on learning outcomes in school vs. enjoyment in the museum.

Table 8.I Documented activities within the educational program. (Table constructed by the authors)

\begin{tabular}{lll}
\hline Framing & Participants & Activities \\
\hline At the school &
\end{tabular}

\section{At the school}

School workshop A

School workshop I

School workshop I

School workshop I

School workshop I

\section{At the museum}

Museum workshop 2 Fourth grade pupils, group A

Museum workshop 2 Fourth grade pupils, group B

Museum workshop 2 Fifth grade pupils, group A

Museum workshop 2 Fifth grade pupils, group B

\section{At the school}

School workshop B All teachers at the school
Introduction to programming Introductory programming Introductory programming Introductory programming Introductory programming

Robot programming

Robot programming

Robot programming

Robot programming

Follow-up workshop 
The framing also affects the design — an exhibit or a workshop at the museum will be designed differently from a textbook or a lesson in school, depending on different expectations and purposes. Here, Designs for Learning refers to the educational program at the museum, which differs from the tasks that are given in schools. Design in our study (about programming) refers to the form as an integral part of the content in a social practice (Kress \& Selander, 2012). It also indicates designs in learning for both teachers and pupils in the series of workshops that involved hands-on practice with programming activities at the two different sites.

The pupils participated in one workshop at the school and one at the museum. We studied how programming, as curriculum content, is represented and transformed across the institutional framings of the school and the museum.

\section{Findings}

\section{Programming as edutainment vs. education?}

The program was designed by the museum with the intention of motivating, through creative processes, children and young people to be interested in technology and science. It involved workshops taught by two museum educators who (after an introductory workshop with the teachers) showed how one could carry out simple programming and collaborative problem-solving with the pupils at the school. It involved simple block programming, a visual and in many ways intuitive puzzle, that the pupils understood fairly quickly. The block programming was done with LEGO robots from LEGO Education and micro:bit coding. The MakeCode editor is a visual, intuitive programming environment with pre-programmed puzzle pieces that can be combined in different sections to create instructions for controlling, for example, a pedometer or a robot.

Eight LEGO robots were placed on the table in the front of the classroom, and the enthusiastic and expectant pupils rushed into their first programming workshop with the museum educators. After a short introduction, it was time for the first task. The pupils were divided into small groups with an iPad, a LEGO robot, and a wax cloth, with an obstacle course for each group. The challenge for the pupils was to program a robot to go through the obstacle path on the wax cloth, steer past various hindrances, and eventually reach the end (Figure 8.1). The workshop was designed for collaborative problem-solving activities, for example, how to manage the robot through the obstacle path. In the workshop, programming was represented by way of the technically modified toys-in this case, the robot and the colourful small symbols in the micro:bit coding. In the first workshop, programming was represented as a playful game.

In the second workshop, at the museum, the coding of the robot's movements was transformed in a new and different way. The pupils, in groups of three, were asked to build an alarm system. Their coding would give the robot a new 


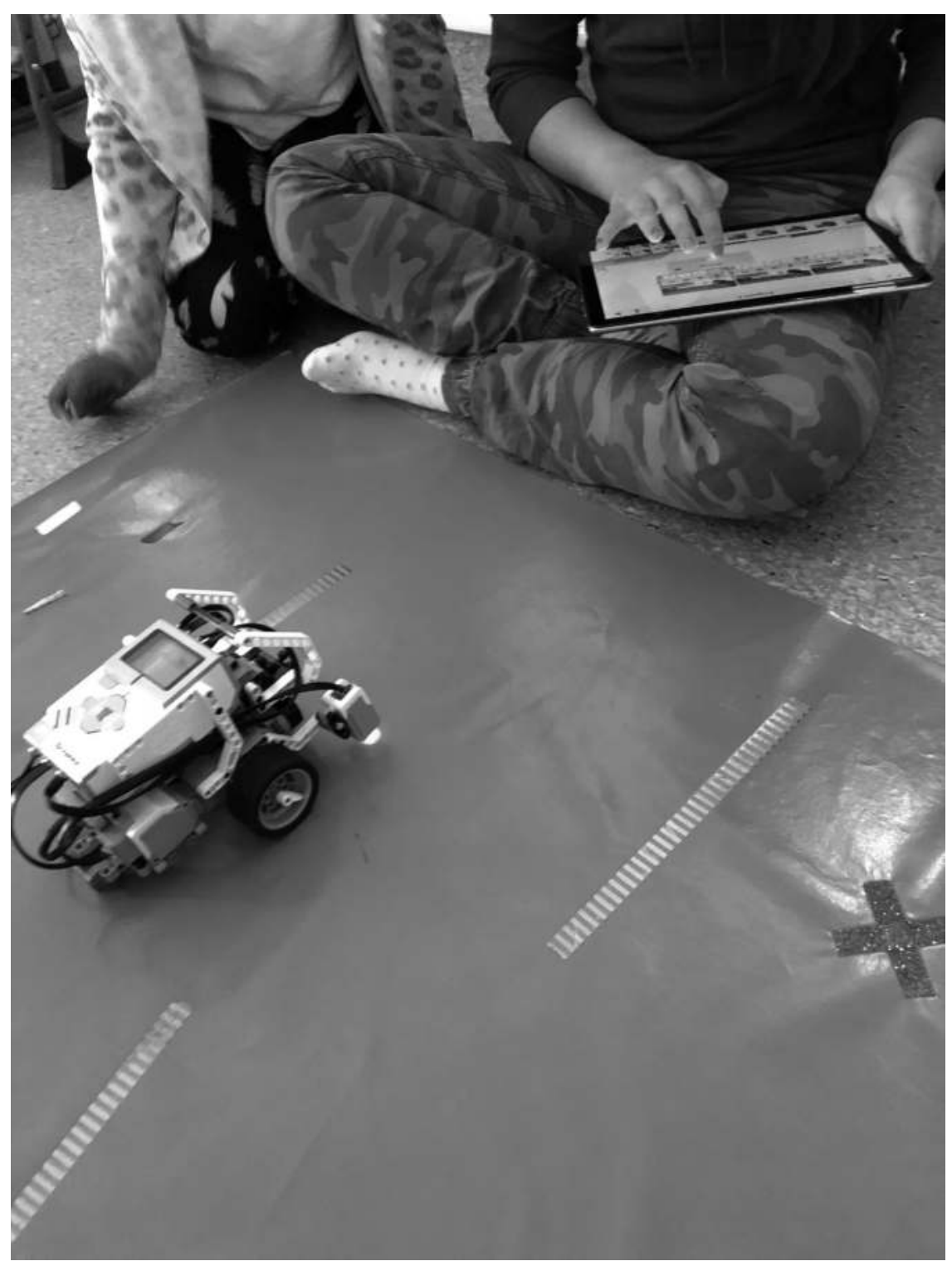

Figure 8.I A LEGO robot on the wax cloth.

Source: (Photographed by Lisa Öhman, ownership by chapter authors)

movement by attaching a bell or other object to one of the robot's parts (Figure 8.2). This was a more difficult task than the previous one; it was not as intuitive and demanded more creative solutions and logical thinking. However, most groups succeeded in solving this problem as well. Finally, they got to present their 


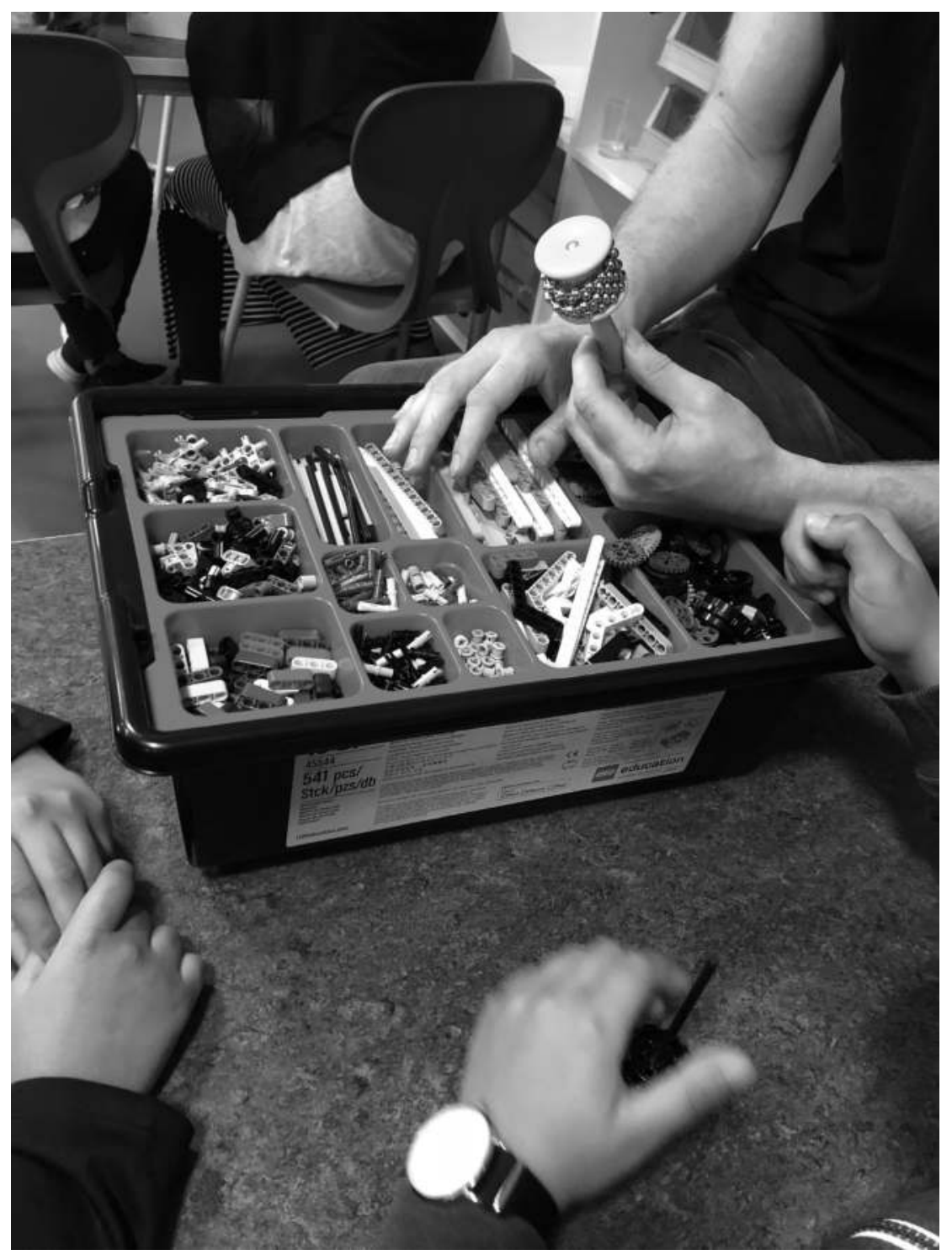

Figure 8.2 The rattle to be attached to the LEGO robot.

Source: (Photographed by Lisa Öhman, ownership by chapter authors)

solutions to one another. In this second workshop, programming was represented in terms of problem-solving.

As stated in their interviews, the educators at the museum wanted to support young people's interest in programming and, following the museum's mission 
statement, contribute to a wider recruitment to technical education. They also wanted to offer resources in order to attract new types of visitors to the museum. Yet another aim was to empower teachers, and to provide them with tools to stimulate young people's interest in programming. What came to be recognized as an important side-effect of the program was that the museum educators found the communication with the school meaningful. This is worth mentioning, because, as mentioned above, it is not unusual for museum educators to be critical of the teachers' lack of involvement and lack of competency (Griffin, 2007).

In this specific project, as noted above, the school and the museum had joint interests in programming, although from two different points of view. The teachers at the school had twofold objectives when participating in the program: to support the pupils' knowledge in programming, and to create a plan for further progression concerning their own digital competence. The museum educators' interest was not primarily in learning, but in offering meaningful and fun activities to support the pupils' interest. This also could be noticed in their choice of, for example, material and collaborative activities.

ME1: After all, we cannot teach them to crack a code. We may not have the goal that they should be able to go home and hack into their neighbours' network or something, it is rather that they should go home with a sense of-wow-this is fun, I want to continue with this.

(Museum educator)

In contrast to the museum's goals of creative work and of having fun, the school teachers pointed out that the project was not just a fun event. Instead, they talked about the need for increased skills and improved learning outcomes. They wished for their pupils to understand what programming could be in the school context, and to understand its importance for professional life and for the future. In other words, they wanted the pupils to be empowered (see Findings below). Further, the teachers wanted to transform programming so it could fit into their curriculum goals, according to the institutional framing of the school.

\section{Power relations and institutional clashes}

The institutional framing of the school involves an emphasis on programming as part of the curriculum. Representing the program as something serious, and not only a fun event, became a way for the teachers to legitimize the meaning and the value of programming at the school. However, one of the responsible teachers in the school's digital competence group revealed that, at different schools, teachers did not agree on what programming is, or how it could be taught. There were, for example, disagreements concerning the assessment of the learning outcomes. The mathematics teachers seemed unwilling to include programming in their teaching, arguing that it was not included in the syllabus. 
Other teachers tended to be more interested in using both digital and analogue tools to explore programming in the teaching of their subjects.

T4: There are two different factions in the school right now. Like many other schools we have a local educational plan just to secure the knowledge of programming because we have been given an assignment to get it into different school subjects. But then we have different factions where the math teachers say it is not in the knowledge requirements in the syllabusso we do not need to work with robots or Scratch program block programming ... in the way they do it in algebra, where there are some exercises similar to block programming, you work with binary numbers and they are also included in the programming.

Teachers are facing new challenges when it comes to understanding the role of digital competence in the organization of schoolwork. The school we visited had not yet decided on a strategy for how to approach programming, but intended to devise a local plan after the collaboration with the museum ended. The expectation was that the museum's program would provide knowledge for teachers as well as for pupils, and that the collaboration would be a helpful first step in the school's work to produce their own strategy for teaching programming. Previous studies have pointed out the difficulties regarding the power relations between schools and museums (e.g., Mathewson \& McKeon, 2002). However, this is not the case in our example, since the collaboration seemed to be equally fruitful for both parties, and the development of programming in the school appeared to cause changes in teaching and learning practices.

\section{Importance of materiality and place}

According to the teachers, hands-on materials make it easier for children to reach the goals of digital competence. The museum does not only show and tell, but also encourages children to do and experience programming. The design of the workshops - with hands-on material and the guidance of the museum educators - also made it easier for the teachers to understand what programming might entail. A fruitful approach, according to the museum educators, seems to be "to talk less but do more" and to let both teachers and pupils discover and work by themselves.

The teachers underlined that the workshops needed to be clearly planned: The pupils needed to know what was expected and to get an idea of what was going to happen. Otherwise there could have been a loss of focus and interest. For the pupils, not only was planning central, but also being able to work with multiple modes of expression including hands-on materials. The museum educators used a projector to show how the activity would be performed step by step and how the robots worked, which was helpful to many pupils with Swedish as a second language. The teachers concluded that the visual aids and the 
concrete materials supported learning. The museum educators also highlighted the museum as an opportunity for, and an alternative to, school learning, as something that could attract curiosity and a desire to learn:

ME2: I think it creates curiosity like it's good fun when you sometimes receive classes and then you go down the stairs "wow!" it is going to be so cool as well so I think it creates a bit of curiosity in the same way that maybe hopefully workshops do with programming.

The museum educators reflected on the fact that, within the framework of the program, they did not make the most of the museum's resources. Initially, in their presentation to the teachers and pupils, the educators talked about what constitutes a museum and what it offers, but they reflected later that the objects and collections could have been used much more. The program mostly offered science-centred activities and other types of installations, but not all of the museum's (potential) resources were used. The educators concluded that they could actually interweave stories about objects with the technology-historical aspects in the programming lessons. The institutional framing of the museum, with its collections and exhibitions, was not fully utilized.

\section{Empowerment vs. competence}

The teachers expressed that the socially vulnerable areas in which the program was carried out had a lack of economic, social, and cultural resources. The school could not rely on families when it came to developing digital skills. For example, many parents did not know how to find information online. They did not have computers or iPads at home, although most families had cell phones. Another lack of resources was manifested in that these families did not visit museums, and did not even go into the central part of the city. The teachers, on the other hand, saw the entire city as a social resource, as a way of being part of the entire community. And since the kids were not used to going to museums, they had not developed norms about how to move and behave in a museum. An important aspect of participating in the program was thus not only about programming as such, but also about understanding the institutional framing and developing a broader social competence-empowerment.

T1: So this is sooo important, they look forward to everything like this, they become hyperactive when they know they are going to be on a school trip. We know that their parents do not go out with them like this . . they can talk about this for several days before it is time to go

T2: So just the bus trip is so big and having lunch there is so important, it is so important

T1: And when they come to the entrance, when it's big and bright ... 
Another important part of empowerment was, according to the teachers, language development, and that the museum educators introduced and used domain-specific words related to both museums and programming.

T4: They left the museums with new concepts; sensor, alarm, new words for them. . I remember the educators repeated them several times, but they can also be written somewhere, also as a teacher you could get a glossary before the visit ...

However, not all museum educators were able to adapt their language to this particular social group of pupils. If the children did not understand, they lost interest and commitment. Both educators and teachers commented on the differences between their agendas and how they could allow for better collaboration. Considering the needs of this particular group of pupils, the challenge for the museum educators is to take advantage of the institutional framing of the museum whichcompared to the school—offers other possibilities for empowerment.

\section{Conclusion and discussion}

In this chapter, we have presented some of the challenges and opportunities for teaching and learning in the collaboration between a school and a science and technology museum. Using a design-theoretic perspective, we demonstrated how the museum contributed to the curricular aims of the school by offering an activity which took place not only at the museum but also at the participating school's site (see Phillips et al., 2007). As Griffin (2007) asserted, museum educators and school teachers need a better understanding of each other's pedagogical contexts and strategies in order for the partnership to succeed. By way of developing something in common, the two partners came to understand each other's educational roles better, as well as how their different institutional framings shaped different strategies for developing programming. The experiences from the collaboration could feed into the discussions at the school where the teachers were expected to develop their local educational plan for programming, including both enjoyment and programming skills. The findings illustrate not only how institutional aims and norms frame learning in different ways, but also that there is a space for doing things differently and trying out new patterns for learning. This is despite the fact that the museum often put the purposes of education and enjoyment first, whereas the school was more focused on curricular aims and learning outcomes.

From the museum's perspective, the Touring Science Centre programme was designed to spark an interest in programming, through the choice of materiality and activities. Programming was represented as a playful game, as was the case with the robot obstacle course that could be mastered through collective problem-solving. In contrast to this, the school teachers talked about the need for increased skills in programming. They pointed out that their reasons 
for participating were not just to have fun, but to make sure that the curricular goals were met. Another goal was to develop pupils' self-confidence and their competence to take charge of their own growth for participation in society.

It seems clear that even though the school and the museum each framed programming differently, in terms of either enjoyment or learning, this did not cause any problems in terms of power relations between the two professional groups, museum educators and school teachers. Rather, participating in the museum's programme became a useful first step for the teachers in their work to develop the school's local strategy for programming. In this case, museum educators and school teachers each had well-defined roles, and were both involved in the activities that took place in school and at the museum (cf. Mathewson \& McKeon, 2002; Griffin, 2007). The design of the workshops-with hands-on materials and the guidance of the museum educators-made it easier for the teachers to gain an understanding of what programming could involve.

The specific resources of the museum - both material and human-were considered an important part of understanding and doing programming. However, the museum educators reflected on the fact that, within the framework of the program, they did not really use the museum's collections as much as they could have. A "collection" is often seen as "the" central hub, as a starting point for the museum's activities. In this program, the opposite was true-it was through the practical materials in the workshops that it was possible to frame programming as science and technology during the museum visit. In this way, teachers could benefit from and contribute to the school's curricula, inspired by the informal learning environment at the science centre (see Cox-Petersen et al., 2003; Allen, 2004).

The teachers emphasized that the socially vulnerable areas where the program was carried out had a lack of economic as well as social and cultural resources. They saw great value in being able to visit a museum, but this was something new for both the school and the pupils' families. The participation in the program also contributed to the empowerment of these pupils. Another important aspect of empowerment is the competence to use the Swedish language in a broader as well as in a more domain-specific way than it is used in day-to-day talk among pals. Therefore, it was important that the museum educators introduced and used domain-specific words related to programming, as well as talking about the museum in more general terms that strengthened the empowerment of the pupils, something which complements the work in the formal framing of the school (cf. Bowler et al., 2016; Mesiti et al., 2019; Moore et al., 2020).

However, it could also be noted that, in terms of language learning, there seems to be a lack of deeper dialogue between the museum and the school. The Touring Science Centre programme has been running and evaluated for a number of years, and has also been re-designed and transformed during those years. Nevertheless, the museum's educators did not specifically perceive the language issue as prominent when we discussed their work in this socially 
vulnerable area. In the preparations for the visit to the schools and the museum, the museum educators' focus was primarily on rules and behaviour rather than on creating a dialogue about possible forms of language support. Although the programming instructions were visualized through the use of symbols during the workshops, the teachers stressed that a glossary would have been supportive in relating the domain-specific concepts to the students' everyday lives. The interviews with the teachers highlight how language development could be emphasized in the programme as a design for learning, and in that way contribute to the design and transformation of programming within the formal framing of the school.

\section{Note}

11994.

\section{References}

Allen, S. (2004). Designs for learning: Studying science museum exhibits that do more than entertain. Science Education, 88(1), 17-33.

Bowler, L., \& Champagne, R. (2016). Mindful makers: Question prompts to help guide young peoples' critical technical practices in maker spaces in libraries, museums, and communitybased youth organizations. Library and Information Science Research, 38(2), 117-124.

Cigdemoglu, C., \& Köseoğlu, F. (2019). Improving science teachers' views about scientific inquiry: Reflections from a professional development program aiming to advance science centre-school curricula integration. Science \& Education, 28, 439-469.

Cox-Petersen, A., Marsh, D. D., Kisiel, J., \& Melber, L. M. (2003). An investigation of guided school tours, pupil learning, and science reform: Recommendations at a museum of natural history. Journal of Research in Science Teaching, 40(2), 200-218.

Griffin, J. (2007). Pupils, teachers, and museums: Toward an intertwined learning circle. In J. H. Falk, L. D. Dierking, \& S. Foutz (Eds.), In principle, in practice: Museums as learning institutions. AltaMira Press.

Kjällander, S., Åkerfeldt, A., \& Petersen, P. (2016). Översikt avseende forskning och erfarenheter kring programmering i förskola och grundskola [Overview regarding research and experiences of programming in preschool and primary school]. Skolverket.

Kress, G., \& Selander, S. (2012). Multimodal design, learning and cultures of recognition. The Internet and Higher Education, 15(4), 265-268. https://doi.org/10.1016/j.iheduc.2011. 12.003

Mathewson, D., \& McKeon, P. (2002, December 1-5). Disrupting notions of collaboration: The problematic engagement of museums and schools. Paper presented at the Annual Conference of the Australian Association for Research in Education, Brisbane. www.aare.edu.au/data/ publications/2002/mat02555.pdf. Retrieved 2020-05-20.

Mesiti, A. L., Parkes, A., Paneto, S. C., \& Cahill, C. (2019). Building capacity for computational thinking in youth through informal education. Journal of Museum Education, 44(1), 108121. https://doi.org/10.1080/10598650.2018.1558656

Moore, S., Roche, J., Bell, L., \& Neenan, E. E. (2020). Supporting facilitators of maker activities through reflective practice. Journal of Museum Education, 45(1), 99-107. https://doi.org/ 10.1080/10598650.2019.1710688 
Nouri, J., Zhang, L., Mannila, L., \& Norén, E. (2020). Development of computational thinking, digital competence and 21st century skills when learning programming in K-9. Education Inquiry, 11(1), 1-17. https://doi.org/10.1080/20004508.2019.1627844

Phillips, M., Finkelstein, D., \& Wever-Frerichs, S. (2007). School site to museum floor: How informal science institutions work with schools. International Journal of Science Education, 29(12), 1489-1507. https://doi.org/10.1080/09500690701494084

Swedish National Agency for Education. (2011). Curriculum for the compulsory school, preschool class and the recreation centre, Lgr11 (revised 2018). Skolverket. 


\title{
Exhibition development through cross-institutional collaborative design
}

\author{
Eva Insulander and Eva Svärdemo Åberg
}

\section{Introduction}

Over the years the interest in collaboration between different professionals in order to develop knowledge has increased. Many different ways of conducting collaborative design projects have also been recognized by scholars in the field of design research (McKenney \& Reeves, 2019; Wang \& Hannafin, 2005; van den Akker, 1999). Doing collaborative design projects has many benefits and it has also been described in terms of conducting development research. van den Akker (1999) defines some key features of such research and these include collaboration (e.g., participants and researchers working together with a focus on practice development), intervention (developing more or less theory-based solutions for designs), and iteration (conducting repeating cycles of investigation, development, testing, and refinement).

To plan and implement an exhibition is a complex project. In museums it is increasingly common to bring together a cross-departmental team of experts, each of whom is familiar with their own area of knowledge. A curatorial team may consist of a project manager (or curator), educators, discipline specialists, exhibit designers, media producers, as well as carpenters, technicians, and so on. It has also become more common to involve external participants in exhibition projects (Mygind et al., 2015). Participatory exhibition development is about inviting participants who are not museum staff to actively contribute to different phases of the exhibition process. It can be about generating ideas and themes, making selections of objects, arranging the exhibition space, or contributing to overall concepts or approaches (Davies, 2010). Such curatorial processes can also include community or visitor participation. However, it is also known that multidisciplinary teams can encounter difficulties when sharing and developing practice (Zahedi et al., 2017).

In this chapter, we will focus on the collaboration between two teams: museum professionals and university researchers. We will also use the concept of cultures of recognition to unfold some aspects of the collaborative design process (Kress \& Selander, 2012; Selander \& Kress, 2010) where the participants gradually reach an understanding of some target questions, transform their ideas over 
time, and realize them by different means (modes and media) in an exhibition. We hereby also wish to contribute theoretically to the education field, adapting and expanding on the notion of cultures of recognition to describe and interpret knowledge change in cross-institutional collaboration.

We describe how the collaboration between museum professionals and university researchers contributed new ideas for the development of an exhibition-by way of discussions about the goals, collaborative problem-solving, an ongoing iterative dialogue, and critical reflection. We will describe how the collaborative design project started, what the different teams chose to focus on, how ideas were introduced and recognized, and how representations of ideas were realized and transformed in workshops and further materialized in the new exhibition. The chapter concludes by discussing some of the possibilities identified and constraints for meaning-making that may be involved in a crossinstitutional collaborative design process between museum professionals and education researchers.

\section{The collaborative design project}

The collaborative design process started as a project between museum staff and education researchers when an older exhibition had been closed due to a planned reconstruction. The museum was about to change its exhibition on evolution by shifting the focus from how the earth (stones and minerals) developed during different periods of time to a focus on living organisms (plants and animals) before humankind evolved. During the collaborative design process, representations of evolution were negotiated and transformed into a new exhibition, and the modes and media were used in different ways to focus on different aspects of evolution.

In the process of re-designing the exhibition, a group of researchers from a university was invited by the curatorial team to take part in the design process. The curatorial team consisted of a project manager, an assistant project manager, two museum educators plus two consulting educators, four experts responsible for the academic content, an exhibit designer, a carpenter, two technicians, and a media producer. The research team consisted of four researchers in education who were asked to contribute with a design-oriented, multimodal perspective on knowledge representations, as well as contribute to the revision and "modernization" of the design of the exhibition.

The role of the researchers was that of critical friends who could act as a sounding board to the project team by providing feedback and asking questions that would prompt critical reflection (cf. Greenwood \& Levin, 2007; Selander, 2017). More specifically, the role of the researchers was (a) to introduce some themes from the Designs for Learning framework for the purpose of presenting basic concepts for collaborative reflection upon elements within the design process; (b) to discuss design in terms of the relations between text panels and labels, artefacts, and moving images during the shaping of the new exhibition; 
and (c) to discuss with the curatorial team how design could affect visitors' opportunities to engage with the new exhibition. From the very beginning of the collaboration, it was made clear that the material realization and actual re-design was the responsibility of the curatorial team-they were the content experts and exhibition experts. Overall, this seemed to be fruitful for both parties in relation to the interests of each of the teams.

The two teams - the curatorial team and the research team-collaborated in a series of conversations, meetings, and workshops over a period of three years. The two teams met at the museum a total of eight times. Data included photos from the various stages of exhibition work; photos from the old exhibition, from works in progress, including sketches and models, and photos from the new exhibition. During each meeting, the researchers took photographs, made field notes, and collected different types of documents from the project team: an exhibition synopsis, internal policy documents, as well as the steering document from the government. The target agreement stated that the new exhibition should include, for example, "digital text-carriers," "interactive exhibits that activate several senses," "content corresponding with new research findings," and "new reconstructions and objects that contribute to a narrative." The exhibition should also have "a trend-setting and timeless form."

\section{Cultures of recognition and esoteric and exoteric ideas}

According to Selander and Kress (2010) and Kress and Selander (2012), the term culture of recognition has to do with what is valued as relevant knowledge within a specific context. We could compare this term with how Fleck (1997) defined the social aspect of knowledge as something which is formed when two, or several, people exchange ideas on what is to be accepted as knowledge in a certain time and context. Such cultures are constructed as people make ideas and representations of knowledge visible within social organizations, something which results in stronger bonds. An organization also tends to create mutual affirmation and sometimes even intolerance of what may be perceived as new, foreign, or different. The organizations that are strictly delimited by regulations, rules, and guidelines help to maintain recognized ideas and knowledge- the cultures of knowledge. Cultures of recognition are likewise created and shaped through communication, recurring meetings, and collaboration between the people involved. Knowledge gains its recognition and legitimacy when members negotiate and repeat values within the specific organization.

Cultures of recognition can also be seen as effects of the use of social power, and in that way some actors (e.g., teachers) will have greater legacy and capacity to act and decide than others (e.g., pupils). Recognition can thus be linked to overall institutional social organizations, for example, relationships between and among individuals and social groups. Value systems, interests, norms, and 
rules of a particular social group form and transform the cultures of recognition and influence what counts as valuable knowledge.

What is then recognized as knowledge is developed and shaped over time in relation to collective ways of thinking and acting within these social groups or organizations. For example, museum professionals and education researchers usually belong to different social organizations with differing cultures of recognition. Cultures of recognition can nevertheless change and evolve if the organization is open and democratic. In such cases, the influence of esoteric and exoteric ideas (cf. Fleck, 1997) are crucial, as they may enable different ideas of recognition to affect one another and make possible changes in the culture. An exoteric idea (outward-facing) emerges from a culture that is less familiar with a knowledge domain. Members use everyday concepts, for example, instead of subject specific language and they often position themselves as novices. On the other hand, an esoteric idea (inward-facing) is recognized by its scientific value. People who address esoteric ideas have an initiated position towards the subject matter. They can easily recognize what is perceived as quality within the culture, and they use a precise language that either includes or excludes other perspectives on the subject knowledge.

Knowledge development takes place, as we see it, in the interplay between individuals, organizations, and cultures and in the traditions, norms and values that have developed around a specific knowledge domain. An individual may act more or less in relation to a certain culture of recognition. But this does not mean that the individual only acts on the basis of knowledge from one group and culture. Each individual can also take part in communication and collaboration within several different social organizations. One main difference between cultures of recognition is how they perceive the status of knowledge.

In the groups where esoteric ideas and actions occur, knowledge is often seen as more provisional or temporary and fallible. In these cultures, knowledge is recognized as time-bound, dynamic, and dependent on other facts. In cultures where exoteric ideas and actions dominate, perceptions about knowledge may be expressed in more secure and objectified ways. The relationship between these esoteric and exoteric ideas can be more or less open and reciprocal, more or less hierarchical. An open dialogical relationship allows influence from both sides, as an ongoing dialogue between different ideational positions. One can argue that if groups are open to the thoughts and ideas of others and allow themselves to recognize these ideas, the cultures of recognition might develop and change towards openness, democratic values, and advancement of knowledge. Nevertheless, this is far from being easy to achieve. Resistance or counter ideas are not easy to embrace, nor to work against. What is recognized as truth is affected by ideas from different cultures of recognition, but this does not mean that truth is something arbitrary or that all ideas can be treated equally. On the contrary, scientifically substantiated knowledge should not easily be rejected. At a time when science denial and conspiracy theories are widespread, it is important to distinguish knowledge from mere opinion. 
In the following, we will relate the reasoning about cultures of recognition to our empirical case. We will show how the two teams communicate their different perspectives regarding the exhibition, and how their perspectives and views of knowledge are influenced by esoteric and exoteric ideas in their respective cultures.

\section{Some central activities within the collaborative design process}

In retrospect, we can identify three central (core) activities, which formed the collaborative design process in the museum project: (a) initial orientation, (b) designing a series of workshops, and (c) mutual evaluation and critical reflection on practice and on moving theory forward.

\section{Initial orientation}

The collaborative design process began when the two teams, the curatorial team and the research team, met for the first time at the museum. The initial orientation was informal and gave the original team members the opportunity to get to know each other, and to identify some common ground of interests and issues to discuss. After establishing the first contact, more team members were recruited and became involved in the collaborative design process, together with the research team. Despite the fact that the groups had different knowledge interests, the meetings were characterized by mutual curiosity about each other's areas of knowledge. Each team and their participants came from different scientific disciplinary cultures, with different ideas of what counts as knowing. The two groups had differing interests and perceptions of core topics or agendas which related either to issues of developing practice or to issues of developing educational knowledge. There were also cultural differences internal to each of the teams, especially in the curatorial team which encompassed a wide variety of professionals ranging from experts responsible for content (such as a paleontologist) to the exhibit designer (with a strong background in art). However, the two teams came together to share the overarching goal of developing the exhibition; they also showed an interest in learning from each other.

The new exhibition needed to be re-framed by means of representation; these were both more attuned to current research and more in line with contemporary aesthetics. After the initial orientation, and at the very beginning of the collaboration, it became clear that the material realization and the actual re-design of the exhibition was an assignment for the curatorial team. It was they who were the experts in museum content and exhibition design; the role of the research group was to critically discuss certain takenfor-granted ideas, and to discuss how different design elements could be understood from the perspective of communication and education. Overall, this seemed to be a fruitful way of collaboration for both parties in relation 
to the interests of each of the teams. The researchers were asked to contribute with a theoretical understanding of Designs for Learning and a multimodal perspective on knowledge representations, as well as to contribute to the revision and "modernization" of the exhibition. In general, the museum professionals had a focus on epistemology, technology, and design, while the university researchers focused on interpretation and communication, as well as contributing to a reciprocal critical reflection upon certain representations in the old exhibition.

\section{Designing a series of workshops}

The two teams, the museum curatorial team and the university researcher team, met together several times over a period of three years, and collaborated in a series of workshops at the museum. Conducting a collaborative design process can be described as a social commitment, where the two professional teams gradually get to know each other and learn to develop successful means of communication. The first steps in this collaborative design process were informal, and the researchers' task was to receive information about the curatorial team's ways of doing things by asking questions. The researchers followed the curatorial team members around the museum; they re-visited the old exhibition and discussed questions concerning how the curatorial team perceived different objects or texts in the exhibition, and how they viewed different ways of solving the problems identified by the curatorial team. The researchers positioned themselves as friendly outsiders because of their limited knowledge of evolution. However, the focus was on the idea of working together and on challenging previous conventions so that divergent ideas, expectations, and new understandings of the task could emerge.

New questions and topics of conversation were continually developed from the frequent communication and collaboration between the two professional teams. In an early workshop the curatorial team outlined that the overall goal of the new exhibition was to change and adjust the design of the exhibition to address current conceptions of evolution and contemporary aesthetics. A new paradigmatic frame required new means of representation which were on the one hand more attuned to current research, and on the other more in line with contemporary aesthetics.

The curatorial team described the old exhibition as "outdated" by which they meant that it did not conform to contemporary theory. The old exhibition was based on a paradigmatic account of evolution in terms of chronology and development. The members of the curatorial team argued that this was evident in its overall focus as well as in the resources that dominated in its design. One example was the way fossils were arranged in the showcases. The fossils were placed next to each other without any context, only showing development from simple to more advanced species. A label explained how the evolution of species happens. 
In a dialogical discussion with the researchers, an exoteric idea which acknowledged the perspective of the visitor was recognized by the curatorial team. This was that the old paradigm was represented by a geological timeline in the exhibition design. The idea of development was also represented in the old exhibition through the display of fossils in dioramas, arranged in geological periods, such as Cretaceous, Jurassic, and Triassic. During the workshops, the university researchers continually asked critical questions about the layout, such as the arrangement of the displays of fossils. The research team, adopting more of an exoteric perspective (i.e., the audience and visitor's perspective), asked questions out of curiosity, and sometimes naïve questions, about the knowledge displayed in the different arrangements. Examples of the questions asked by the research team include:

- What story about evolution does the arrangement in this diorama represent?

- Why are these resources typically arranged in this way?

- What kind of knowledge is foregrounded/backgrounded?

- How are the resources used to design the story of change?

Different members of the curatorial team explained what they saw as some of the core problems with the old exhibition concerning how the story (narrative) of the evolution was represented. A new exhibition, the curatorial team argued, was going to be framed by a paradigmatic account of evolution in terms of ongoing change (rather than development), which should involve representations of evolution based upon processes whereby individual organisms' characteristics change from one form to another in successive generations. At the same time, the curatorial team saw that an overall message of the new exhibition was needed to illuminate that knowledge itself is something changeable, due to continual new research findings and paradigms in natural history research.

Evolution as we know it today steers organisms' abilities to reproduce. Organisms do not "strive" or "seek" to be perfectly adapted to their environment. Both the process of random events and natural selection in heredity control evolution. However, the concept of chronology was still considered a valid esoteric idea that the curatorial team argued should continue to be represented in the new exhibition. They did not approve of a thematic layout, even though this exoteric idea was discussed previously when the research team introduced it.

During one of the workshops and a re-visit to the old exhibition, the paradigmatic framing of development was recognized through the arrangements of material resources and objects from the museum collection. It was equally represented in detailed models in the dioramas, built environments with fabricated plants, colour-painted landscapes, and written labels. The curatorial team described the setting as dark and "spooky," which was something that they wanted to change. Geological periods and systems were also represented by 
colour-painted landscapes in dioramas. In addition, one person in the curatorial team outlined the ambition to re-conceptualize evolution by replacing the concept of development with the concept of change, but she still believed it was important to keep chronology as a crucial concept in representing evolution. The other team members agreed that evolution has no direction or goal. This recognition of another esoteric idea led to it being considered necessary to be realized in the exhibition.

The curatorial team members then argued that the concept of development should be replaced by that of change, as they considered evolution to be nonlinear and explained that "man is not the crowning achievement of creation." One question asked by the researcher team was "how can we then represent on-going change in the exhibition?" The curatorial team argued that one idea was to represent change, and particularly the extinction of species, as a blue light that would appear at certain points in a tunnel. However, later in the series of workshops, the curatorial team concluded that the extinction of species was not such an important aspect of evolution because extinction happens all the time. They further argued that evolution is the combination of many different factors, and the focus of the exhibition was to demonstrate its complexity and scope. The curatorial members decided, instead, to represent and name extinction using written text rather than lights or any other mode.

In another workshop at an early stage, the curatorial team wanted to install a globe, intended to show the movement of the continental plates, at the entrance of the exhibition. Such representations, they argued, would explain the origin of life and illuminate change from a paradigmatic frame. They also wanted a time-tunnel, so-called, to be placed directly after the entrance and the globe, which would represent the long journey through time up to the present day. In the time-tunnel the ceaseless flow of time would sometimes be interrupted and explained through important steps or new directions in evolution. It was also regarded as important to place the fossils, objects, and landscapes within a context framed by a contemporary account. A modern touch would be offered by resources such as aesthetic illumination, digital resources, and playing cards (similar to Pokémon cards but with fossils as a motif) on digital tablets. During the whole visit the visitor would thus be able to walk around and search for information displayed on a digital tablet.

The position of dinosaurs in the exhibition was also discussed within the collaborative design process. In the old exhibition, the dinosaurs were gathered together in groups in a larger area that would give the feeling of being in natural surroundings. However, the curatorial team considered it problematic that dinosaurs from different periods were placed together. This previous way of arranging dinosaurs and plants was considered unscientific, and therefore considered as an exoteric idea. It was also argued that the dinosaurs attracted too much attention, something considered to be problematic because visitors often went directly to these dinosaurs without paying any attention to the chronology. For the new exhibition, the idea was to form and arrange separate 
islands according to a new updated, and more scientifically correct, discourse of chronology. The curatorial team argued that this archipelago of islands would help the visitor to slow down and understand the chronology. On the islands, dinosaurs were placed together with fossils on podiums. The natural surrounding with plants and trees was removed, since these belonged to an older esoteric idea of how to display prehistory. A new esoteric idea had emerged in the curatorial team, which challenged exhibits that could not be supported scientifically.

An important story to tell, and something which all curatorial team members agreed upon, is that evolution continues. The re-designing of the exhibition was also going to be followed chronologically by yet another exhibition about the journey of humankind. The curatorial team wanted to link the two exhibitions to one another in order to show that our predecessors are traceable way back in time.

During discussions in the workshops, the researcher team challenged the curatorial team several times with knowledge-seeking questions. Such questions illustrated how imaginative visitors could perceive the knowledge about the relationships between these different time periods. The questions from the researchers pointed at exoteric ideas of evolution as constant change. In line with this, the curatorial team recognized these exoteric ideas, and decided to use footprints on the museum floor as representations of this continuum. A dinosaur footprint turned into a bird's footprint and a mammal footprint. The exhibition, they argued, needed an indistinct closure so as to represent continuity and constant change; something that led into the next exhibition.

\section{Evaluation and critical reflection on practice and on moving theory forward}

After the exhibition was designed and ready to be re-opened, the curatorial team invited the researchers to re-visit the museum and go through the new exhibition. An evaluation and critical reflection on practice took place through recognition of the different design elements that affected the outcome of the exhibition. During the tour, both teams recognized that the meaning of evolution was re-framed around the two concepts of change and chronology. The curatorial team argued that this was represented in three different ways: in dioramas, in a time-tunnel, and in an archipelago with islands.

The initial plan for the entrance to the new exhibition was to use a large hanging globe with digital "glowing" projection onto it. It would visualize change through the movement of continents, and emphasize that the history of life begins with this glowing globe. This focus on geology as a starting point for evolution was an important and often recurring esoteric idea expressed by some members of the curatorial team. Sometime later, this idea was challenged by another competing esoteric idea expressed by a member of the curatorial team. This member expressed the opinion that such a geological representation 
would give the wrong idea of what this exhibition was about; it was not about Earth and the movement of continents but about life. Stressing that the globe would represent something dead rather than alive, the member expressed that she wanted to see life growing. In the final version of the exhibition the suggested globe was removed. Instead, the entrance involved an open stand similar to an amphitheatre, and a panel with written text that named the exhibition and introduced its content about life on Earth and the changes that constitute evolution. The globe was replaced by images of extinct animals, for example, a flying dinosaur over water, framed by an introductory text.

After the entrance, visitors were invited to go through the time-tunnel that represented a long journey through time until the present. It had five sections and contained written text on panels, objects, as well as moving and still images. The representation of the time tunnel demonstrated important steps or new directions in evolution, such as the emergence of the skeleton and of predators, and the step and the transition of life from water to land. The esoteric idea of chronology and a continuing story thus became more accentuated through the different steps. For example, both chronology and change were represented by dinosaurs' footprints on the floor, which continued and morphed into bird and mammal footprints. The concept of change made it possible to produce knowledge about the extinction of species.

The meaning of evolution was also represented by resources such as dioramas, digital applications, and stationary tablets. The curatorial team was careful not to make materializations without scientific proofs. This change resulted in a modern representation, which focused more on aesthetics. Dinosaurs were now more scientifically correct compared to the old exhibition; islands and dioramas were arranged in a sequence following a suggested walking path. Fossils were also displayed differently, in a way that would demonstrate their value, almost like expensive jewellery displayed in a shop.

The aesthetic design was represented by conventional resources such as sound, colour, light, and the use of new digital resources which had an emotional impact in the new setting. The dark and naturalistic setting of the old exhibition, intended to create an atmosphere that appeared somewhat mysterious, was now gone. The re-designed exhibition, which was brighter and more modernistic, intended to move away from the previous ambience, and instead give value to the objects on display. During the final tour both teams recognized these changes of representation. In the new exhibition, the lighting was strongly focussed on floors and podiums, contributing a certain drama and vividness. As all podiums had different forms, the lighting created shadows and contrasts which were visual and visible to visitors. While the old exhibition contained rather few objects, the new exhibition included many objects in the form of fossils. The two teams discussed how objects had become more attractive to the audience. They were displayed to shine and sparkle like precious objects in a jewellery shop. Purple colour in the islands' showcases could be made to glitter by means of lighting. The curatorial team intended that the 
objects could be more highly valued, and the museum could teach the visitors to see what the museum appreciates and recognises as valuable knowledge. The team argued that by offering such a narrative, an aesthetic experience may be construed. An overarching message of the new exhibition was that knowledge is something changeable, due to the ongoing development of new research findings and paradigms in research. During the process of re-design, the different paradigmatic standpoints or ideas of chronology, development, and change became a meaningful challenge to be united in the exhibition.

\section{Conclusions}

In this final section, we will summarize our argument and draw some conclusions regarding the concept of cultures of recognition and how the museum professionals and university researchers made meaning and contributed to the collaborative design process. We will argue that the fusion of the different professional roles and expertise together framed and formed choices of esoteric and exoteric ideas for the development of the new exhibition.

The design-oriented framework presented by the university researchers and used in the workshops contributed new ideas to the exhibition development process. The esoteric ideas were considered by the curatorial team to be the most important knowledge in the narration of the new exhibition. These ideas differ from what can be included as important and significant knowledge from the perspective of other disciplinary areas. The esoteric ideas are often perceived as the core of the subject area, and they are often realized in representations of knowledge that are considered non-negotiable. So, what is recognized as an esoteric or an exoteric idea within a knowledge domain depends on the purpose of the area of use and the target group. In the analysis of the collaborative design process, the concept of cultures of recognition helped us discover some tensions between what was recognized within and across the professional groups. The exoteric ideas that university researchers expressed represented the visitor's perspective, and these ideas were also posed from a novice and an outsider perspective. These ideas represented knowledge that was considered less sacred. The esoteric ideas, on the other hand, were recognized by the curatorial team as conceptual requirements and valid scientific representations which foregrounded the overall account of the exhibition.

The scientific knowledge provided by the (differently skilled) museum professionals resulted in the need for negotiation as well as competition internally regarding the content and form of the exhibition. At the same time, as representatives of the museum they could make independent judgements and choices, and take stances that affected the outcome of the exhibition. On only one occasion was an esoteric idea (namely, the representation of geology in the globe) challenged by one of the curatorial team members who introduced an exoteric idea (representations of life) instead. The university researchers played a central role as critically reflective peers in the design process, and 
their collective body of knowledge afforded the museum professionals the means that became thinking devices, which also influenced the design process to a certain extent. This collaboration thus allowed scope for agency for the museum professionals.

In this chapter, we have shown how the concept of cultures of recognition is open to change through its relation to design. In this study, the participants had a mutual goal in the design of the exhibition, even though they were likely to have had different interests and understandings of the knowledge area and/ or subject matter. The participants' mutual interest in learning from each other meant that a change in ways of thinking was possible. Finally, the concept of culture of recognition helped us as researchers to recognize those views or ideas that were preferable in comparison to others.

\section{Acknowledgements}

We want to thank Staffan Selander and Tore West, who were participating researchers in this process.

\section{References}

Davies, S. M. (2010). The co-production of temporary museum exhibitions. Museum Management and Curatorship, 25(3), 305-321. https://doi.org/10.1080/09647775.2010. 498988

Fleck, L. (1997). Uppkomsten och utvecklingen av ett vetenskapligt faktum: Inledning till läran om tankestil och tankekollektiv [The genesis and development of a scientific fact: An introduction to the theory of thought style and thought collective]. Symposion.

Greenwood, D. J., \& Levin, M. (Eds.). (2007). Introduction to action research: Social research for social change. Sage Publications.

Kress, G., \& Selander, S. (2012). Multimodal design, learning and cultures of recognition. Internet and Higher Education, 15, 265-268.

McKenney, S., \& Reeves, T. (2019). Conducting educational design research. Routledge.

Mygind, L., Kahr Hällman, A., \& Bentsen, P. (2015). Bridging gaps between intentions and realities: A review of participatory exhibition development in museums. Museum Management and Curatorship, 30(2), 117-137. https://doi.org/10.1080/09647775.2015.1022903

Selander, S. (2017). Didaktiken efter Vygotskij-Design för lärande [Post-Vygotskian education: Designs for learning]. Liber.

Selander, S., \& Kress, G. (2010). Design för lärande_Ett multimodalt perspektiv [Designs for learning: A multimodal perspective]. Norstedts.

Van den Akker, J. (1999). Principles and methods of development research. In J. van den Akker, R. Branch, K. Gustafsson, N. Nieween, \& T. Plomp (Eds.), Design approaches and tools in education and training (pp. 1-14). Kluwer Academic Publishers.

Wang, F., \& Hannafin, M. (2005). Design-based research and technology-enhanced learning environments. Educational Technology Research and Development, 53(4), 5-23.

Zahedi, M., Tessier, V., \& Hawey, D. (2017). Understanding collaborative design through activity theory. The Design Journal, 20(sup1), S4611-S4620. https://doi.org/10.1080/14 606925.2017 .1352958 


\section{Epilogue}

\section{Design beyond the classroom and for the future of learning}

\section{Lisa Björklund Boistrup and Staffan Selander}

In this volume a group of researchers have illuminated a design-oriented perspective from a variety of interests and starting points. Here we will reflect upon the Designs for Learning-perspective-in and beyond the classroom-with an orientation towards the future.

\section{Learning in different, and intersecting, contexts}

In Chapter 1, Selander describes the Learning Design Sequence model which is used throughout this book. The three versions - the non-formal, the semiformal, and the formal models_-can be addressed one by one, in different research or development projects. The decision on which version to adopt depends on the context of the project. If the project includes an interest in how learning might occur in settings which are not designed with formal learning as their aim (as in a school), the semi-formal or non-formal LDS models are the most relevant. It should also be noted that one profound idea behind these versions of the model is that even if a situation is not designed with formal learning as its aim, the design of the environment and the resources still affect the opportunities to learn.

An example of a semi-formal learning context would be when the first author (Boistrup) took a stroll in a coastal area. There she found that the municipality had installed informational signs describing an archaeological find, a wreck from the 15 th century, recently discovered by scuba diving marine archaeologists at the bottom of the sea just nearby. Here the installation was designed with visitors' potential learning and interest as a clear aim, and the designers had included several modes, such as a text with different fonts, pictures, and diagrams. The centre of the largest sign was a transparent circle, with the silhouette of an island and an additional painted arrow, helping the spectator to identify the location of the wreck. For the visitor, the learning was facilitated by the design of the information, without any requirement to actually "learn" anything about the wreck or about this specific historical period of time, as probably would have been the case in a formal context. 
In addition, our contention is that a DFL perspective is also helpful in analyzing learning across different institutional settings, where the design of the formal setting is influenced and developed, with guidance, drawing on learning affordances found outside the school (see Chapters 5, 7 and 8, this volume). We can also observe that strong traditions in a given area may restrict what can be visualized by the participants, for example, when a tradition of learning by printed texts excludes multimodal representations, or when viewing the world through a mathematical lens precludes an aesthetic appreciation. In such cases, discussions with professionals in other settings such as between teachers and museum workers, or the use of artefacts and resources from non-formal or semi-formal contexts, may affect a new design that goes beyond such traditions. One example is Chapter 8 (by Insulander \& Öhman, this volume), where the teachers were inspired by the museum staff when developing programming activities with students in school. Another example is Chapter 5 (by Boistrup \& Hällback, this volume), where the formal learning of mathematics was inspired and transformed by a vocational knowledge area such as hair or makeup styling. For future learning, we see great potential in such transformations where the attention is not on only one of the LDS-sequences, but on two or more.

\section{Educational research taking new steps}

Research in line with Designs for Learning was initially carried out to conceptualize learning in the intersection between multimodal, social semiotics, and a sociocultural approach, based on qualitative research inspired by ethnographical and other approaches including field studies (Selander, 2017; see also Chapters 2 (Lindstrand \& Selander), 3 (Lindstrand), 8 (Insulander \& Öhman) and 9 (Insulander \& Svärdemo-Åberg) in this volume). Over the years, we have also developed research carried out with professionals, instead of on them (see, e.g., Chapters 5 (Boistrup \& Hällback), 6 (Kjällander), and 8 (Insulander \& Öhman), this volume). This development also included a stronger focus on research ethics. Chapter 4 by Åkerfeldt and Boistrup outlines how this development can create tensions in relation to current formal requirements of ethical approval, but also how a DFL perspective facilitates ethical quality in research, such as when professionals become actors in the research project, instead of "objects" being researched. Thus, the DFL perspective is different from the kind of design research where a researcher designs a certain model to be adopted in teaching, and where the teachers are instructed as to how to carry out the teaching, so that the researcher can conduct analyses on the data collected.

Thus, we not only study the conditions for learning and learning processes, but the actual processes themselves. We also have an interest in taking part in practices for change, keeping an eye out for constraining frames, power relations, diversified interests, and moments of friction (see also Dorst, 2015; Marion \& Fixson, 2018). As we see it, DFL-inspired research in collaboration with professionals facilitates educational research to take new steps. The Learning 
Design Sequence considers the complexities of education, with the setting (including resources, curriculum, institutional norms and regulations) and the transformations during activities, such as in lessons. The multimodal approach clearly includes interactions in educational settings, where meaning-making is communicated through a broad range of modes such as body movements, speech, figures, and the like. When professionals are part of the research project in collaboration with researchers, it is even more likely that the complexities of educational settings are integral parts of the research, and that the research becomes relevant to the particular context being studied.

\section{Stability and change}

Social practices can be characterized in terms of stability and change. We have layers of rules and regulations, traditions, habits, and norms, as well as metaphors and classifications that influence our being in the world, our organizations, ideals and ways of thinking (Bourdieu, 2010; Douglas, 1986; Douglas, 1996; Kofman, 1993; Lakoff \& Johnson, 1980). However, this does not mean that societies reproduce themselves "exactly the same." It is, for example, not difficult to notice drastic changes after periods of war, or by way of major scientific breakthroughs (Badiou, 2012). More difficult is to capture the stream of ongoing, small and accumulated changes, which happen in both social communication and acting (Geertz, 1993; Gustavsson \& Selander, 2011). In this book, we have tried to elaborate further on processes with a focus on communication, meaning-making, and learning sequences within different settings.

In our view, Designs for Learning is a perspective that covers both structures of stability and processes of change. The design perspective looks at factors that frame activity settings and thinking, and it is also sensitive to spaces of agency and how material and semiotic resources are used. With this attention, the perspective can be elaborated in different ways (as can be seen in Part II of this volume).

\section{Learning, teaching, and research in a digitized era}

It is not too much to say that the network society and Artificial Intelligence (AI) are profoundly changing our society and conditions for living, learning, and working (Castells, 1998; Ford, 2018; Susskind \& Susskind, 2017). This means that schools are changing as well, and many of us may notice an increased anxiety, perhaps even fear, about what is going to happen in our society. The changes seem as pervasive as those when the agrarian society became industrialized. At that time, one of the answers to the increased social tensions and the need for new, structured knowledge was to build up a school system. However, this does not imply that the school "as an answer" to the problems of the industrialized era is also an answer to the problems of the emerging, hybrid society. It might, in fact, be the opposite. 
We, as editors and authors of this volume, rather think that it is time to discuss fundamental questions for teaching and learning, without dreaming of the good old days of stability (and were they always that good?). The kind of school that prepared pupils for that labour market may even not be relevant for today's society, where only a tiny portion of the population actually seems to be able to get regular jobs. We must ask ourselves: What learning is necessary? What does it mean to learn core knowledges? What will be the future of teaching, and who will be the future teachers? And what are the things they should be able to do? We, as researchers, also must ask ourselves: what will the future of research be about? Will there be a role for research in innovative designs for learning?

Well, of course, we both hope and think so, but then we need relevant methodological and theoretical tools. We must not only be able to study what people think and reflect upon, but also to study their actions. We should also shape such tools through which we might be able to collaborate with different professionals in learning designs and detect learning sequences and knowledge representations in all their richness-not only those aspects that can be assessed through the standardized test procedures of the current school organization. Today most discussions about learning seem to refer to such test procedures, which means that learning is coupled with the market principles of doing your best in each situation, no matter what that might be in terms of content or knowledge. If we want to focus on knowledge, skills, and bildung, including the competences to act and to reflect, creativity and collaboration, knowledge about scientific and aesthetic fields, and the ability to handle tricky problems along with environmental demands, then we must ask ourselves what that could mean for the future organization of learning. Our hope is that the DFL perspective is a way to frame research which focuses on such current challenges.

\section{Dynamic and innovative designs}

To develop research that can be part of innovative designs and processes of change is a challenge. It will not be easy to do. It will involve a new kind of scientific openness, including ongoing internal and external dialogues, as well as the novel involvement of professionals in research, and of researchers in relation to professionals within other fields. We need to think anew the work that already has already started in terms of 21 st century skills or competences. It is our hope that this book will serve as an inspiration and as a systematic grounding for doing 21 st century research.

\section{References}

Badiou, A. (2012). Ethics: An essay on the understanding of evil. Verso.

Bourdieu, P. (2010). Distinction: A social critique of the judgement of taste. Routledge. 
Castells, M. (1998). Nätverksamhällets framväxt. Informationsåldern: ekonomi, samhälle och kultur. Band 1 [The information age: Economy, society and culture. Volume 1: The rise of the network society]. Daidalos.

Dorst, K. (2015). Frame innovation: Creating new thinking by design. The MIT Press.

Douglas, M. (1986). How institutions think. Syracuse University Press.

Douglas, M. (1996). Thought styles: Critical essays on good taste. SAGE.

Ford, M. (2018). Architects of intelligence: The truth about AI from the people building it. Packt.

Geertz, C. (1993). Local knowledge: Further essays in interpretative anthropology. Fontana Press.

Gustavsson, A., \& Selander, S. (2011). Transformations and changes in social knowledge: Towards the dynamics of meaning-making. In M. Chaib, B. Danermark, \& S. Selander (Eds.), Education, professionalization and social representations: On the transformation of social knowledge (pp. 17-33). Routledge.

Kofman, S. (1993). Nietzsche and metaphor. The Athlone Press.

Lakoff, G., \& Johnson, M. (1980). Metaphors we live by. University of Chicago Press.

Marion, T. J., \& Fixson, S. K. (2018). The innovation navigator: Transforming your organization in the era of digital design and collaborative culture. University of Toronto Press.

Selander, S. (2017). Didaktiken efter Vygotskij—Design för lärande [Post-Vygotskian education: Designs for learning]. Liber.

Susskind, R., \& Susskind, D. (2017). Professionernas framtid. Hur teknologin kommer att förändra experters arbete [The future of professions: How technology will transform the work of human experts]. Daidalos. 


\section{Index}

Page numbers in italics indicate figures and page numbers in bold indicate tables.

action research 54, 61, 63, 66, 79

affordance: activation and 39; agency and 38-46; defining 36, 41; DFL framework and 35-37, 45-46, 48, 150; digital tools and 99; discourse and 43-44; of the environment 36-39, 41-42, 45 ; information and communication technology (ICT) 39; institutional social life and 44; knowledge representations and 11 ; materiality and $11,36,42$, 45; meaning-making and 40, 45, 116; meaning potential and 16n20, 40-41, 44; modal 42-43, 66; museums and 55; as a relational notion 37,46 ; resources and 36-39, 41, 45-46; semiotic 39, 41-43

agency: actions of distinguishing and 45; affordances and 38-46; collaborative design and 148; decision-making and 26; DFL framework and 151; environment and 45 ; institutional framing and 118 , 120, 120; learning and 30-31, 39; personal interactions and 28, 31

Åkerfeldt, A. 14, 14n1, 15n6, 51-52, 54, 150

Allen, S. 123

anthropology of the didactics (ATD) 66-67 artificial intelligence (AI) 59, 83, 151

assessment practices: cultures of recognition and 11, 13, 24; formative assessment and 66, 107; institutional norms and 52-53; knowledge focus and 118, 120; learning outcomes and 123,130; rationality of 17n29; sites of learning and 120, 120; standards for 120; summative assessment and 66, 107
Bakhtin, M. 17n23

basic knowledge see knowledge

Bernstein, B. 16n21, 62

Bezemer, J. 25, 42

Bogost, I. 114-115

Boistrup, L. B. xii, 14, 51-54, 61-63, 67, 150

Bourdieu, P. 16n19

Caillois, R. 15n11

Calkins, L. 84

Castela, C. 66

Chevallard, Y. 62, 66, 74

Chomsky, N. 17n28, 24

Ciampa, K. 84, 106

Cigdemoglu, C. 124

coding $17 \mathrm{n} 25$

coherentism 17n23

collaborative design: cultures of recognition and 137-141, 147-148; DFL framework and 138-139, 142; evaluation and critical reflection 145-147; exhibition development 137-139, 141-148; initial orientation in 141-142; participants and 56, 59n1; pedagogical contexts and strategies 124, 133; power relations and 57,123 ; research and 56,137 ; researchers and professionals $7,48,50$, 52-58; workshops and 84-86, 105-106, 142-145

collaborative teaching: analysis of 68-69, 78; design of 61, 65-66, 79; LDS model and 79; open-mindedness and 79; vocational mathematics education and 62-63 communication: cultures of recognition and 139 ; feedback and 51; institutional 
framing of $8,15 \mathrm{n} 3,126$; LDS model and 13-14; learning and 24; materiality and 48; modes and 25; multimodal 6-7, 15n12, 54; non-verbal 54; sign-making and 42; social 15n12, 16n18, 43, 151 computer screen recordings 51-52, 54 Conole, G. 39

content teaching 61-62, 66, 69, 78-79 contextualization $16 \mathrm{n} 21,62,124$

cultures of recognition: assessment and 11 , 13, 24; collaborative design and 137-141, 147-148; communication and 139; defining 139; DFL framework and 14; esoteric/exoteric ideas and 140,147; gaming and 116; institutional framing of 118; knowledge and 11, 139-140; learning and 13, 24; resources and 35-36; social power and 139-140

design: defining 7-8; as dynamic perspective $6-7,14$; in education $\mathrm{x}$, xi, xii, xiii; form and content in 127; learning and xi, xii, 8; partnerships and 14; see also Designs for Learning (DFL); Learning Design Sequence (LDS)

design in learning: digital tools for preschools and 82, 107; learning processes and 8, 23, 30-31; museum engagement and 117; programming activities and 127

design-oriented thinking 7, 13, 16n14, $16 n 16$

design research: building trust in

52; collaboration and 56; ethical considerations and 48-59; on others/ with others $48-54,56,58$; video data and 51-52, 54; see also education research

Designs for Learning (DFL): affordances and $35-37,43,45-46,48,150$; collaborative design and 56-57, 138-139, 142; digital tools for preschools and 82; education research and $16 \mathrm{n} 16,17 \mathrm{n} 30$, 50, 150-152; ethical considerations and 48, 51, 58; formative assessment and 107; framing and 126; institutional norms and power relations in 124 ; learning environments and 6,14, 150; learning process and 8 ; modes of 51 , 53-54; multimodal social semiotics and 42, 150; resources and 35-36; stability and change in 151; workshop series design and 86-87 digital tools: affordances and 99; artificial intelligence (AI) and 83; competencies and 124-125, 130-131, 133-134; educator intervention in 86,91 ; LDS model and 84, 86; materiality and 131-132; mathematics learning and 83; national curriculum and 124; preschools and 82-83, 96; visual programming and 124; workshop series design and 86-108

Dilthey, W. 16n14

discourse 43-44

distributed information 5

Dyke, M. 39

education research: assessing learning and $\mathrm{x}$, xi; collaborative 59n1, 138, 140; community research design and 58; critical researchers and xi; DFL framework and 16n16, 17n30, 50, 150-152; ethical considerations and 14 , 48-50; feedback and assessment 52-53; LDS model and xii, 13-14; learning process and $\mathrm{x}$; learning standards and $\mathrm{x}$; multimodal feedback and 51-52; see also design research; research

emblematic framing 9, 112

Engeström, Y. 62

environment: affordances of 36-39, 41-42, 45; agency and 45; authentic artefacts and 117; formal learning contexts 123-124; gaming and 115; hybrid 14; non-formal learning contexts 134 ; outdoor 40, 40, 41; semi-formal learning contexts 123-124; setting and 88-89; social $13,31 \mathrm{n} 1$

epistemological commitments 25-26, 42 epistemological framing 9-10, 16n21 esoteric ideas 140, 147

ethical considerations: design research and 48-59; DFL framework and 48, 51, 58; empirical material and 51, 54, 58-59; formal research approval and 48-50; institutional setting 48-49, 52-53, 57-58; natural sciences research and 50; non-formalized relationships and 49; research transparency and 56-57; video data and 51-52, 54

exoteric ideas 140,147

film-making: composition and 25; multimodal knowledge representations and 25; shared interest in 27-28; 
storyboard 29-30, 30; student agency in 31 ; syntax and 25; transduction and 27,

31 ; transformation and 27, 31; writing a synopsis 28-29; youth collaborative case study $27-31$

FitzSimons, G. E. 62

Fleck, L. 139

formal learning contexts: contextualization and 16n21; DFL framework and 150; digital competencies and 124-125; environment and 123-124; evaluation and 4-5, 15n4; institutional framing and 9; knowledge focus in 120; LDS model and 4, 4, 149; learning in 120; learning resources and 112; school-museum collaboration and 124-125; schools as 118-120, 123; setting and 10; sloyd education 3

Formal Learning Design Sequence 4, 4, $15 n 6$

formative assessment xi, 66, 107

Foucault, M. 43

foundationalism $17 \mathrm{n} 23$

framing: defining 9; design and 127; DFL and 126-127; emblematic 9, 112; epistemological 9-10, 16n21; individual 9, 16n20; institutional 9, 16n18, 57-58, 61, 120, 124, 126-127, 130-133; organizational 126; power relations and 9, 130-131; problem-solving and 10; re-framing and 9; resources and 112, 116; social 38,45 ; teaching contents 61-62; thematic 9

Frejd, P. 62, 78

Gallagher, C. $15 \mathrm{n} 11$

Gibson, J. J. 36-39, 41, 46

Goffman, E. 16n18

Griffin, J. 124, 133

Gudhem monastery museum 118

Guillou, J. 118

Haack, S. 17n23

Haake, M. 87

habitus $16 \mathrm{n} 19,24,31 \mathrm{n} 1$

Hällback, M. 61, 63

Halliday, M. A. K. 16n22, 40

Halverson, E. 17n30

Halvorson, R. 17n30

hidden curriculum 13

hierarchical order 111

hybrid education 5,12 information and communication

technology (ICT) 39

institutional regulations 48

Insulander, E. 55

interactions: classroom 58, 69, 74-75, 151; educator-research 55; multimodal 54; signs of learning in 106; transformation units and $53-54$; see also social interactions

interactive texts $11, \mathbf{1 2}$

Kagan, J. 16n14

Kalmar County Museum 117

Karoff, H. S. 15n11

Kjällander, S. xii, 55, 124

knowledge: cultures of recognition and 139-140; development of 140; distributed information and 5; factual 5; individual growth and 5, 15n9, 15n10; power relations and 5 ; society and 5 ; styles of 8, 16n17; see also multimodal knowledge

knowledge representations: affordances and 11; available resources and 35; defining 11 ; interactive texts 11 ; material resources and 118-119, 121; modes of 25, 117; multimodal 11, 23-25, 31, 113; museums and 116-118; in schools 119; semiotic resources and 11, 24, 120-121; as signs of learning 23; text and 11, 12; textbooks and 119

Köseoglu, F. 124

Kress, G. 16n20, 16n22, 25, 26, 42, 139

Kvinge, Ø. R. 14n1, 15n6

Lagerlöf, S. 5

language learning 17n28, 24, 134-135

LDS see Learning Design Sequence (LDS)

learning: as creative engagement 11, $17 \mathrm{n} 23$; cultures of recognition and 24 ; defining 13, 17n27, 24; design and xi, xii, 27; formal 3-4, 120; institutional norms and 48, 52, 61, 65-66, 97, 124; meaning-making and 121; non-formal $1-3,113,120$; power relations and 124; re-design and 121; rhizomatic webs and 2-3, 24; semi-formal 2, 10, 55, 116, 120; signs of $12-13,23$; as social practice 13, 15n3, 23; sociological views on 6; standards for $\mathrm{x}, 4,23$; student agency in 30-31, 39; textbook resources 118-119; transformation and 26 
learning-by-teaching 83

Learning Design Sequence (LDS): aspects of knowledge and 66-68, 68, 69, 78; collaborative teaching and 79 ; designing teaching $65,65,66$; education research and xii, 13-14; educator-research interactions 55; ethical considerations and 48,58 ; formal learning contexts 49, 149; learning situations and 8; meaning-making and 85; multimodal approach and 151; non-formal learning contexts 149; planning learning sequences with 14; praxeology and 66, $68,68,69$; primary transformation unit 89 ; resources and 62 ; revised model 68,85 ; semi-formal learning contexts 149; setting and 88, 88, 89; styling and 69-70; transduction and 63; transformation units and 53-55, 66, 69, 88; workshop design series and 83-108; see also primary transformation unit; secondary transformation unit

Levinsen, K. 84, 86-87, 106, 108

Lindstrand, F. xii

$\log 0$ 67, 67, 68-69

materiality: affordances and 11, 36, 42, 45; communication and 48; digital competencies and 131-133; knowledge representations and 11 ; resources and 36; transduction and 26-27; transformation and 26

mathematics education: collaborative teaching and 61; digital tools for preschools and 83,86 ; educator intervention in 86 ; as practical vocational knowledge 61-62; praxis-logos knowledge 67, 67, 68; recontextualization and 62 ; summative assessment and 107; as theoretical knowledge 61; workplace 62; workshops and 95; see also vocational mathematics education

meaning-making: affordances and 40, 45, 116; behavioural observations and 6; interviewing and 6,15n12; LDS model and 85 ; learning and 121 ; meaning potential and 40-41; modes of 25, 42; museums and 36-37; semiotic resources and 42; situated 6; social actions and 6, $15 n 12$

meaning potential 16n20, 40-41, 44, 119
Middle Ages: defining 111; gaming and 112-116, 120-121; learning in video games 115-116; in museums 116-118, 120-121; representations of 112, 119-120; in schools 118-121; in Sweden 111, 119

modes: affordances and 42-43, 66; communication and 25; computer screen recordings and 51-52, 54; DFL and 51, 53-54; epistemological commitments of 25-26, 42; knowledge representations and 25; meaning-making and 25, 42; re-design and 11, 16n22; semiotic 11 ; social interactions and 66; video data and 51-52, 54

Muhrman, K. 62, 78

multimodal communication 6-7, 15n12, 54 multimodal knowledge: assessment of 6; design-oriented thinking and 7; re-design and 23, 31; representations of $6,23-25,113$; signs of learning and 113; symbolic forms and 24

multimodal texts $11, \mathbf{1 2}$

museum exhibition development: collaborative design and 137-139, 141-148; evaluation and critical reflection 145-147; initial orientation in 141-142; workshop series design and 142-145 museums: affordances and 55; DFL framework and 8, 138-139; enjoyment and 126, 130; institutional framing of 117, 132-133; knowledge representations and 116-118; meaning-making and 36-37; Middle Ages in 116-118, 120-121; power relations and 123, 131, 134; school partnerships and 123-135; semi-formal learning and 2, 10, 55, 116, 123; visitor engagement in 117-118; see also science and technology museums

network models 111

non-formal learning contexts: DFL framework and 150; digital competencies and 124; gaming and 112-116, 120; knowledge focus in 120; LDS model and 149; learning in 113, 120; learning resources and 112-113; personal interest and $1-2$; rhizomatic webs and 2-3; school-museum collaboration and 124; setting and 10

Non-formal Learning Design Sequence 2, 2

Nordin, A.-K. 54 
Norman, D. A. 41

Nouri, J. 14n1, 15n6

Ogborn, J. 42

Öhman, E. 55

Ørngreen, R. 84, 86-87, 106, 108

Pellegrini, A. D. $15 \mathrm{n} 11$

Penuel, W. R. 56, 58

Pippin, R. B. 25

playing $6,15 \mathrm{n} 11$

praxeology 66-67, 67, 68-69, 74

praxis $67, \mathbf{6 7}, 68-69$

preschools 82-83, 96, 107

primary transformation unit: analysis of 96 ; educator interventions and 66, 90, 91, 96; forming and 93-94, 96; knowledge formation in 66; LDS model and 89, 89; non-verbal communication and 54; structured brainstorming in 92-93, 94; task types and 69; techniques and 71-72; theory and 74; transforming and 91-92, 96; workshop series design and 89-90 programming: computational thinking and $17 \mathrm{n} 25$; digital competencies and 124-125, 130-134; as edutainment vs. education 127, 130, 132-133; institutional framing of 127, 130-131, 133-134; language learning and 134-135; LEGO robots 125, 127, 128, 129; power relations and 131; problemsolving and 129; science and technology museums 124-130; transformation and 127-130

recontextualization 62,78

re-design: defining 10; learning and 11 , 121; multimodal knowledge and 23, 31; transduction and 11, 16n22, 25-27; transformation and $11,16 \mathrm{n} 22,25-27$ research: collaborative design and 137; democratization of 50-51; designoriented 7; ethical considerations and 48-51; workshops and 84, 87; see also design research; education research researchers: affordance and 35, 39, 41; building trust 52 ; collaboration with professionals 7, 48, 50, 52-58; ethical considerations and 49-50, 58; integrity and 55 ; interactions with educators 55 resources: affordances and 36-39, 41, 45-46; cultures of recognition and 35; DFL framework and 35-36; knowledge representations and 35; materiality and

36, 121; semiotic 39, 41-42, 121

rhizomatic webs $2-3,24,26,28$

Rosvall, P.-A. 61

schooling: basic knowledge and 5, 152; digital competencies and 124-125, 130-134, 151; history education in 118-119; institutional framing of 127 , 130-131; institutional norms and 66, 69, 78; knowledge representations in 119; learning outcomes in 126; mathematics education 61-62; Middle Ages in 118-121; museum partnerships and 123-126, 126, 127-135; power relations and 131, 134; textbook resources 118-119, 121; vocational education $61-66$

science and technology museums: domainspecific words and 133-135; institutional framing of 132, 134; mobile platform for 125-128, 133-134; programming and 124-133; resources of 134; school partnerships and 123-125, 126, 127-135; teacher empowerment and 130, 132-133 secondary transformation unit: analysis of 96; formation of physical representations 94; interactions and 53, 66; metareflection and discussion 94-95; modes and 66; non-verbal communication and 54; technologies and $69,72,76$

Selander, S. xii, 35, 42, 50, 62, 65, 68, 87, 107, 126, 139, 149

semi-formal learning contexts: DFL framework and 150; knowledge focus in 120; LDS model and 149; learning in 120; learning resources and 112; museums and 2, 10, 55, 116, 120 , 123; rhizomatic webs and 2-3; schoolmuseum collaboration and 124-125; setting and 10; social environments and 2 Semi-formal Learning Design Sequence 2, 3 semiotic affordances $41-43$

semiotic potential 39, 41-42

semiotic resources: discourses and 43;

knowledge representations and 11, 24, 120-121; LDS model and 4; meaningmaking and 42; multimodal 7, 11 , 24; semi-formal learning contexts 2 ; semiotic potential and 39, 41; text as 11 setting: communication and 48 ; defining 10; environment and 88-89; formal learning contexts and 10, 48, 118-120, 
120; institutional norms and 48, 52-53, 78, 101, 104, 106, 150; LDS model and 85-86; lesson and 65, 69, 75; non-formal learning contexts and 10, 112-113, 120, 120; recontextualization and 62 ; research and 55; semi-formal learning contexts and $10,48,116-117,120,120$

sign-making 42-43

signs of learning $7,12-14,23,45,106$, 107, 112, 113

Skinner, B. F. $17 \mathrm{n} 28$

Snow, C. P. 16 n14

social communication 15n12, 16n18, 43, 151 social interactions: collaboration and 86 ; common language and 107; interests and 90; modes and 66; multimodal analysis of $15 \mathrm{n} 12$; primary transformation unit and $66,90,91$; secondary transformation unit and 96; workshop series design and 86, 90, 91, 96, 106-107

social practice 13-14, 15n3, 23, 127, 151

social sciences $16 \mathrm{n} 14,50$

stability 151-152

summative assessment 66, 107

Svärdemo Åberg, E. 52

Sweden: decentralized educational system in 118; digital skills in national curriculum 124; goal-governed schools in 123; Middle Ages in 111, 119; vocational education in 61,63

Swedish Research Council 86

Sydow, S. L. 57

symbolic understanding 24

syntax 25

tasks $67,69-72,74$

teachable agents 83

teaching: content and 61-62, 66, 69, 78-79; empowerment and 130 , 132-133; institutional norms 66; LDS model and 65, 65, 66; see also schooling

techniques $67,69-72,74,77,79$

technologies 67, 69-70, 72, 74, 76-77, 79

textbook resources $118-119,121$

texts: cultural artefacts as 42 ; interactive

11, 12; knowledge representations and 11-12, 12; as material resources 118-119, 121; multimodal 11, 12; as visual representations 11

thematic framing 9

theory: logos and 67; styling and 69, 70, $72,74,74,75,77$; teaching contents and
61; technologies and 67; transformation units and 69

Tolan, K. 84

Touring Science Centre 125-126, 133-134

transduction: brainstorming and 96; film-making and 31; LDS model and 63; re-design and 11, 16n22, 25-27; transformation and 63

transformation: film-making and 31; re-design and 11, 16n22, 25-27; researcher-educator interactions and 107; transduction of knowledge and 63

transformation units 53-55, 66, 69, 88; see also primary transformation unit; secondary transformation unit

Van den Akker, J. 137

van Leeuwen, T. 38-42

video data $51-52,54$

video ethnography 87

video games: coding orientation and 113; environment and 115; epistemological framing and 9-10; hack and slash genre 114; interactivity and 115 ; knowledge representations in 113; learning in 115-116; Middle Ages in 112-116, 120-121; modality and 113; as performative expressions of knowing 115-116; positioning 114-115; procedural rhetoric of 115 ; stealth genre 113-114; strategy genre 114 visual programming 124 visual representations 11 vocational education: academic knowledge in 61; hair styling and 61, 63, 64, 65-66; institutional norms and 61, 65-66, 69; as practical knowledge 61; recontextualization and 62 ; Swedish 63; tension between workplace and academic knowledge 61, 79 vocational mathematics education: CHAT and 62; collaborative teaching and 62-63; knowledge aspects $67,67,68-69$; praxeology and 66-67, 67, 68, 71; problem-solving and 62 ; recontextualization and 62 , 78; styling and 63, 64, 65-73; teaching contents 61

Wake, G. 62

Williams, J. 62

Wood, L. 50, 58

words 24, 133-135 


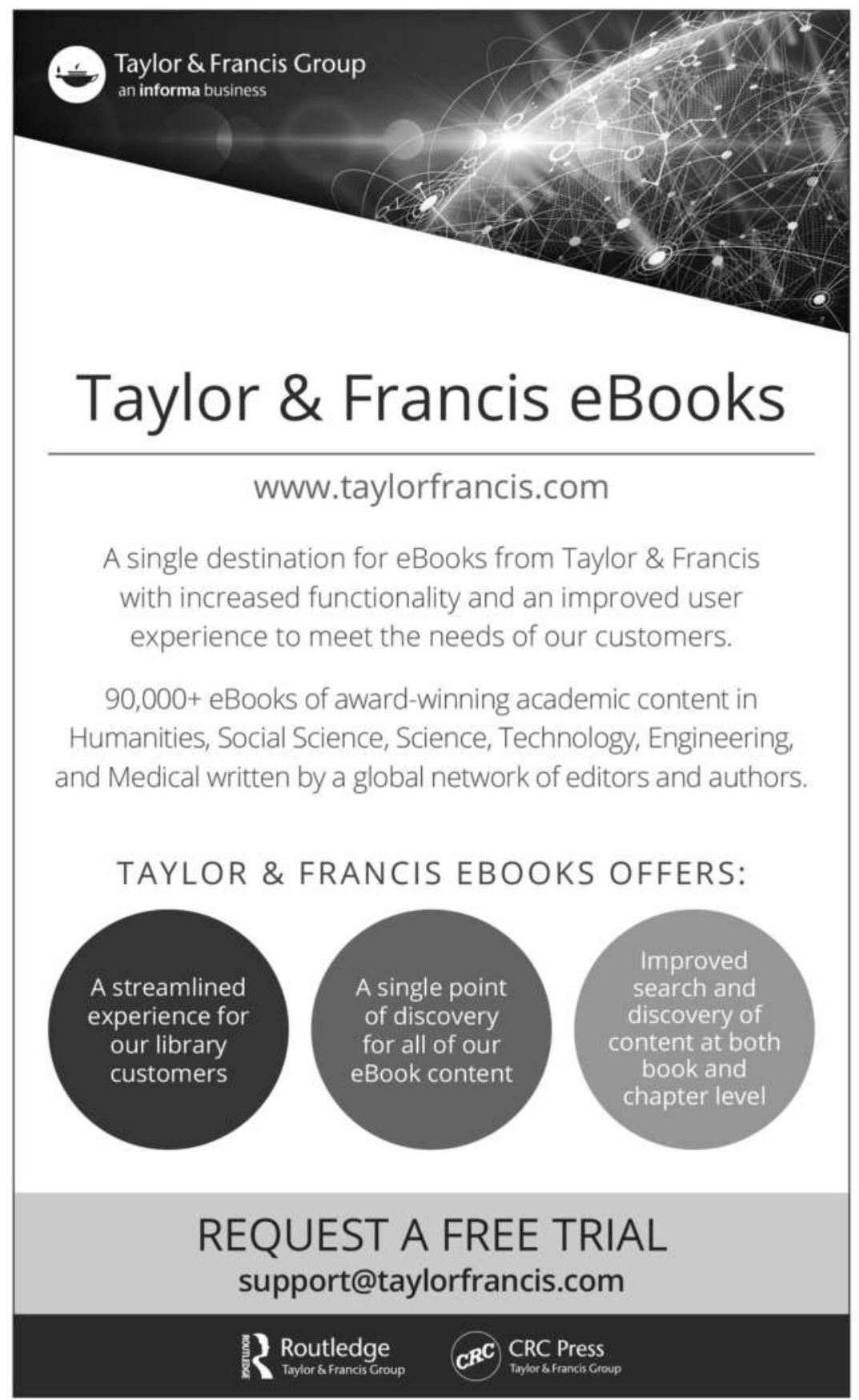

